Article

\title{
Realistic Traffic Condition Informed Life Cycle Assessment: Interstate 495 Maintenance and Rehabilitation Case Study
}

\author{
Katie E. Haslett $(\mathbb{D}$, Eshan V. Dave * and Weiwei Mo® \\ Department of Civil and Environmental Engineering, University of New Hampshire, Durham, NH 03824, USA; \\ keh11@wildcats.unh.edu (K.E.H.); weiwei.mo@unh.edu (W.M.) \\ * Correspondence: eshan.dave@unh.edu; Tel.: +1-603-862-5268
}

Received: 10 May 2019; Accepted: 3 June 2019; Published: 12 June 2019

check for updates

\begin{abstract}
As construction costs continue to rise and adequate amounts of funding continues to be a challenge, the allocation of resources is of critical importance when it comes to the maintenance and rehabilitation (M\&R) of highway infrastructure. A Life Cycle Assessment (LCA) methodology is presented here that integrates realistic traffic conditions in the operational phase to compare M\&R scenarios over the analysis period of a $26-\mathrm{km}$ stretch of Interstate-495. Pavement International Roughness Index (IRI) were determined using American Association of State Highway and Transportation Officials (AASHTO) PavementME System. Meanwhile, vehicle fuel consumption and emission factors were calculated using a combination of Google Maps ${ }^{\circledR}$, the United States Environmental Protection Agency (EPA) Motor Vehicle Emission Simulator, the second Strategic Highway Research Program (SHRP2) Naturalistic Driving Study, and MassDOT's Transportation Data Management System. The evaluation of pavement performance with realistic traffic conditions, varying M\&R strategies, and material characteristics was quantified in terms of Life Cycle Cost (LCC), Global Warming Potential (GWP), and Cumulative Energy Demand (CED) for both agencies and users. The inclusion of realistic traffic conditions into the use phase of the LCA resulted in a 6.4\% increase in CED and GWP when compared to baseline conditions simulated for a week long operation duration. Results from this study show that optimization of M\&R type, material selection, and timing may lead to a $2.72 \%$ decrease in operations cost and $47.6 \%$ decrease in construction and maintenance costs.
\end{abstract}

Keywords: pavement; LCA; LCCA; asphalt; realistic traffic conditions; rehabilitation

\section{Introduction}

The United States road infrastructure received a report card grade of a D from the American Society of Civil Engineers (ASCE) in 2017 [1]. ASCE reported 6.9 billion hours of delay in traffic, equating to an average of $42 \mathrm{~h}$ of delay per driver [1]. In addition to traffic delays, TRIP (a private nonprofit organization that researches, evaluates, and distributes economic and technical data on surface transportation issues) reported that $44 \%$ of the nation's highways were in poor or mediocre condition in 2018, causing U.S. road users $\$ 130$ billion ( $\$ 599$ per driver) in extra vehicle repairs and operating costs [2]. In general, current practice of pavement design and maintenance and rehabilitation $(M \& R)$ plans are based on performance and economic factors, while neglecting environmental impacts. Furthermore, the majority of cost impacts of the roadway M\&R decisions are driven by agency costs only, neglecting the impacts incurred by road users. There is a growing need to perform a life cycle assessment (LCA) and life cycle cost analysis (LCCA) as part of the decision process to ensure that resources, time, and money are being allocated efficiently to maintain highway infrastructure systems. 
A holistic approach to pavement management should incorporate a balance of costs (both user and agency) and environmental impacts. Furthermore, the costs and environmental impacts should be assessed over the life-time of a roadway by incorporating traffic (both volumes and flow characteristics), pavement materials and their performances through lab or field measured properties, reliable pavement performance evolutions (such as changes in pavement roughness with time), and maintenance and rehabilitation treatments and their impacts on pavement performance evolutions. Often times a non-holistic approach is adopted for pavement management systems that either only focuses on life cycle costs or does not account for operational (user) costs. Moreover, the majority of these approaches do not have the necessary physical relationships to link factors such as congestions or slow-downs to impact calculations.

Incorporating an LCA-LCCA approach into the pavement design and M\&R process will help to improve the pavement management of highway infrastructure systems [3-5]. It will also help to identify explicit and implicit costs incurred by both agencies and users. To date there has been an extensive amount of recent research focused on the development of LCA frameworks for pavements, which can be attested by a series of Pavement LCA symposia (2010, 2012, 2014, and 2017) and the corresponding compilation of proceedings [6-9]. Transportation agencies are also increasingly becoming aware and involved in the development of LCA tools for pavements. For example, the U.S. Department of Transportation and Federal Highway Administration (FHWA) recently released a pavement LCA framework document in an effort to aid the implementation and adoption of LCA principles in the pavement design process [10]. In addition to the LCA framework, this report also provided guidance on the overall approach, methodology, system boundaries, and identified current knowledge gaps in pavement LCA. The report also identified current research gaps in the LCA framework, including topics such as traffic delay, rolling resistance, pavement albedo, and end of life allocation.

A study in 2018 focused on the development of an integrated LCA-LCCA framework to aid in the decision making process for pavement M\&R activities during the entire pavement life cycle [5]. It was concluded in the study that material, construction-related traffic congestion, and pavement surface roughness effects are three major contributors to energy consumption and greenhouse gas (GHG) emissions for pavement M\&R activities [5]. When considering a high-traffic-volume highway, such as Interstate 495, which was selected as the case study location, energy and GHG savings accumulated during the use phase of the LCA due to rolling resistance can become even more significant compared to the energy use and GHG emissions from material production and construction in pavement M\&R activities. Several other studies have shown the effect of pavement roughness on vehicle operation costs in terms of extra fuel consumption, vehicle repairs and maintenance, and tire wear during the use phase of the LCA [3,11-14].

The motivation of this study is to use a LCA-LCCA approach to evaluate pavement performance over the design life with the inclusion of realistic traffic conditions, different pavement $M \& R$ alternatives, and pavement material characteristics. Building upon a study performed by DeCarlo et al. in 2017, where a section of interstate highway in the New England region was selected to investigate the impact pavement structure and $M \& R$ treatment timing, the present study aims to include realistic traffic conditions in the operational phase of a pavement LCA [15]. The study presented herein has three primary objectives: (1) to perform a LCA on an interstate highway with the implementation of real time traffic data (RTTD) and M\&R strategy decisions to optimize performance over a given pavement analysis life; (2) to evaluate pavement performance with realistic traffic conditions, varying M\&R strategies, and material characteristics in terms of Life Cycle Cost (LCC), Global Warming Potential (GWP), and Cumulative Energy Demand (CED) for both agencies and users; and (3) to quantify the increase in fuel consumption and resulting emissions due to decrease in ride quality (as expressed by the International Roughness Index, IRI) caused by accumulated distress and pavement degradation over the analysis period. Ultimately, when an LCA-LCCA approach is utilized, pavement performance over a given analysis period can be optimized to determine a cost-effective and eco-friendly pavement M\&R plan [5]. 
In the subsequent sections a brief summary of the materials and methods utilized in this study are presented. Information regarding the selection of the case study location, details relating to the construction, use, and M\&R phase of the LCA are discussed followed by key results and a sensitivity analysis of select variables. Lastly, a discussion of the LCA results is presented and the importance of incorporating realistic traffic conditions into the LCA framework is demonstrated.

\section{Materials and Methods}

\subsection{Case Study Location}

A $26 \mathrm{~km}$ section of Interstate I-495 in Massachusetts was analyzed, from Chelmsford to Methuen, as shown in Figure 1. This section of interstate was selected as it consists of a high volume of commuter traffic. Temporal traffic volume data on this interstate section were collected from the Massachusetts Department of Transportation (MassDOT, Boston, MA, USA) data management system [16]. Interstate I-495 consists of 3 lanes in each direction, with a distributional factor of $50 \%$ (of 24-h peak volume). The annual average daily traffic (AADT) was approximately 121,000 vehicles. Of this volume, the business commercial vehicles (FHWA Class 4 and above) consisted of $9243(8 \%)$ vehicles (detailed traffic distribution is provided in Appendix A.3).

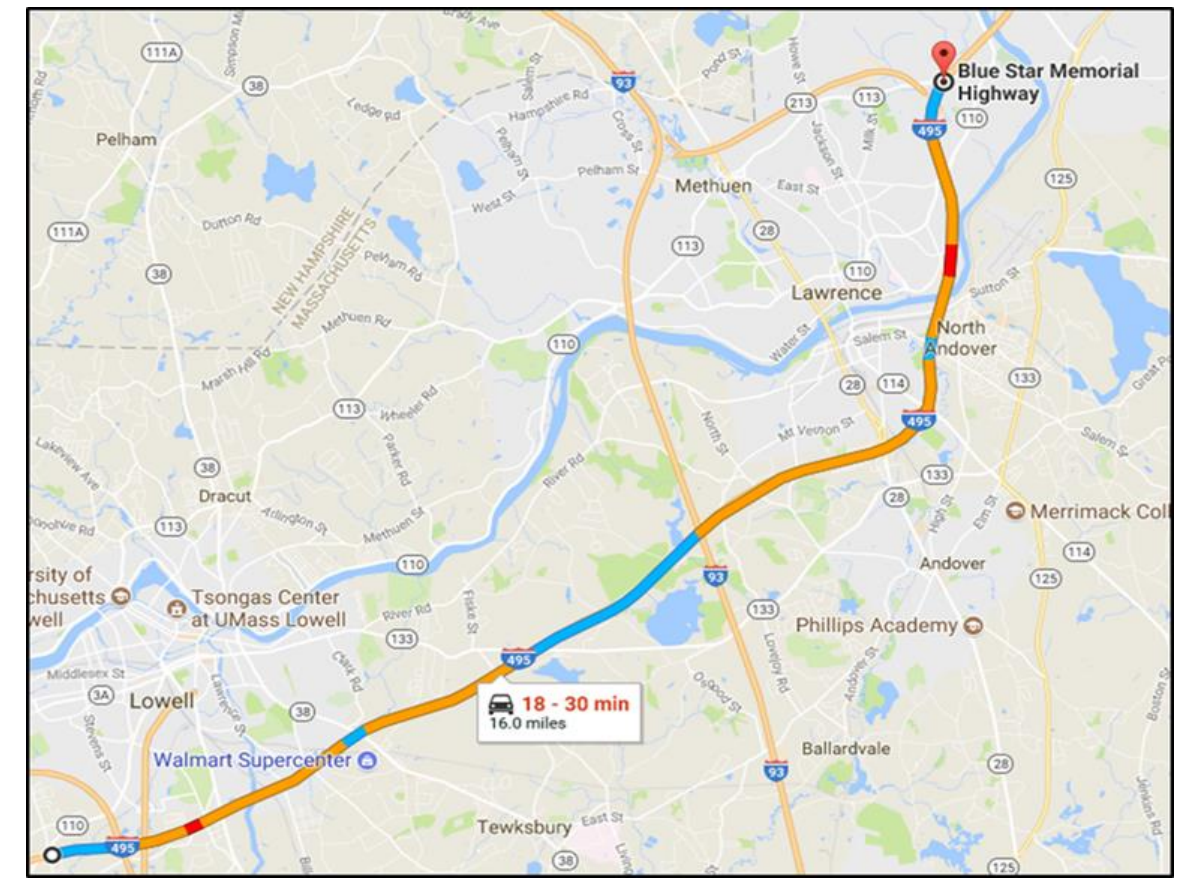

Figure 1. Map of $25.7 \mathrm{~km}$ roadway on I-495 from Chelmsford to Methuen, Massachusetts [17].

\subsection{General Methodology}

A typical pavement LCA system boundary includes raw materials and excavation, material transportation, construction, operation and maintenance, and end-of-life. In this study, a focus was placed on the initial construction, use, and maintenance phases from both an agency and user perspective. The end-of-life phase was neglected because of the challenges associated with accurately accounting for reclaimed asphalt pavement (RAP) material and its impacts beyond the analysis period of the given section of I- 495 being investigated as part of this study. Three types of impacts were investigated: life cycle cost, cumulative energy demand (CED), and global warming potential (GWP). Figure 2 describes the general process of the LCA-LCCA approach that was followed. In the subsequent sections, the construction phase, use phase, and the M\&R strategies are described in greater detail. 


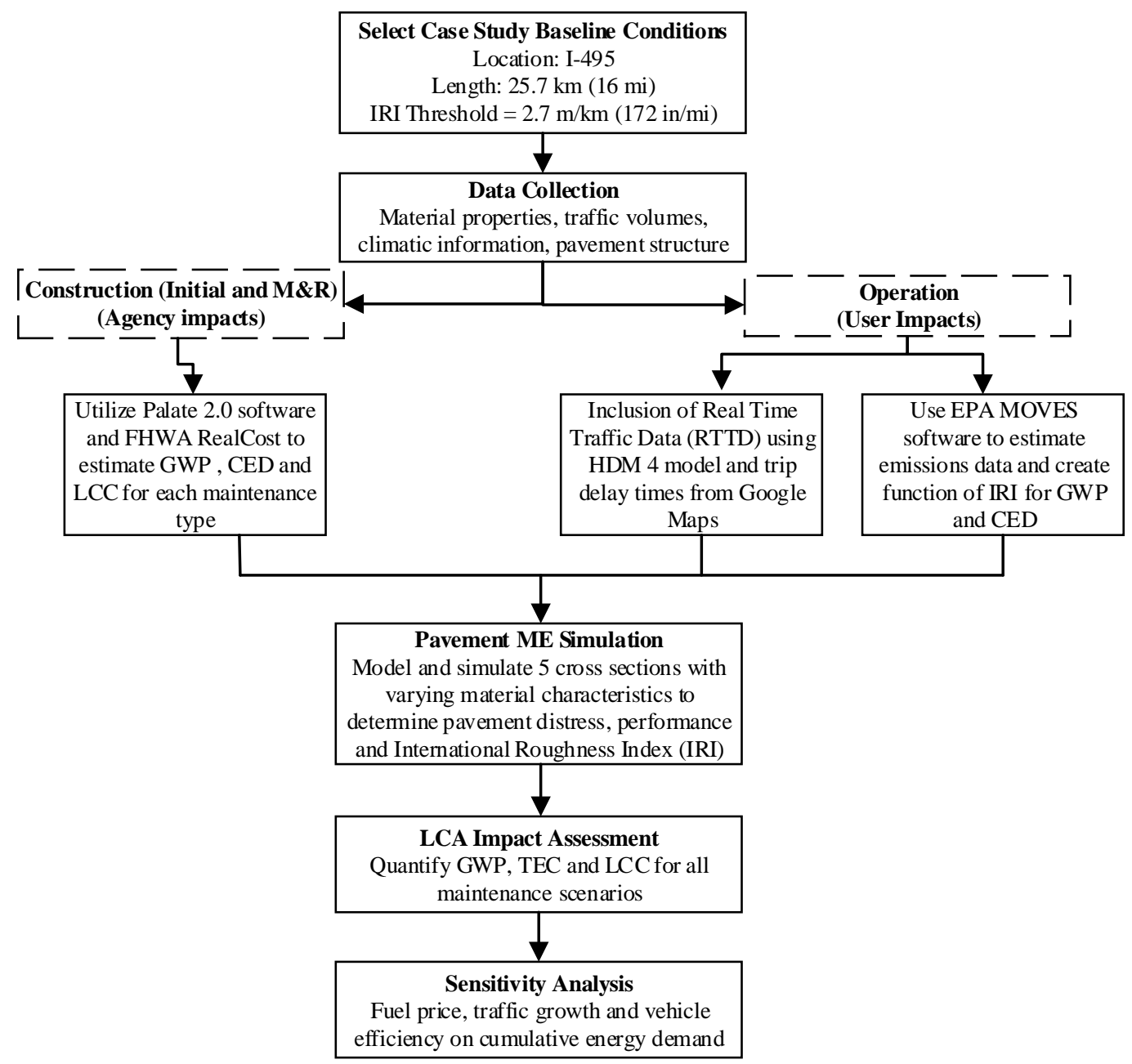

Figure 2. Flow chart of life cycle assessment (LCA) case study.

As shown in Figure 2, once the case-study location was identified the first step in the process involved collection of various spatial and temporal data that are necessary to capture various facets of the LCA process. The analysis was divided into two primary phases of activities for pavements: (1) Construction (initial, M\&R), and (2) Operation. Construction activities included in the analysis are initial construction, maintenance, rehabilitation, and reconstruction. The operational phase analysis was conducted using both steady-state and realistic traffic conditions. Impacts of pavement roughness on various life time impacts and costs were included in the analysis. Lastly, a sensitivity analysis was conducted to assess effects of changing traffic volume, vehicle fuel efficiencies, and fuel prices over the course of analysis duration.

\subsubsection{Construction Phase: Materials and Pavement Cross-Sections}

An inventory of raw materials required to construct the $26-\mathrm{km}$ stretch of road was developed based upon typical New England mixture characteristics. The various cross-sections are comprised of a combination of a wearing or surface course, binder course, base course, granular base, and subgrade. Base and subbase layer designs were held constant, while five different surface courses with varying material properties were evaluated as part of this study (Table 1). Therefore, each simulated cross-section had the same overall thickness on top of the existing subgrade $(105 \mathrm{~cm})$ - the factor that varied was the surface course material properties. The materials chosen for surface course represent typical asphalt mixtures and binders used in the New England region [18]. 
Table 1. Summary of materials used in simulated pavement cross-sections.

\begin{tabular}{ccccc}
\hline Mixture Name & $\begin{array}{c}\text { Course } \\
\text { Description }\end{array}$ & $\begin{array}{c}\text { Layer } \\
\text { Thickness } \mathbf{( c m )}\end{array}$ & $\begin{array}{c}\text { Asphalt } \\
\text { Binder Type }\end{array}$ & $\begin{array}{c}\text { Amount of Recycled Asphalt } \\
\text { Pavement in the Mix } \\
\text { (\% by Total Weight of Mix) }\end{array}$ \\
\hline ARGG-1 & Surface & 5 & PG 58-28 & 10 \\
ARGG-2 & Surface & 5 & PG 58-28 & 0 \\
T-1 & Surface & 5 & PG 64-28 & 19.3 \\
THS-1 & Surface & 5 & PG 76-28 & 19.3 \\
SHM-1 & Surface & 5 & PG 70-34 & 0 \\
B-1 & Binder & 20 & PG 64-28 & 25 \\
BB-1 & Base & 20 & PG 64-28 & 25 \\
GB & Granular Base & 60 & - & - \\
\hline
\end{tabular}

Each cross-section design will present its own unique degradation trajectory, which is further modeled through Pavement ME by altering the material properties of the asphalt layer. The baseline unit raw material and construction impacts and costs associated with each process were obtained from two LCA software programs, Simapro 8.3 and the Pavement Life-Cycle Assessment Tool (PaLATE 2.0) [19,20]. Further detailed information on the inventory unit impacts is provided in Appendix A.1. Transportation distances of the materials were quantified based upon the manufacturers' locations, contracted out by the Massachusetts Department of Transportation (MassDOT) for previous pavement projects. It was assumed that the transportation distance from the plant to the job site location was 10 miles.

\subsubsection{Construction Phase: Maintenance and Rehabilitation}

A total of $6 \mathrm{M} \& \mathrm{R}$ strategies were compared in this study using a combination of Pavement ME design software and existing literature on the impacts of M\&R strategies on IRI. Typical surface treatments, such as crack sealing and microsurfacing, were included as pavement preservation or pavement maintenance strategies, while common pavement rehabilitation strategies, including cold-in-place recycling and mill and overlay, were explored.

Initial and terminal IRI values were set based on Pavement ME default values of $1 \mathrm{~m} / \mathrm{km}$ and $2.7 \mathrm{~m} / \mathrm{km}$, respectively. As it is commonly recommended for pavement life cycle cost analysis [21], a minimum of 3 full maintenance cycles for each type of $M \& R$ was used in the analysis prior to selecting the terminal year of the analysis period. This was done to ensure that a sufficiently long analysis period was used to make a relatively fair comparison among different M\&R strategies, specifically when converting various costs to net present value (NPV) and equivalent annual costs (EAC). The analysis periods vary from 92 to 135 years depending on the type of $M \& R$ and cross-section material properties. A brief description of each M\&R alternative is listed below.

- Do nothing and reconstruct (DNR): The first M\&R scenario is simply the choice to perform no maintenance or rehabilitation and to reconstruct at the end of the pavement system's service life (reached the terminal IRI). The pavement performance curves in terms of IRI and time for this scenario are determined using Pavement ME.

- Crack sealant (CS): The next M\&R alternative evaluated the use of a crack sealant every two years during the service life of the pavement until the terminal IRI value was reached and the pavement system was reconstructed. Crack sealant is a common preventative maintenance treatment to fill cracks at the surface of the pavement structure to prevent water from infiltrating. It was found in literature that the overall pavement service life is extended by 2 years when applying crack sealant as a pavement preservation technique [22]. For simplicity, it was assumed that the pavement continues to deteriorate at the same rate after applying the crack sealant treatment but a two-year extension of the service life was applied before reaching the terminal IRI trigger value. It should also be noted that crack sealant is a preservation treatment and does not address structural issues, as a M\&R strategy does. 
- Microsurfacing (MS $2.2 \mathrm{~m} / \mathrm{km}$ ): Microsurfacing was applied when an IRI trigger value of $2.2 \mathrm{~m} / \mathrm{km}$ was reached. Microsurfacing is a common M\&R treatment type that applies a mixture of water, asphalt emulsion, aggregate, and chemical additives to an existing asphalt pavement surface in order to preserve the underlying pavement structure. It provides a new pavement driving surface, and according to a study by MnDOT, it resets the IRI by approximately $0.7 \mathrm{~m} / \mathrm{km}$ [23]. A type III microsurface was molded in this study. It should be highlighted that microsurfacing is a pavement preservation treatment and does not address underlying structural issues.

- Microsurfacing (MS $2.5 \mathrm{~m} / \mathbf{k m}$ ): Microsurfacing was applied when an IRI trigger value of $2.5 \mathrm{~m} / \mathrm{km}$ was reached. Once again, IRI was reset by approximately $0.7 \mathrm{~m} / \mathrm{km}$ [23].

- Cold-In-Place (CIR) Recycling: CIR is a pavement rehabilitation technique that involves reclaiming $50 \mathrm{~mm}$ to $100 \mathrm{~mm}$ of the existing pavement structure. It is a similar process to cold plant mix recycling, except that it is performed directly in the field, typically by a paving train of equipment. Once the terminal IRI value has been triggered, the CIR treatment is performed and the IRI decreases by approximately $1.1 \mathrm{~m} / \mathrm{km}[24,25]$. The simulated cross-section after CIR was performed, consisting of a 5-cm asphalt concrete (AC) surface course, 5- $\mathrm{cm}$ AC base course, $10-\mathrm{cm}$ of cold recycled asphalt pulverized in place, and $60-\mathrm{cm}$ granular base. CIR is generally being accepted as a pavement rehabilitation strategy that has the ability to address structural distresses. Pavement ME was used to determine the pavement performance curves when CIR was used as a M\&R strategy.

- Mill and Overlay (MO): Mill and overlay of approximately $50 \mathrm{~mm}$ was performed once the terminal IRI value was reached. On average, the IRI is reset by $(0.95$ to $1.26 \mathrm{~m} / \mathrm{km})$, therefore this M\&R alternative scenario reset the IRI to the initial value of $1 \mathrm{~m} / \mathrm{km}$ and then allowed the pavement cross-section to reach the terminal IRI value of $2.7 \mathrm{~m} / \mathrm{km}$ before reconstruction [26,27]. Reconstruction was performed after one MO treatment to avoid the impractical scenario of constant MO highway pavement systems. MO often falls in the gray area as a mix between a surface treatment or a rehabilitation strategy. For the purpose of this study, MO is considered as a rehabilitation treatment capable of addressing structural distresses. Pavement ME simulations were conducted for each cross-section with use of MO treatment to determine the pavement performance curves.

Figure 3 provides an example of the M\&R timing sequence over the analysis period for the ARGG-1 cross-section. The terminal year of year 135 from the present time was determined when a minimum of 3 full cycles of each M\&R strategy were completed. The M\&R timing sequences for other pavement cross-sections are provided in Appendix A.2.

\subsubsection{Use Phase}

In order to incorporate realistic traffic conditions into the use phase of the LCA, hourly traffic congestion patterns over the course of a week on the target pavement segment from Google Maps ${ }^{\circledR}$ were obtained. A representative week of hourly congestion patterns was then repeated to form a year (52 weeks) of realistic traffic conditions. MassDOT's Transportation Data Management System was used to collect information regarding daily traffic volume for each vehicle type on the target pavement segment.

Next, acceleration and deceleration rates obtained from the SHRP 2 NDS databases were assigned to all vehicles based on the congestion condition and the expected vehicle speeds under each traffic congestion condition (Appendix A.3, Tables A3-A5) [28]. Note that same acceleration and deceleration rates were used for different vehicle classes, however the vehicle specific power for each of these classes differ and are accounted for in the emissions calculations. The Motor Vehicle Emission Simulator MOVES2014a software was used to convert the volume and pattern of traffic (i.e., vehicle type, speed, and acceleration) to GWP and CED estimates [29]. However, it should be noted that MOVES assumes constant pavement performance (highest smoothness), while the influence of pavement 
degradation on vehicle fuel consumption and emissions is neglected. To address this gap, pavement distresses over the design life were modelled using the Pavement ME design software for the 5 different pavement cross-section types [30]. The International Roughness Index (IRI) was used to assess pavement degradation and ride roughness. IRI measures the simulated transient vertical movement of a generic motor vehicle to the roughness in a single wheel path of the road surface, and is typically reported in meters per kilometer [31]. IRI correlates with vehicle fuel usage and the associated costs and emissions [12]. The approach taken in this paper is one of several approaches that researchers have proposed to link pavement condition to user costs; for example, Loprencipe et al. have developed relationships between pavement condition index (PCI) and vehicle operating costs (VOC) [32]. The approach adopted by authors in the current work was chosen to ensure that realistic traffic conditions can be incorporated within user cost estimates.

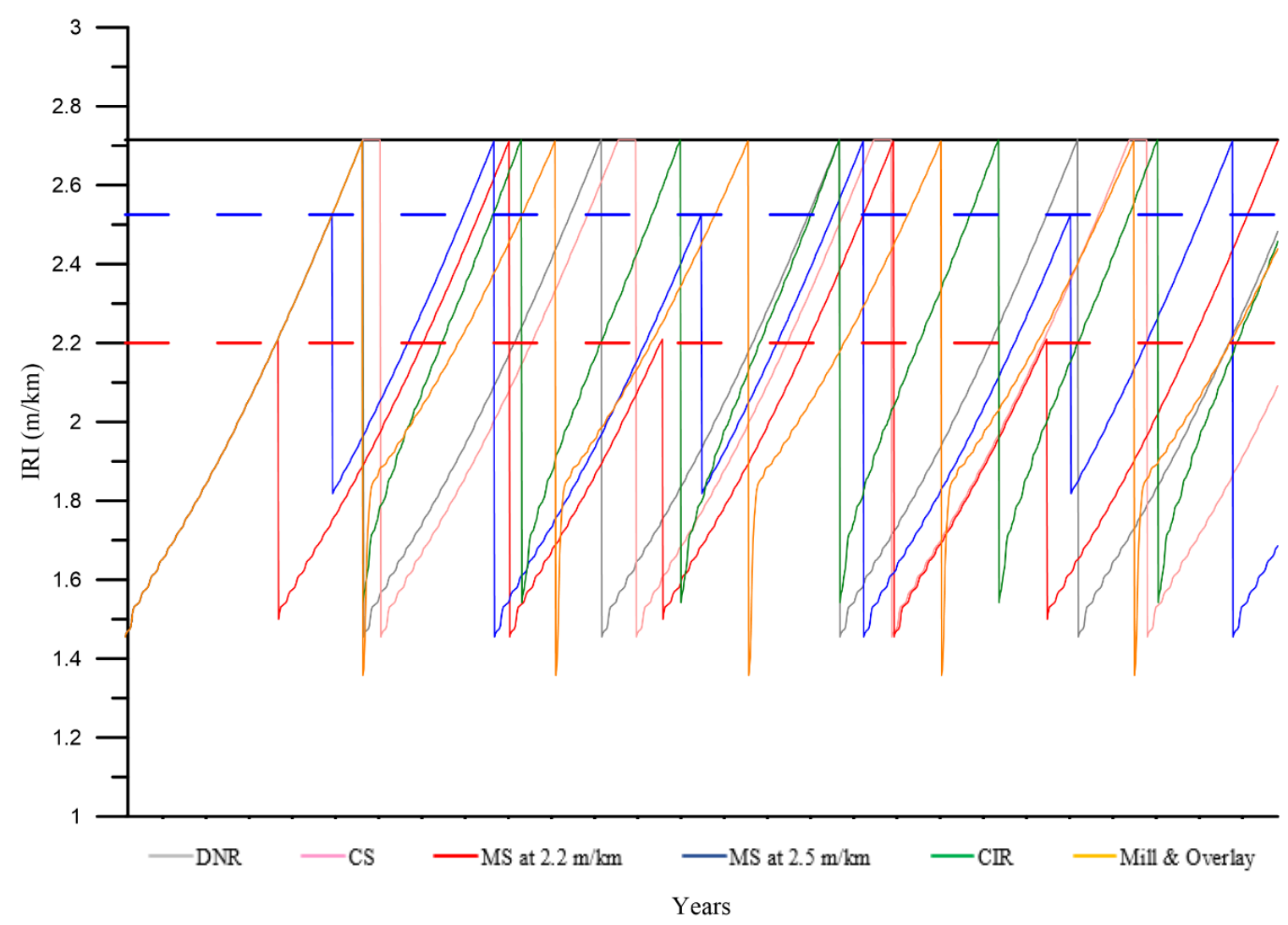

Figure 3. Example of a maintenance and rehabilitation timing sequence for ARGG-1 cross-section over the analysis period with a terminal year of 2154.

It is important to note that while $M \& R$ is being performed on the roadway it often requires lane closures. Traffic congestion may arise, resulting in an increase in emissions. These delays were not included in this study at the present time, however, the inclusion of idle time and traffic congestion from daily traffic was included. Idle time was incorporated into the results by assuming, on average, vehicles idle for $10 \mathrm{~min}$ per $\mathrm{km}$ for the $130 \mathrm{~km}$ of mildly congested (typically shown as red on Google Maps ${ }^{\circledR}$ ) roadways per week, and for $30 \mathrm{~min}$ per $\mathrm{km}$ for the $6.6 \mathrm{~km}$ of highly congested (typically shown as dark red on Google Maps ${ }^{\circledR}$ ) roads on I-495. By incorporating realistic traffic conditions into the use phase of the LCA, the increase in emissions due to traffic delays without consideration of lane closures was accounted for. It is recommended that the impact of lane closures be investigated further to determine the significance of $M \& R$ lane closure times associated with each strategy (i.e., lane closure time to perform crack seal versus time to perform mill and overlay) may have on the overall LCA impacts.

The inclusion of realistic traffic conditions followed a six step process. The first step used vehicle characteristics from Chatti and Zabaar [12]. Some examples of these characteristics include 
mass, drag coefficient, frontal area, and rolling resistance tire factors. They were then utilized in HDM-4 tractive force model equations to account for aerodynamic forces and rolling resistances [33]. The tractive forces were used to determine the vehicle specific power. Vehicle Specific Power (VSP) is a measure of a vehicle's instantaneous power per mass. VSP reveals how driving conditions affect emissions. It is a function of speed, roadway grade, acceleration, IRI, and many other variables. Since MOVES is not set-up to directly incorporate effects of IRI change on fuel usage, the results from Chatti and Zabaar were used to calibrate VSP bins for each vehicle class with respect to different pavement IRI. Once VSP bins were compiled for each variation in vehicle type, speed, and acceleration, these vehicle specific powers were used as inputs to the MOVES software.

Next, MOVES simulations were performed to obtain values of CED and GWP per length traveled. It is necessary to obtain emissions per length so they can be applied to varying traffic conditions. The MOVES outputs were then altered to allow the incorporation of the International Roughness Index (IRI). Due to the generalization of VSP Bins in MOVES software, a change in IRI does not produce a significant change in the output from MOVES for acceleration, deceleration, or idle phases. This is not unexpected, since during acceleration and deceleration the power demands associated with those activities are substantially higher than that coming directly from change in pavement roughness. Similarly, during the idle stage, there is no motion, and thus pavement surface characteristics have no impact on fuel consumption.

Lastly, the altered MOVES outputs were then combined with vehicle counts and classifications from MassDOT's Transportation Data Management System and traffic conditions from Google Maps ${ }^{\circledR}$. This was only completed for one week of hourly traffic data because Google Maps ${ }^{\circledR}$ generalizes each week day and weekend day to have the same traffic conditions throughout the entire year. In other words, a Friday in July will have the same results as a Friday in January in terms of traffic delay estimates. Therefore, in total 168 traffic conditions were evaluated for a single week's worth of traffic on an hourly basis. The process outlined above to obtain a week's worth of traffic data was then scaled to represent the traffic conditions over the course of a year, and ultimately over the entire LCA analysis period. The implementation of RTTD was completed for both southbound and northbound directions over the $26 \mathrm{~km}$ stretch of roadway on I-495.

\subsection{Life Cycle Cost Analysis}

LCC was estimated using a discount rate of $4 \%$ and converted to net present value (NPV). A $4 \%$ discount rate was assumed in this study based on guidance from FHWA Life-Cycle Cost Analysis in the Pavement Design report that stated long-term trends for real discount rates hover around $4 \%$ and a discount rate between 3 to $5 \%$ is an acceptable range, as it is consistent with historical values in Appendix A of Office of Management and Budget (OMB) Circular A-94 [34]. Costs were converted to net present value (NPV) using Equation (1), where FV is the future value, $r$ represents the discount rate $(4 \%)$, and $\mathrm{n}$ is the number of years in the future the price must be brought back to present value.

$$
\mathrm{NPV}=\frac{\mathrm{FV}}{(1+\mathrm{r})^{\mathrm{n}}}
$$

\subsection{Sensitivity Analysis}

A sensitivity analysis on the price of fuel, traffic growth rate, and vehicle energy efficiency was performed to assess their influence on the economic performance of the LCCA. Table 2 summarizes the price of gasoline and diesel considered in the sensitivity analysis.

Traffic growth rate varied by $1 \%, 2 \%$, and $3 \%$ with respect to the baseline conditions, which assumed no traffic growth. To account for the improvement in motor vehicle technology, cumulative energy demand (CED) was reduced every decade by $1 \%, 2 \%$, and 3\%. All pavement sections and M\&R strategy combinations (24 total) were evaluated using low, current, and high fuel price values for a total of 84 scenarios. 
Table 2. Gasoline and diesel prices used for three scenarios used in sensitivity analysis from U.S. Energy Information Administration (EIA) 2017 Report [35].

\begin{tabular}{ccc}
\hline Scenario & Gasoline Price (\$) & Diesel Price (\$) \\
\hline Low & 1.64 & 1.71 \\
\hline Current & 2.80 & 3.00 \\
\hline High & 4.04 & 4.66 \\
\hline
\end{tabular}

\section{Results}

\subsection{Effect of Realistic Traffic as Compared to Steady Speed}

First, to validate the importance of including realistic traffic conditions in the use phase of the LCA, a comparison to baseline traffic conditions was conducted. LCA results showed that using real time traffic data resulted in a 6.4\% increase in CED and GWP, in comparison to baseline conditions during a given week. These percentages were based on a daily traffic count of approximately 133,000 vehicles. Therefore, the inclusion of RTTD is equivalent to accounting for the impact of an additional 8512 vehicles per day. Figure 4 highlights the difference in CED when realistic traffic conditions are included. A similar trend in GWP is observed when RTTD is included in the operations phase of the LCA.

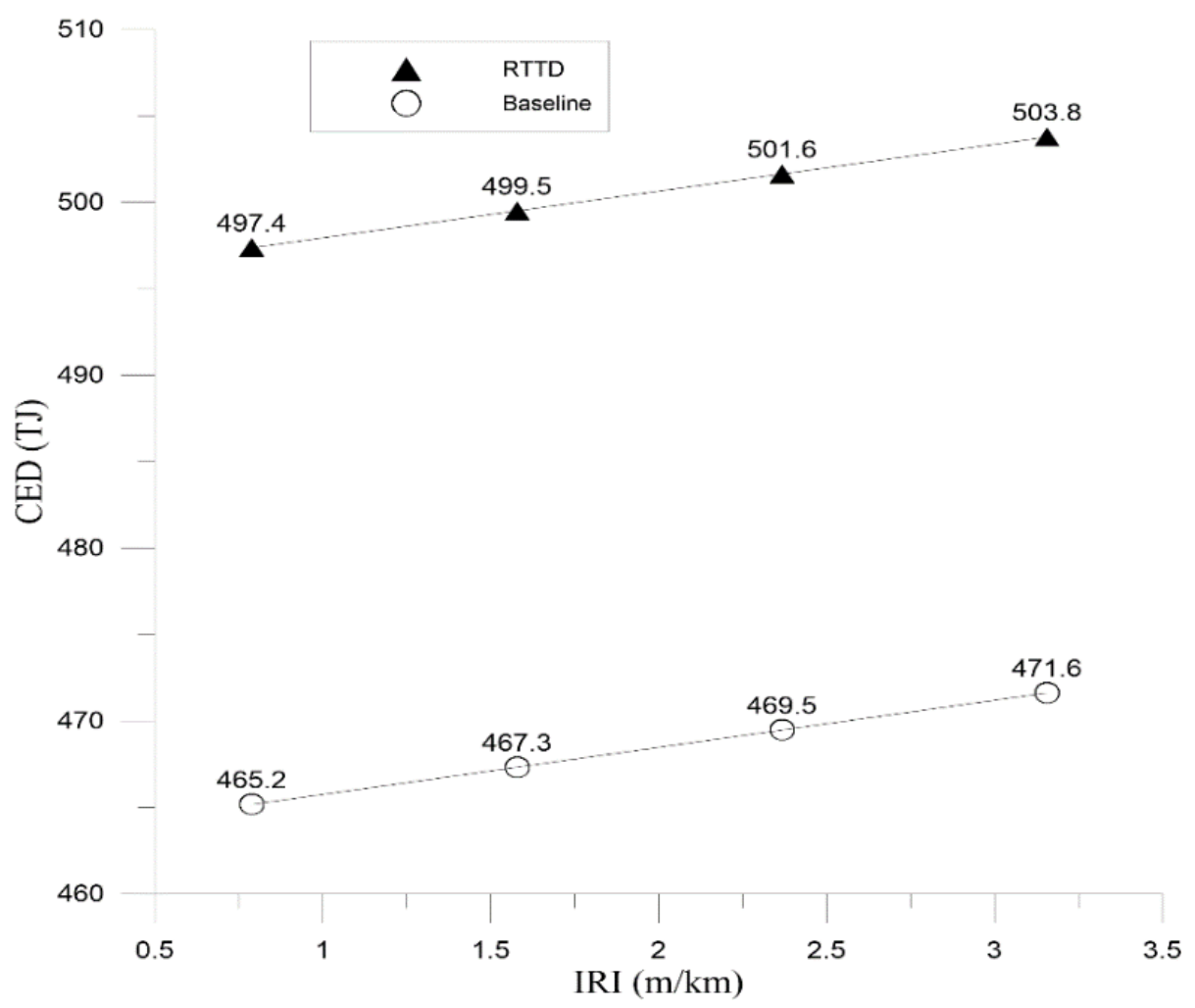

Figure 4. Comparison of baseline traffic scenario and the inclusion of realistic traffic conditions (indicated by real time traffic data).

\subsection{Overall LCA Results}

\subsubsection{Global Warming Potential (GWP)}

From this point on, all results are presented with the inclusion of RTTD. Figure 5a,b shows the two most contrasting cross-sections (ARGG-1 and T-1) in terms of percent difference in GWP. 
User impact is represented by the solid black bars, while agency impact is shown by the grey hashed bars. Table 3 includes the results for all five cross-sections for comparison of GWP impact in terms of Gigagrams of $\mathrm{CO}_{2}$ equivalent.

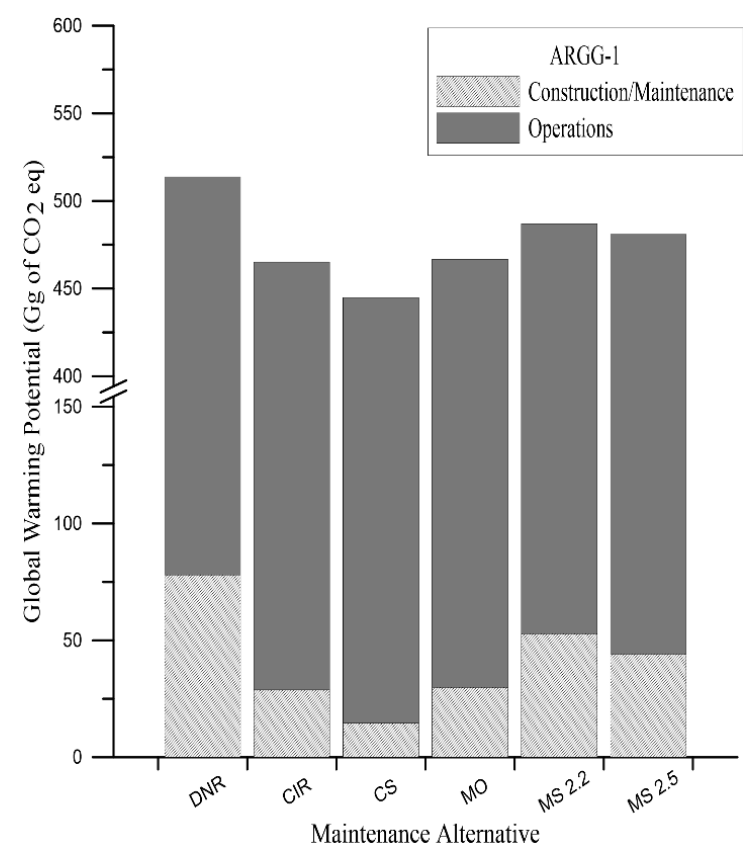

(a)

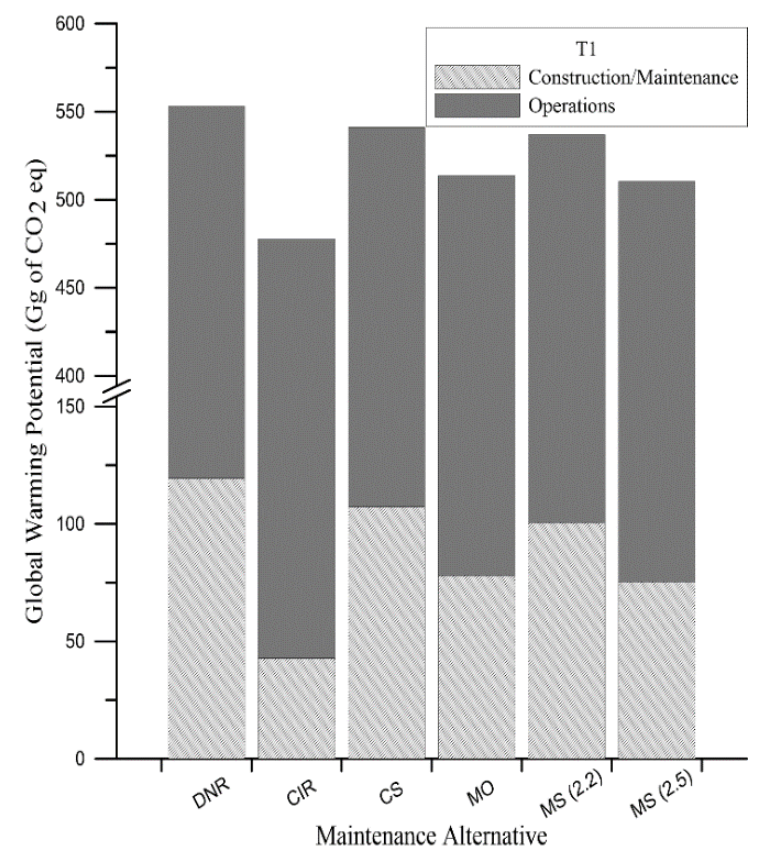

(b)

Figure 5. Global warming potential (GWP) impact broken down into construction and M\&R, and operations of vehicles over LCA analysis period for (a) ARGG-1 and (b) T-1 pavement cross-sections.

Table 3. Summary of M\&R alternative scenario results in terms of GWP impact incurred by agencies and users for all 5 cross-sections.

\begin{tabular}{|c|c|c|c|c|c|c|c|c|c|c|c|c|}
\hline \multirow{4}{*}{ Cross-Section } & \multicolumn{12}{|c|}{ Maintenance Alternative } \\
\hline & \multicolumn{2}{|c|}{ DNR } & \multicolumn{2}{|c|}{ CIR } & \multicolumn{2}{|c|}{ CS } & \multicolumn{2}{|c|}{ MO } & \multicolumn{2}{|c|}{ MS $2.2 \mathrm{~m} / \mathrm{km}$} & \multicolumn{2}{|c|}{ MS $2.5 \mathrm{~m} / \mathrm{km}$} \\
\hline & $\mathrm{C} / \mathrm{M}$ & O & $\mathrm{C} / \mathrm{M}$ & O & $\mathrm{C} / \mathrm{M}$ & O & $\mathrm{C} / \mathrm{M}$ & O & $\mathrm{C} / \mathrm{M}$ & O & $\mathrm{C} / \mathrm{M}$ & $\mathrm{O}$ \\
\hline & \multicolumn{12}{|c|}{$\mathrm{GgCO}_{2} \mathrm{eq}$} \\
\hline ARGG-1 & 78 & 436 & 29 & 436 & 15 & 430 & 30 & 437 & 53 & 434 & 44 & 437 \\
\hline ARGG-2 & 77 & 435 & 26 & 435 & 72 & 436 & 29 & 435 & 52 & 435 & 55 & 438 \\
\hline SHM-1 & 73 & 430 & 27 & 436 & 52 & 435 & - & - & 54 & 436 & 26 & 437 \\
\hline $\mathrm{T}-1$ & 119 & 434 & 43 & 435 & 107 & 434 & 78 & 436 & 101 & 436 & 75 & 435 \\
\hline THS-1 & 83 & 435 & 34 & 437 & 91 & 435 & - & - & 75 & 436 & 61 & 435 \\
\hline
\end{tabular}

Note: $\mathrm{C} / \mathrm{M}=$ Construction and maintenance (agencies); $\mathrm{O}=$ Operations (users); $\mathrm{DNR}=$ Do nothing reconstruct; $\mathrm{CIR}=$ Cold in-place recycling; $\mathrm{MO}=$ Mill and overlay; $\mathrm{MS}=$ Microsurface.

It can be inferred from both Figure 5 and Table 3 that while the type of pavement cross-section and the use of different asphalt mixtures have an impact of the life cycle costs and impacts, this is not as significant as the type and timing of $M \& R$ performed over the design life of a pavement structure. All GWP user impacts are relatively similar, ranging from 430 to $438 \mathrm{Gg}$ of $\mathrm{CO}_{2}$ equivalent. In contrast, the agency impact ranges from 15 to $119 \mathrm{Gg}$ of $\mathrm{CO}_{2}$ equivalent depending on the type and timing of M\&R.

The cross-section and M\&R alternative that had the lowest operational impact in terms of GWP for both users and agencies is associated with the ARGG-1 cross-section combined with CS. By simply maintaining the pavement system using crack sealant to prevent water infiltration and rapid 
degradation of the pavement surface, it benefits not only the users of the roadway but the agency in which it is responsible for maintaining the pavement infrastructure. In terms of policy or practical implications, these findings support the need for implementing pavement preservation treatments, whereby if a highway network is routinely treated with preventative maintenance using a preservation treatment such as CS, the need for pavement reconstruction could be avoided, resulting in a lower operational costs for users and agencies. Furthermore, the asphalt rubber gap-graded mixture without inclusion of recycled asphalt pavement appears to have better performance and lower life cycle impacts.

In comparison, the highest user (operational) GWP impact is associated with the ARGG-2 cross-section using MS 2.5. The highest construction and M\&R GWP impact resulted from the combination of the using SHM- 1 cross-section and the DNR alternative. For all cross-sections the M\&R alternative to do nothing and reconstruct (DNR) had the highest total impact, including both agency and user impacts, with T-1 cross-section performing the worst with $553 \mathrm{Gg}$ of $\mathrm{CO}_{2}$ equivalent.

\subsubsection{Life Cycle Cost (LCC)}

The last comparison of cross-section and M\&R alternatives considered in this study was in terms of LCC. All LCC presented below are in terms of NPV. Figure $6 \mathrm{a}, \mathrm{b}$ shows results for cross-section ARGG-1 and T-1 to be consistent with GWP comparison in Section 3.2.1. However, Table 4 may be referenced for further comparison of all 5 cross-sections, broken into user and agency LCC impacts.

LCC impact is not constant among the five cross-sections and depends on material properties, $M \& R$ treatment, and the application timing over the service life. For example, comparing Figure $6 \mathrm{a}$ (ARRG-1) and Figure $6 \mathrm{~b}$ (T-1), crack sealant every two years followed by reconstruction once terminal IRI is reached resulted in the overall highest total LCC for ARGG-1 cross-section, but for the T-1 cross-section it was from the DNR scenario. It is important to note that while total LCC is highest for this case, depending on the cross-section, the distributions of user and agency LCC are different. In other words, the total bar height is comprised of different user (black portion) and agency (gray portion) costs.

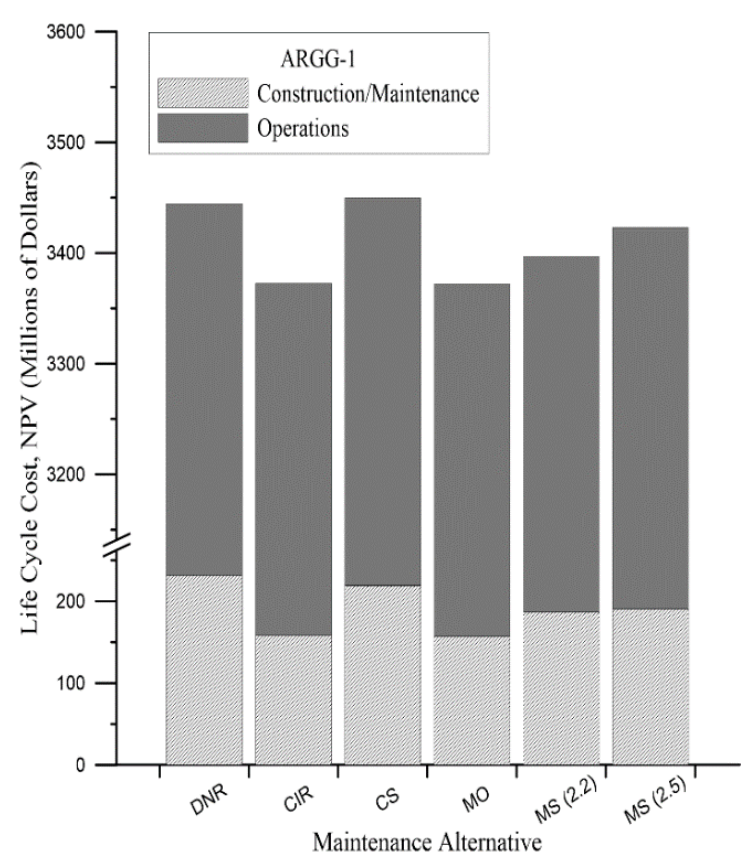

(a)

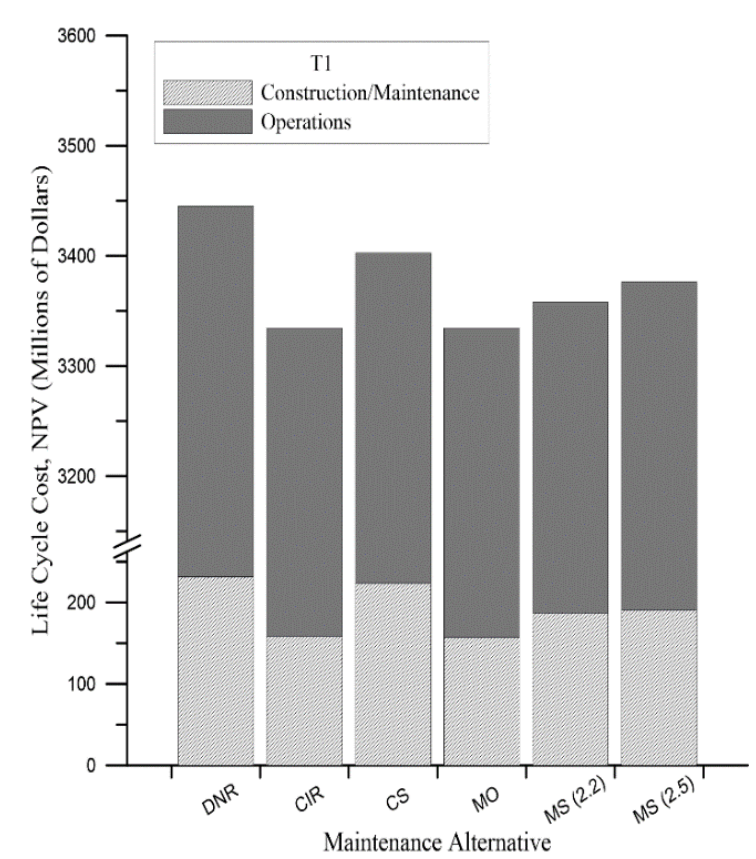

(b)

Figure 6. LCC impact broken down into construction and maintenance, and operations of vehicles over LCA analysis period for (a) ARGG-1 and (b) T-1 pavement cross-section. 
Table 4. Summary of M\&R alternative scenario results in terms of LCC impact incurred by agencies and users for all 5 cross-sections.

\begin{tabular}{|c|c|c|c|c|c|c|c|c|c|c|c|c|}
\hline \multirow{4}{*}{ Cross-Section } & \multicolumn{12}{|c|}{ Maintenance Alternative } \\
\hline & \multicolumn{2}{|c|}{ DNR } & \multicolumn{2}{|c|}{ CIR } & \multicolumn{2}{|c|}{ CS } & \multicolumn{2}{|c|}{ MO } & \multicolumn{2}{|c|}{ MS $2.2 \mathrm{~m} / \mathrm{km}$} & \multicolumn{2}{|c|}{ MS $2.5 \mathrm{~m} / \mathrm{km}$} \\
\hline & $\mathrm{C} / \mathrm{M}$ & $\mathbf{O}$ & $\mathbf{C} / \mathbf{M}$ & O & $\mathrm{C} / \mathrm{M}$ & $\mathbf{O}$ & $\mathbf{C} / \mathbf{M}$ & O & $\mathbf{C} / \mathbf{M}$ & $\mathbf{O}$ & $\mathbf{C} / \mathbf{M}$ & $\mathrm{O}$ \\
\hline & \multicolumn{12}{|c|}{ Millions of Dollars } \\
\hline ARGG-1 & 232 & 3213 & 158 & 3214 & 219 & 3231 & 157 & 3215 & 187 & 3209 & 191 & 3232 \\
\hline ARGG-2 & 231 & 3213 & 158 & 3215 & 219 & 3219 & 157 & 3216 & 187 & 3210 & 156 & 3224 \\
\hline SHM-1 & 299 & 3145 & 160 & 3147 & 277 & 3146 & - & - & 253 & 3144 & 215 & 3145 \\
\hline $\mathrm{T}-1$ & 232 & 3213 & 158 & 3177 & 224 & 3179 & 157 & 3178 & 187 & 3171 & 191 & 3186 \\
\hline THS-1 & 267 & 3209 & 159 & 3203 & 252 & 3196 & - & - & 219 & 3200 & 199 & 3193 \\
\hline
\end{tabular}

Note: $\mathrm{C} / \mathrm{M}=$ Construction and maintenance (agencies); $\mathrm{O}=$ Operations (users); DNR = Do nothing reconstruct; $\mathrm{CIR}=$ Cold in-place recycling; $\mathrm{MO}=$ Mill and overlay; $\mathrm{MS}=$ Microsurface.

The overall lowest total LCC impact between these two cross-sections was the MO scenario. The lowering of LCC with mill and overlay is resulting from greater structural contribution from an overlay and having the IRI of the pavement return to new pavement condition with each application of overlay. It should be highlighted again that these results are made with realistic traffic conditions without consideration to lane closure time associated with the varying $M \& R$ strategies during the use phase. With the realistic traffic conditions and assumptions made in this study, it can be concluded that by optimizing M\&R type, material selection, and timing of treatment, decision makers can achieve a $2.72 \%$ difference in operations costs (users) and $47.6 \%$ difference in construction and maintenance costs (agency).

The varied LCC from agencies' and users' perspectives may lead to substantial economic and environmental tradeoffs for agencies and users. In comparing the GWP results to the LCC results, the most environmentally conscious decision may not appear as the most economical decision, assuming that economics is only assessed in terms of the construction and operational costs. Depending on whether decisions are being made from a user's perspective, agency perspective, or an overall combination of the two, the most economical and environmental alternative varies. Furthermore, future studies necessitate inclusion of GWP and LCC in a combined manner to optimize the costs, as well as financial impacts associated with unit GWP. Implementing a LCA-LCCA approach can help to identify those tradeoffs and identify both a cost-effective and eco-friendly pavement M\&R plan.

\subsection{Sensitivity Analysis}

A comparison for all M\&R options was performed as part of the sensitivity analysis, however, only results for the ARGG-1 cross-section are included for demonstration purposes. Figure 7 shows the percent different from baseline conditions ( $0 \%$ traffic growth and current fuel price) in terms of NPV when assuming low versus high fuel price scenario, as defined in Table 2.

There is minimal difference in terms of NPV over the analysis period when using either low or high fuel prices, as seen in Figure 7, with respect to baseline conditions. In general, this trend was consistent among all cross-sections considered in this case study. However, it should be noted that as traffic growth rate increases from 1 to 3 percent, the timing of microsurfacing becomes more critical as the impact on NPV increases.

The SHM-1 cross-section, which consisted of a surface course that was a highly polymer modified mixture, had the same fuel consumption cost regardless of the $M \& R$ treatment alternative, while holding all other parameters constant. In comparison, results for the other four cross-sections showed that microsurfacing at a trigger value of $2.5 \mathrm{~m} / \mathrm{km}$ consistently had a higher cost of fuel consumption as the traffic growth rate increased. 
Fuel Price Sensitivity

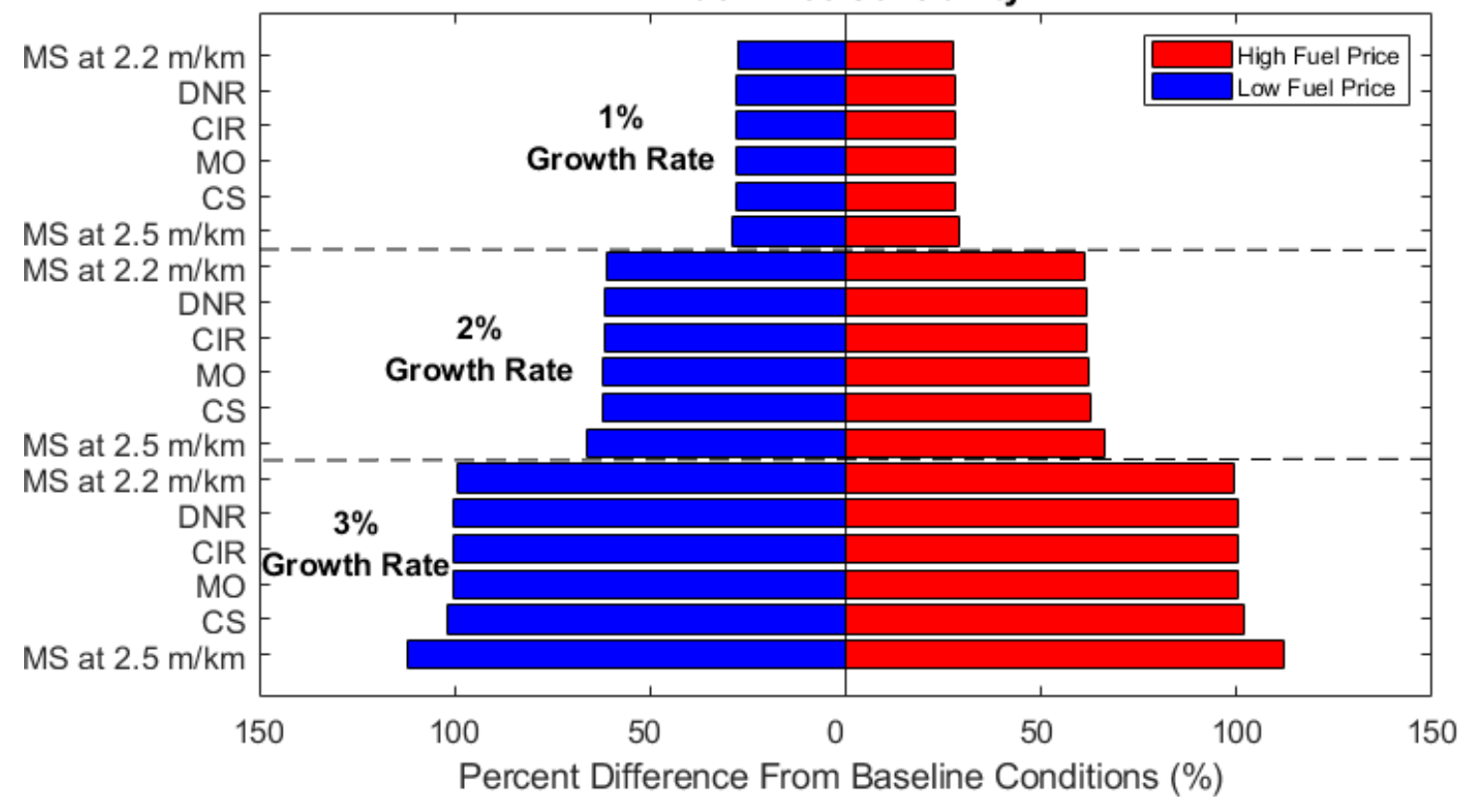

Figure 7. Fuel price sensitivity analysis example for ARGG-1 cross-section showing comparison of low fuel price scenario (blue) and high fuel price scenario (red) at three levels of traffic growth $(1 \%, 2 \%$, and $3 \%)$.

The cost of fuel consumption was not only dependent on traffic growth rate, but with the combination of traffic growth and CED reduction with the improvement of vehicle efficiency each decade. As the percentage of CED improvement and traffic growth rate increased, greater distinction in fuel consumption costs between the different $M \& R$ alternatives was observed. Overall, the MS at $2.5 \mathrm{~m} / \mathrm{km}$ M\&R alternative was the most sensitive to variations in traffic growth and CED improvement.

\section{Discussion}

Results from this study emphasize the importance of utilizing a holistic approach to decision and policy making regarding the M\&R of highway infrastructure systems. Economic and environmental tradeoffs for agencies and users exist and vary depending on the stakeholders considered or prioritized during the decision process. It is recommended that life cycle LCC, GWP, and CED be considered in the decision process. This recommendation is supported by the results presented in this paper, where use of only construction or only use phase LCA impacts may not yield optimal results.

The inclusion of realistic traffic conditions was shown to have an impact on the use phase of the LCA. This finding agreed with the literature review from other studies that have shown pavement surface roughness to affect vehicle fuel consumption and emissions during the use phase of the LCA. The framework presented in this study is unique in providing guidance on how to consider realistic traffic conditions using publicly available data sources. This contribution helps bridge the gap of moving from traditional pavement management to an LCA-LCCA informed approach. It also provided a method to consider not only agency cost but also user costs in the decision process.

From a user's perspective, the results from this study indicated that the most economical decision overall was to perform a microsurface when $2.2 \mathrm{~m} / \mathrm{km}$ IRI was reached (SHM-1 cross-section). The most carbon and energy efficient alternative was to perform crack sealant treatment every two years, followed by reconstruction once the terminal IRI was reached (ARRGG-1 cross-section). Similarly, from an agency-based perspective, the results showed that the most economical decision was microsurfacing at $2.5 \mathrm{~m} / \mathrm{km}$ scenario (ARGG-2 cross-section) and the lowest environmental impact was achieved by the crack sealant M\&R scenario (ARGG-1 cross-section). While this study only 
considered two different trigger values on when to apply the MS treatment, it is recommended that other IRI trigger times be evaluated to truly optimize the proper timing of M\&R strategies. It has been shown by Ogwang et al. in 2019 that agency-wide cracking-threshold policies affect the magnitude of future emissions and costs significantly [36]. It is an essential step to developing a cost-effective and environmentally friendly $M \& R$ plan to determine not only the correct type of $M \& R$ strategy to apply but the optimal timing of that treatment for a given pavement condition.

This study also showed that material characteristics matter, and what may be optimal for one highway will vary for a different highway. As an example, when considering ARGG-1 cross-section only, the optimal M\&R strategy selection is different. The M\&R alternative to perform microsurfacing at $2.5 \mathrm{~m} / \mathrm{km}$ trigger value results in the highest user cost, while allowing the road to degrade and reconstruct after reaching the terminal IRI value (DNR scenario) is the most expensive for agencies. When comparing all cross-sections together, SHM-1 is the worst overall from an agency's perspective and ARGG-1 is the worst overall from a user's perspective.

Meanwhile, from an environmental impact perspective, the highest agency impact for the ARGG-1 cross-section is observed for the DNR M\&R scenario and the highest environmental impact from users is seen with the MO M\&R scenario. Comparing all cross-sections reveals the highest environmental impacts for agencies with the T- 1 cross-section following the DNR M\&R scenario, and from user's perspective the ARGG-2 cross-section following the MS 2.5 M\&R scenario. Therefore, it can be concluded that decision makers must give attention to the pavement structure and its material characteristics, the type of M\&R options that are available within an agency, budget constraints, and potential environmental impacts that are associated with each when developing a long term M\&R plan for highway pavement infrastructure systems. This paper provides a methodology to develop that M\&R plan with the inclusion of realistic traffic conditions to evaluate LCA and LCCA impacts that can be applied to other highways and be implemented within infrastructure asset management systems with varying material properties, traffic conditions, and available M\&R strategies.

\section{Conclusions and Recommendations}

This study highlighted the importance of including realistic traffic conditions into the operations phase of a pavement LCA. A $6.4 \%$ difference in CED and GWP was observed with the inclusion of realistic traffic compared to steady state constant speed conditions. Results from this study also provided valuable insight into the trade-off between GWP, CED, and LCC impacts resulting from performing an LCA on varying pavement cross-sections and M\&R alternatives for both agencies and users. Cross-section type, in addition to the timing and type of M\&R strategy, has an impact on IRI, which translates into changes in GWP, CED, and LCC. In terms of NPV, the mill and overlay M\&R strategy had the lowest LCC for agencies and users. Results from this study also showed that optimization of M\&R type, material selection, and timing may lead to a $2.72 \%$ difference in operations costs (users) and a $47.6 \%$ difference in construction and maintenance costs (agency). Lastly, a sensitivity analysis was performed to assess the robustness of input assumptions, such as traffic growth, fuel price, and vehicle efficiency over the analysis period. Fuel price had minimal impact on LCA results, however traffic growth and CED improvements had an impact on results depending on type of pavement cross-section and the M\&R strategy applied.

It is recommended that further analysis be performed to investigate the effect the number of cycles performed for each M\&R alternative during the analysis period has on the overall LCA results. Since fuel consumption is directly related to CED and ultimately the IRI performance curve, a greater understanding of the effect each M\&R alternative has on the IRI performance is critical. For example, when applying a microsurface treatment at $2.2 \mathrm{~m} / \mathrm{km}$ IRI or $2.5 \mathrm{~m} / \mathrm{km}$ IRI, is it an accurate estimation to reset both IRI values by $0.7 \mathrm{~m} / \mathrm{km}$, or does it vary depending on the IRI value at the time of treatment? It is also recommended that a similar analysis be conducted on other M\&R alternatives, such as chip seal, fog seal, or full depth reclamation, to evaluate other practical M\&R techniques that may be used over the pavement design life. The M\&R scenarios presented in this study were held constant 
throughout the analysis period. However, in reality a combination of $M \& R$ alternatives would be performed on a given cross-section during its service life. A third recommendation would be to include lane closure and traffic delays related to the time to perform each M\&R strategy during the use phase of the LCA. All analysis and results presented in this paper focus on pavement management for a specific highway, however, there is a need to adapt the proposed framework for network level pavement management system implementation. Approaches similar to those discussed by Pantuso et al. could provide a pathway for such implementation [37].

The framework presented in this study may be applied to perform an LCA on a combination of M\&R techniques over the design life of a given pavement section. It is critical to include RTTD in the operation phase of a pavement LCA and to carefully consider the impacts of both users and agencies when making management decisions in order to optimize social, environmental, and economic impacts. The adoption of an LCA and LCCA approach in the pavement design and M\&R decision process can help to identify the most cost effective and environmentally friendly option benefiting all stakeholders.

Author Contributions: Conceptualization, E.V.D. and W.M.; methodology, K.E.H., E.V.D., and W.M.; formal analysis, K.E.H.; writing-original draft preparation, K.E.H.; writing—review and editing, E.V.D., K.E.H., and W.M.; visualization, K.E.H.; supervision, E.V.D. and W.M.; project administration, E.V.D. and W.M.

Funding: This research was partly funded by the University of New Hampshire Center for Infrastructure Resiliency to Climate.

Acknowledgments: Acknowledgement is extended to Shane Majenski for his contributions to the implementation of real time traffic data into the operations phase of the LCA. Thank you to Rasool Nemati for supply material characteristics information and testing results for typical New Hampshire asphalt materials used in this study. Support provided by Jo E. Sias and the UNH Center for Infrastructure Resiliency to Climate is much appreciated by researchers.

Conflicts of Interest: The funders had no role in the design of the study; in the collection, analyses, or interpretation of data; in the writing of the manuscript, or in the decision to publish the results.

\section{Appendix A}

\section{Appendix A.1. Life Cycle Inventory}

Table A1 provides a summary of the life cycle inventory and the corresponding sources used in this study [38].

Table A1. Life cycle inventory unit impact.

\begin{tabular}{|c|c|c|c|}
\hline Impact Unit & Units & Value & Source \\
\hline \multicolumn{4}{|l|}{ Production } \\
\hline Asphalt Concrete & MJ/ton & 641 & SimaPro \\
\hline Asphalt Concrete & $\mathrm{kg} \mathrm{CO}_{2} \mathrm{eq} / \mathrm{ton}$ & 84.7 & SimaPro \\
\hline Gravel & $\mathrm{MJ} /$ ton & 265 & SimaPro \\
\hline Gravel & $\mathrm{kg} \mathrm{CO}_{2} \mathrm{eq} / \mathrm{ton}$ & 14.1 & SimaPro \\
\hline Sand & $\mathrm{MJ} /$ ton & 61.8 & SimaPro \\
\hline Sand & $\mathrm{kg} \mathrm{CO}_{2} \mathrm{eq} / \mathrm{ton}$ & 4.25 & SimaPro \\
\hline \multicolumn{4}{|l|}{ Transportation } \\
\hline Dump Truck transportation & $\mathrm{MJ} /$ ton $\cdot$ mile & 5.134 & SimaPro \\
\hline Dump Truck transportation & $\mathrm{kg} \mathrm{CO} 2 \mathrm{eq} /$ ton $\cdot$ mile & 0.321 & SimaPro \\
\hline \multicolumn{4}{|l|}{ Construction } \\
\hline Asphalt Paver (Productivity) & ton $/ \mathrm{h}$ & 10 & PaLATE \\
\hline Asphalt Rolling-TandemIngersol Rand DD90HF (productivity) & ton $/ \mathrm{h}$ & 395 & PaLATE \\
\hline Asphlat Roller-Pheumatic Dynapac CP134 & ton/h & 884 & PaLATE \\
\hline Unbound Material Placement-Caterpillar $120 \mathrm{H}$ & ton $/ \mathrm{h}$ & 300 & PaLATE \\
\hline Unbound Material Compaction (productivity) & ton $/ \mathrm{h}$ & 1832 & PaLATE \\
\hline Construction Machine Operation & $\mathrm{MJ} /$ ton & 10816 & SimaPro \\
\hline Construction Machine Operation & $\mathrm{kg} \mathrm{CO}{ }_{2} \mathrm{eq} / \mathrm{hr}$ & 72 & SimaPro \\
\hline \multicolumn{4}{|l|}{ Maintenance } \\
\hline Asphalt Milling & ton $/ \mathrm{h}$ & 6.23 & SimaPro \\
\hline Asphalt Milling & $\mathrm{kg} \mathrm{CO} 2 \mathrm{eq} / \mathrm{yd}^{3}$ & 0.409 & SimaPro \\
\hline CIR Recycler 800 hp (Productivity) & ton $/ \mathrm{h}$ & 1713 & PaLATE \\
\hline
\end{tabular}


Table A1. Cont.

\begin{tabular}{cccc}
\hline Impact Unit & Units & Value & Source \\
\hline CIR Recycler 800 hp (Productivity) & $\mathrm{kg} \mathrm{CO}_{2} \mathrm{eq} / \mathrm{yd}^{3}$ & 0.99 & PaLATE \\
Crack Seal Treatment & $\mathrm{MJ}^{2} \mathrm{ft}^{2}$ & 0.92 & Chehovits et al., 2010 \\
Crack Seal Treatment & $\mathrm{kg} \mathrm{CO} 2 \mathrm{eq} / \mathrm{ft}^{2}$ & 0.000067 & Chehovits et al., 2010 \\
Operation & $\mathrm{MJ} / \mathrm{gal}$ & 132 & EPA \\
Gasoline & $\mathrm{lb} \mathrm{CO}$ eq/gal & 19.6 & EPA \\
Gasoline & $\mathrm{MJ} / \mathrm{gal}$ & 137.7 & EPA \\
Diesel & $\mathrm{lb} \mathrm{CO} 2$ eq/gal & 22.4 & EPA \\
Diesel & &
\end{tabular}

\section{Appendix A.2. Life Cycle Analysis Period}

Table A2 summarize how many cycles of each M\&R type were completed during the analysis period by cross-section type. In Table A2, highlighted values in bold denote the M\&R type that controlled the terminal year (i.e., complete 3 full cycles in the longest period of time).

Table A2. Summary of M\&R cycles by cross-section over the course of the analysis period, where numbers in bold represent controlling (longest) maintenance and rehabilitation treatment to complete 3 full cycles.

\begin{tabular}{cccccc}
\hline \multirow{2}{*}{ M\&R Alternative } & \multicolumn{7}{c}{ Cross-Section } \\
\cline { 2 - 7 } & ARGG-1 & ARGG-2 & SHM-1 & T-1 & THS-1 \\
\hline Do Nothing Reconstruct & 5 & 5 & 6 & 5 & 6 \\
\hline Crack Sealant & 5 & 5 & 5 & 5 & 5 \\
\hline Microsurface @ 2.2 m/km & $\mathbf{3}$ & $\mathbf{3}$ & 4 & $\mathbf{3}$ & 4 \\
\hline Microsurface @ 2.5 m/km & 4 & 4 & $\mathbf{3}$ & 4 & $\mathbf{3}$ \\
\hline Cold-In-Place Recycling & 7 & 6 & 9 & 6 & 9 \\
\hline Mill and Overlay & 6 & 6 & & 6 & \\
\hline
\end{tabular}

Figures A1-A5 show the M\&R timing sequences for all cross-sections considered in this study.

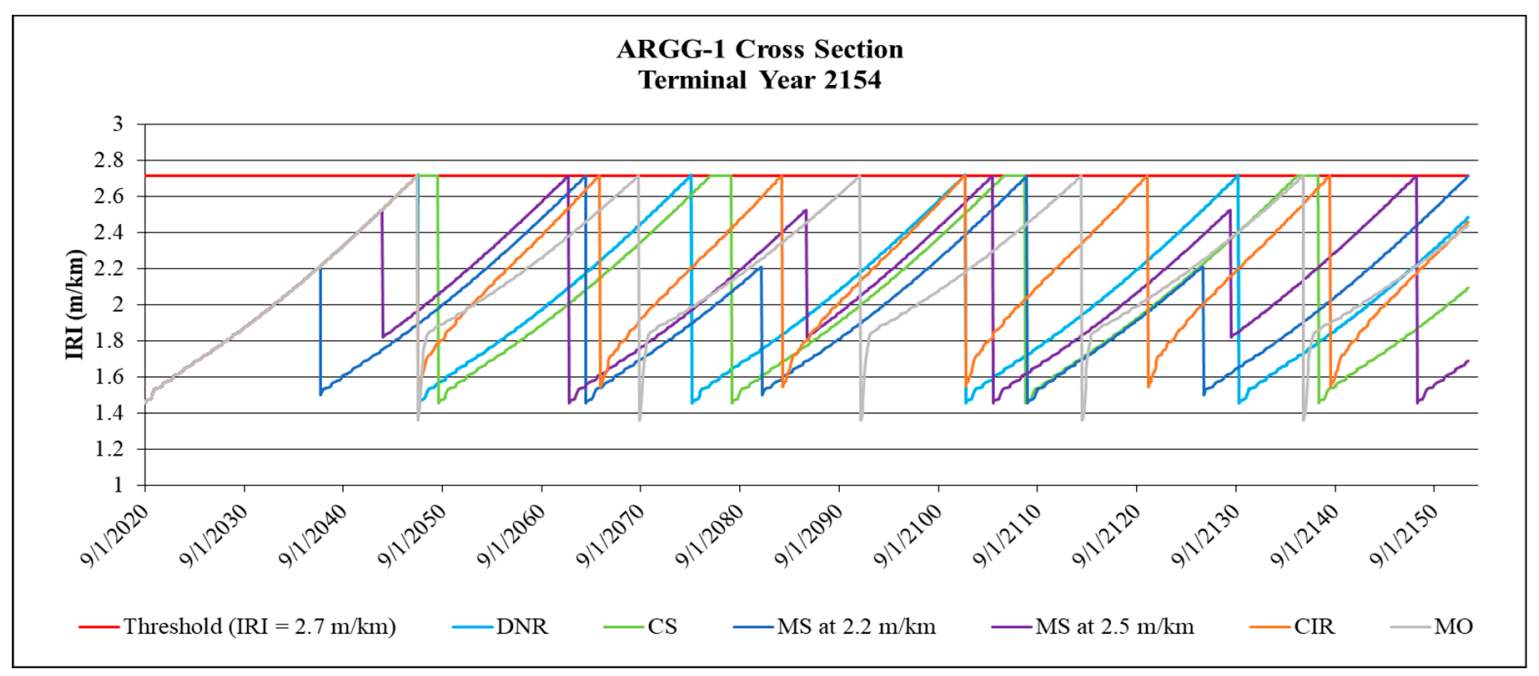

Figure A1. ARGG-1 cross-section M\&R activity timing. 


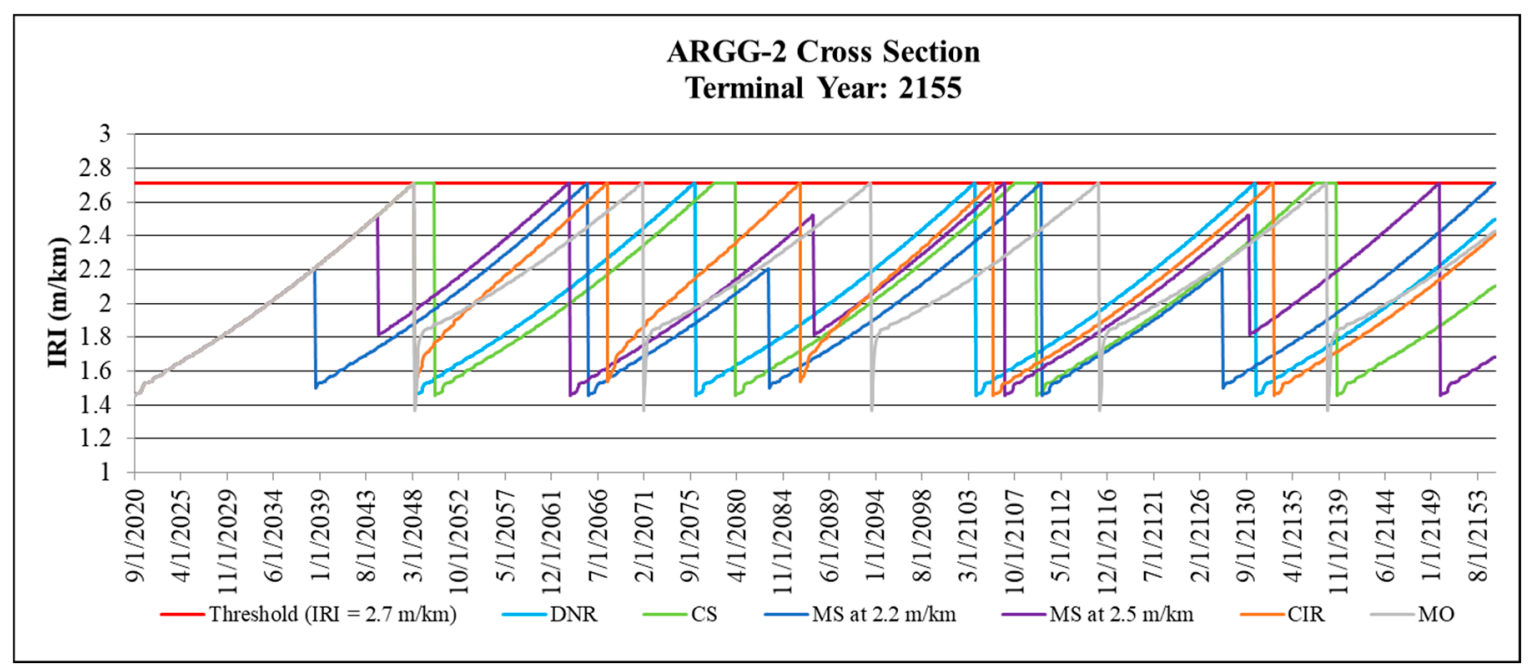

Figure A2. ARGG-2 cross-section of M\&R activity timing.

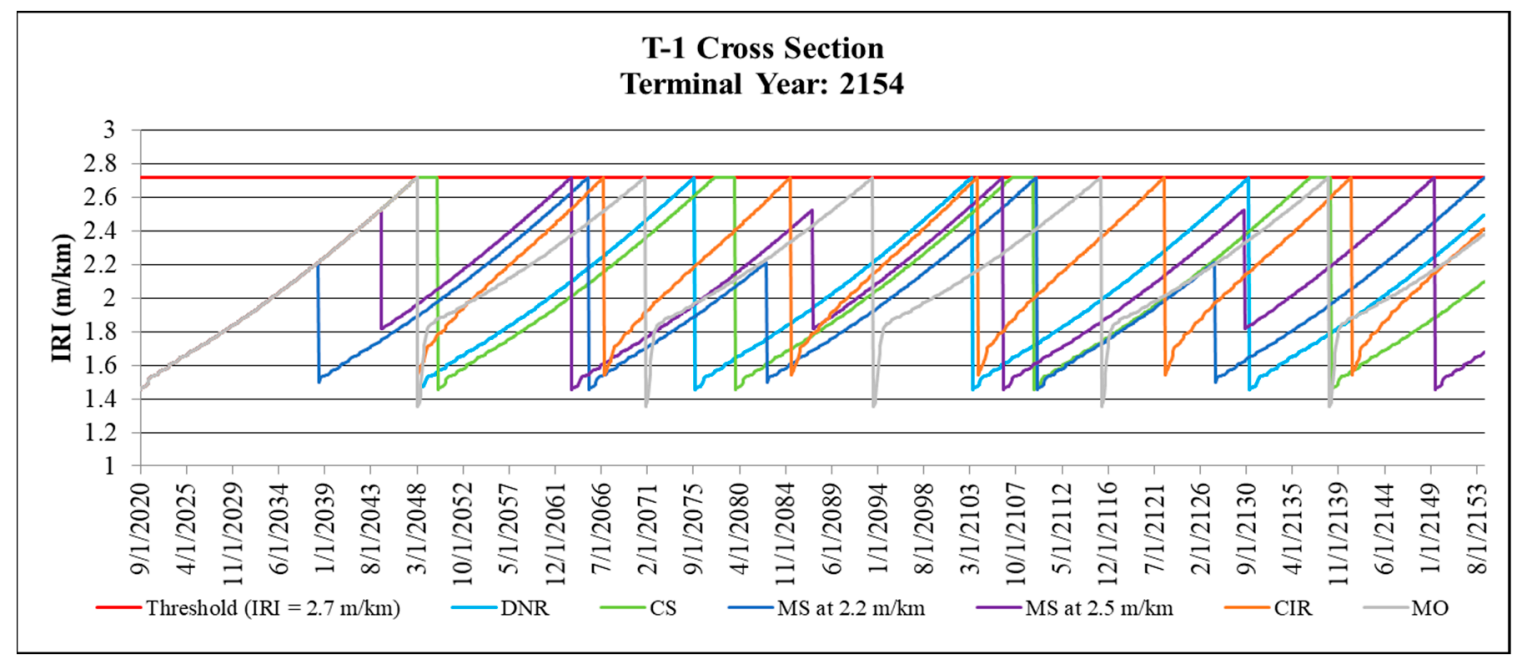

Figure A3. T-1 cross-section of M\&R activity timing.

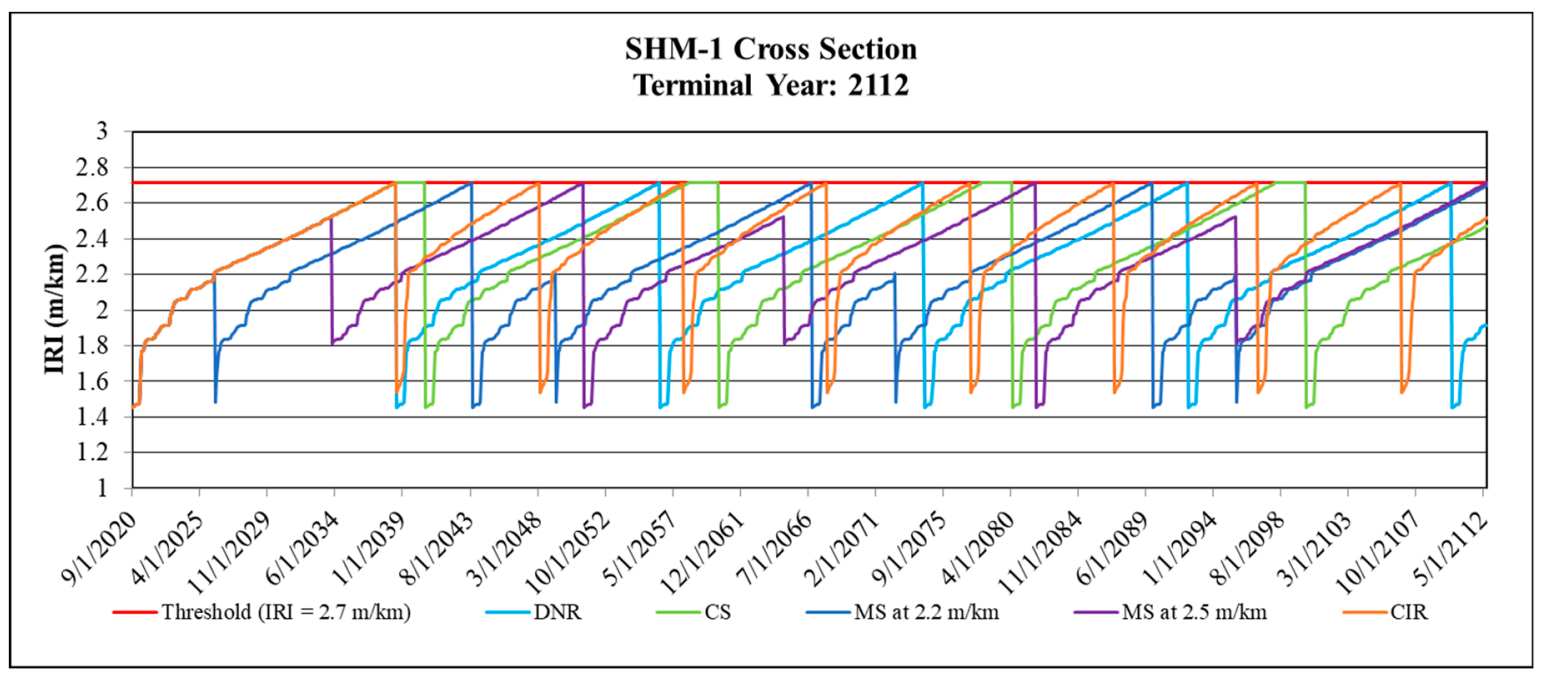

Figure A4. SHM-1 cross-section of M\&R activity timing. 


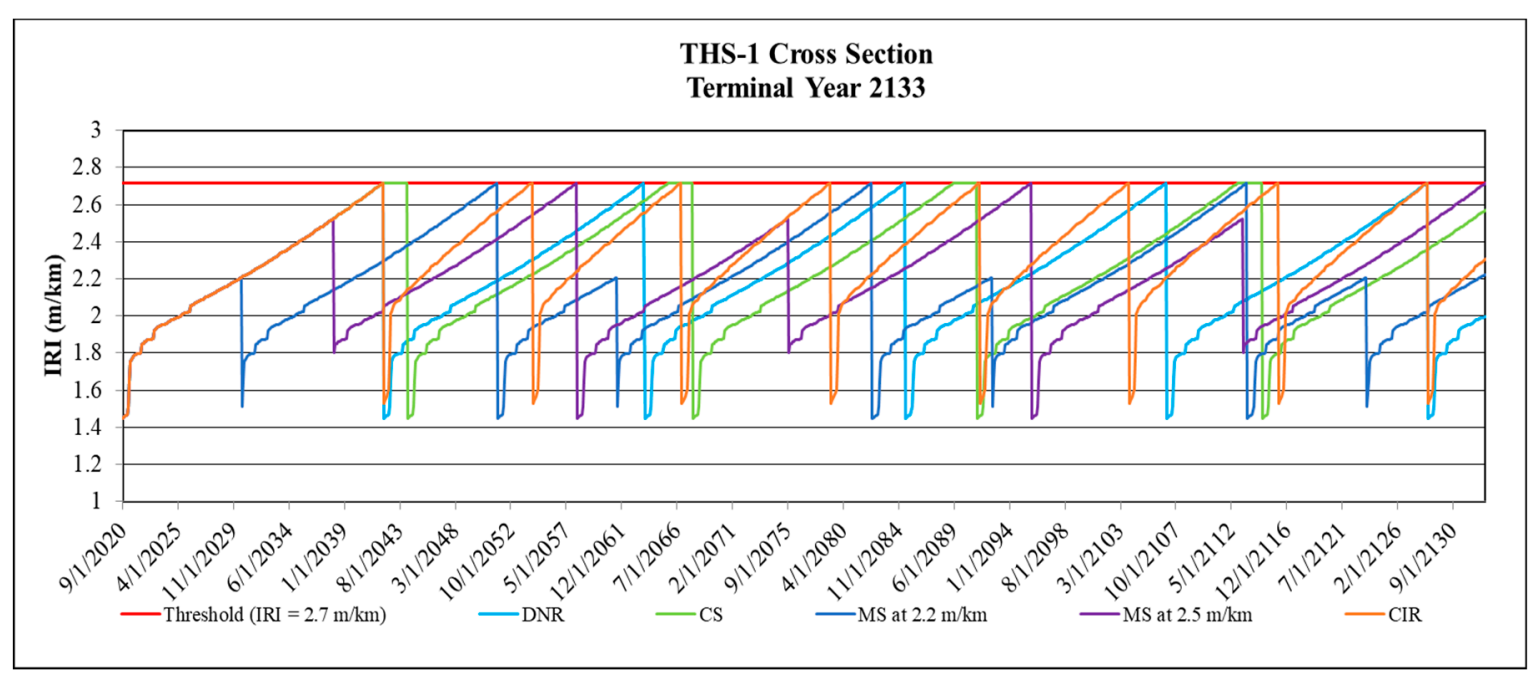

Figure A5. THS-1 cross-section of M\&R activity timing.

Appendix A.3. Implementation of RTTD

Included in Appendix A.3 is a summary of the information used in this study to implement the 6-step process to incorporate realistic traffic conditions in the use phase of an LCA.

Step 1 
Table A3. Step 1, NCHRP-720 default vehicle and tire characteristics [12]

\begin{tabular}{|c|c|c|c|c|c|c|c|c|c|c|c|c|c|c|c|c|}
\hline Vehicle Class & $\begin{array}{c}\text { Number of } \\
\text { Axles }\end{array}$ & $\mathrm{N} w$ & $\begin{array}{c}\mathrm{M} \\
\text { (tons) }\end{array}$ & Kcr2 & $\mathrm{CD}$ & $\begin{array}{l}\mathrm{AF} \\
\left(\mathrm{m}^{2}\right)\end{array}$ & WD & $\begin{array}{l}\text { Tire } \\
\text { Type }\end{array}$ & CR1 & $b 11$ & $b 12$ & $b 13$ & 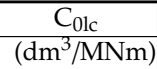 & \begin{tabular}{|c|}
$\mathrm{C}_{\mathrm{tcle}}$ \\
$\left(\mathrm{dm}^{3} / \mathrm{MNm}\right)$
\end{tabular} & $\operatorname{VOL}\left(\mathrm{dm}^{3}\right)$ & VEHF AC \\
\hline Small car & 2 & 4 & 1.9 & 0.5 & 0.42 & 1.9 & 0.62 & Radial & 1 & 22.2 & 0.11 & 0.13 & 0.01747 & 0.001 & 1.4 & 2 \\
\hline Medium car & 2 & 4 & 1.9 & 0.5 & 0.42 & 1.9 & 0.62 & Radial & 1 & 22.2 & 0.11 & 0.13 & 0.01747 & 0.001 & 1.4 & 2 \\
\hline Large car & 2 & 4 & 1.9 & 0.5 & 0.42 & 1.9 & 0.62 & Radial & 1 & 22.2 & 0.11 & 0.13 & 0.01747 & 0.001 & 1.4 & 2 \\
\hline Van & 2 & 4 & 2.54 & 0.67 & 0.5 & 2.9 & 0.7 & Radial & 1 & 25.9 & 0.09 & 0.1 & 0.01602 & 0.00092 & 1.6 & 2 \\
\hline Four-wheel drive & 2 & 4 & 2.5 & 0.58 & 0.5 & 2.8 & 0.7 & Radial & 11 & 25.9 & 0.09 & 0.1 & 0.01602 & 0.00092 & 1.6 & 2 \\
\hline Light truck & 2 & 4 & 4.5 & 0.99 & 0.6 & 5 & 0.8 & Radial & 1 & 29.6 & 0.08 & 0.08 & 0.01602 & 0.00092 & 1.6 & 2 \\
\hline Medium truck & 2 & 6 & 6.5 & 0.99 & 0.6 & 5 & 0.8 & Bias & 1.3 & 29.6 & 0.08 & 0.11 & 0.02999 & 0.00099 & 6 & 1 \\
\hline Heavy truck & 3 & 10 & 13 & 1.1 & 0.7 & 8.5 & 1.05 & Bias & 1.3 & 38.85 & 0.06 & 0.11 & 0.03829 & 0.00135 & 8 & 1 \\
\hline Articulated truck & 5 & 18 & 15.6 & 1.1 & 0.8 & 9 & 1.05 & Bias & 1.3 & 38.85 & 0.06 & 0.2 & 0.04328 & 0.00153 & 8 & 1 \\
\hline Mni bus & 2 & 4 & 2.16 & 0.67 & 0.5 & 2.9 & 0.7 & Radial & 1 & 25.9 & 0.09 & 0.1 & 0.01747 & 0.00092 & 1.6 & 2 \\
\hline Light bus & 2 & 4 & 2.5 & 0.99 & 0.5 & 4 & 0.8 & Radial & 1 & 29.6 & 0.08 & 0.08 & 0.01747 & 0.00092 & 1.6 & 2 \\
\hline Medium bus & 2 & 6 & 4.5 & 0.99 & 0.6 & 5 & 1.05 & Bias & 1.3 & 38.85 & 0.06 & 0.06 & 0.02999 & 0.00099 & 6 & 1 \\
\hline Heavy bus & 3 & 10 & 13 & 1.1 & 0.7 & 6.5 & 1.05 & Bias & 1.3 & 38.85 & 0.06 & 0.06 & 0.03829 & 0.00135 & 8 & 1 \\
\hline Coach & 3 & 10 & 13.6 & 1.1 & 0.7 & 6.5 & 1.05 & Bias & 1.3 & 38.85 & 0.06 & 0.06 & 0.03829 & 0.00135 & 8 & 1 \\
\hline
\end{tabular}


Table A4. Step 1, NCHRP-720, HDM 4 tractive force model vehicle characteristic formulas [12].

\begin{tabular}{|c|c|c|}
\hline Name & Description & Unit \\
\hline Aerodynamic forces $(\mathrm{Fa})$ & $\begin{array}{l}F a=0.5^{*} \rho^{*} C D^{*} A F^{*} v^{2} \\
\text { Drag coefficient }(\text { Table 4-12) } \\
\text { Frontal area (Table 4-12) } \\
\text { Mass density of the air (default }=1.2 \text { ) } \\
\text { Vehicle speed }\end{array}$ & $\begin{array}{l}\mathrm{N} \\
\text { dimensionless } \\
\mathrm{m}^{2} \\
\mathrm{~kg} / \mathrm{m}^{3} \\
\mathrm{~m} / \mathrm{s}\end{array}$ \\
\hline Gradient forces $(\mathrm{Fg})$ & $\begin{array}{l}F g=M * G R * g \\
\text { Vehicle weight (Table 4-12) } \\
\text { Gradient } \\
\text { Gravity }\end{array}$ & $\begin{array}{l}\mathrm{N} \\
\mathrm{kg} \\
\text { radians } \\
\mathrm{m} / \mathrm{s}^{2}\end{array}$ \\
\hline $\begin{array}{r}R \\
\text { Superelevation }(e) \\
N w \\
\text { Tire stiffness }(C s) \\
a 0 \text { to } a 2\end{array}$ & $\begin{array}{l}F_{C}=\max \left(0, \frac{\left(\frac{M * v^{2}}{R}-M^{*} g^{*} e\right)^{2}}{N w * C s} * 10^{-3}\right) \\
\text { Curvature radius (Default }=3000) \\
e=\max (, 0.045-0.68 * L n(R)) \\
\text { Number of wheels (Table 4-12) } \\
C s=a 0+a 1^{*} \frac{M}{N w}+a 2 *\left(\frac{M}{N w}\right)^{2} \\
\text { Model parameter (Table 4-10) }\end{array}$ & $\begin{array}{l}\mathrm{N} \\
\mathrm{m} \\
\mathrm{m} / \mathrm{m} \\
\text { dimensionless } \\
\mathrm{kN} / \mathrm{rad} \\
\text { dimensionless }\end{array}$ \\
\hline $\begin{array}{r}\text { Rolling resistance }\left(\boldsymbol{F}_{r}\right) \\
\qquad C R 1 \\
\text { Rolling resistance parameters } \\
(b 11, b 12, b 13)\end{array}$ & $\begin{array}{l}F r=C R 2^{*}\left(b 11^{*} N w+C R 1^{*}\left(b 12^{*} M+b 13^{*} v^{2}\right)\right) \\
\text { Rolling resistance tire factor (Table 4-12) } \\
\left\{\begin{array}{l}b 11=37^{*} D w \\
b 12=0.064 / D w \\
b 13=0.012^{*} N w / D w^{2}\end{array}\right.\end{array}$ & $\begin{array}{l}\mathrm{N} \\
\text { factor } \\
\text { factors }\end{array}$ \\
\hline $\begin{array}{r}D w \\
\text { Rolling resistance surface factor }(C R 2)\end{array}$ & $\begin{array}{l}\text { Diameter of wheel } \\
=K c r 2[a 0+a 1 * T d s p+a 2 * I R I+a 3 * D E F]\end{array}$ & factor \\
\hline $\begin{array}{r}K c r 2 \\
a 0 \text { to } a 3\end{array}$ & $\begin{array}{l}\text { Calibration factor (Table 4-12) } \\
\text { Model coefficient (Table 4-11) }\end{array}$ & $\begin{array}{l}\text { factor } \\
\text { dimensionless }\end{array}$ \\
\hline $\begin{array}{r}\text { Texture depth using sand patch } \\
\text { method (Tdsp) }\end{array}$ & $T d s p=1.02 * M P D+0.28$ & $\mathrm{~mm}$ \\
\hline $\begin{array}{r}\text { MPD } \\
\text { IRI }\end{array}$ & $\begin{array}{l}\text { Mean Profile Depth } \\
\text { International roughness index }\end{array}$ & $\begin{array}{l}\mathrm{mm} \\
\mathrm{m} / \mathrm{km}\end{array}$ \\
\hline$D E F$ & Benkelman Beam rebound deflection & $\mathrm{mm}$ \\
\hline
\end{tabular}

Table A5. Acceleration rates corresponding to Google Maps predicted congestion level orange, red, and dark red using Strategic Highway Research Program 2 (SHRP2) Naturalistic Driving Study databases.

\begin{tabular}{ccc}
\hline & Car Acceleration $\left(\mathbf{m} / \mathbf{s}^{2}\right)$ & Truck Acceleration $\left(\mathrm{m} / \mathbf{s}^{2}\right)$ \\
\hline Orange & 2.94 & 1.47 \\
\hline Red & 2.94 & 1.47 \\
\hline Dark Red & 2.9 & 1.45 \\
\hline
\end{tabular}

Step 2

$\begin{aligned} \text { VSP } & =\frac{\text { Power }}{\text { Mass }}=\frac{\frac{\mathrm{d}}{\mathrm{dt}}\left(\mathrm{E}_{\text {Kinetic }}+\mathrm{E}_{\text {Potential }}\right)+\mathrm{F}_{\text {Rolling }} \cdot \mathrm{v}+\mathrm{F}_{\text {Aerodynamic }} \cdot \mathrm{v}+\mathrm{F}_{\text {int ernal friction }} \cdot \mathrm{v}}{\mathrm{m}}= \\ & \approx \mathrm{v} \cdot \mathrm{a} \cdot\left(1+\varepsilon_{\mathrm{i}}\right)+\mathrm{g} \cdot \operatorname{grade} \cdot \mathrm{v}+\mathrm{g} \cdot \mathrm{C}_{\mathrm{R}} \cdot \mathrm{v}+\frac{1}{2} \rho_{\mathrm{a}} \mathrm{C}_{\mathrm{D}} \frac{\mathrm{A}}{\mathrm{m}}\left(\mathrm{v}+\mathrm{v}_{\mathrm{w}}\right)^{2} \cdot \mathrm{v}+\mathrm{C}_{\text {if }} \cdot \mathrm{v}\end{aligned}$

Figure A6. Step 2, vehicle specific power formula [29]. 
where $\mathrm{v}=$ vehicle speed, $\mathrm{m}=$ vehicle mass, $\mathrm{a}=$ vehicle acceleration, $\varepsilon_{i}=$ Mass factor, $C_{D}=$ drag coefficient, $C_{R}=$ coefficient of rolling resistance, $\mathrm{A}=$ frontal area of the vehicle, $\rho_{a}=$ ambient air density, $v_{w}=$ headwind into the vehicle.

Step 3

\begin{tabular}{|c|c|}
\hline VSP Bin & Characteristics \\
\hline 0 & Braking \\
\hline 1 & Idling \\
\hline 11 & Low Speed Coasting; VSP $<0 ; 1<=$ Speed $<25$ \\
\hline 12 & Cruise/Acceleration; $0<=\mathrm{VSP}<3 ; 1<=$ Speed $<25$ \\
\hline 13 & Cruise/Acceleration; $3<=\mathrm{VSP}<6 ; 1<=$ Speed $<25$ \\
\hline 14 & Cruise/Acceleration; $6<=\mathrm{VSP}<9 ; 1<=$ Speed $<25$ \\
\hline 15 & Cruise/Acceleration; $9<=\mathrm{VSP}<12 ; 1<=$ Speed $<25$ \\
\hline 16 & Cruise/Acceleration; $12<=$ VSP; $1<=$ Speed $<25$ \\
\hline 21 & Moderate Speed Coasting; VSP $<0 ; 25<=$ Speed $<50$ \\
\hline 22 & Cruise/Acceleration: $0<=\mathrm{VSP}<3 ; 25<=$ Speed $<50$ \\
\hline 23 & Cruise/Acceleration; $3<=\mathrm{VSP}<6 ; 25<=$ Speed $<50$ \\
\hline 24 & Cruise/Acceleration; $6<=\mathrm{VSP}<9 ; 25<=$ Speed $<50$ \\
\hline 25 & Cruise/Acceleration; $9<=\mathrm{VSP}<12 ; 25<=$ Speed $<50$ \\
\hline 26 & Cruise/Acceleration; $12<=\mathrm{VSP} ; 25<=$ Speed $<50$ \\
\hline 27 & Cruise/Acceleration; $12<=\mathrm{VSP}<18 ; 25<=$ Speed $<50$ \\
\hline 28 & Cruise/Acceleration; $18<=\mathrm{VSP}<24 ; 25<=$ Speed $<50$ \\
\hline 29 & Cruise/Acceleration; $24<=\mathrm{VSP}<30 ; 25<=$ Speed $<50$ \\
\hline 30 & Cruise/Acceleration; $30<=$ VSP; $25<=$ Speed $<50$ \\
\hline 33 & Cruise/Acceleration; VSP $<6 ; 50<=$ Speed \\
\hline 35 & Cruise/Acceleration; $6<=\mathrm{VSP}<12 ; 50<=$ Speed \\
\hline 36 & Cruise/Acceleration; $12<=$ VSP; $50<=$ Speed \\
\hline 37 & Cruise/Acceleration; $12<=\mathrm{VSP}<18 ; 50<=$ Speed \\
\hline 38 & Cruise/Acceleration; $18<=\mathrm{VSP}<24 ; 50<=$ Speed \\
\hline 39 & Cruise/Acceleration; $24<=\mathrm{VSP}<30 ; 50<=$ Speed \\
\hline 40 & Cruise/Acceleration; $30<=$ VSP; $50<=$ Speed \\
\hline
\end{tabular}

Figure A7. Step 3, MOVES vehicle specific power (VSP) Bins examples.

Step 4

\begin{tabular}{|c|c|c|}
\hline \multirow[t]{5}{*}{ Run } & Header Item: & Item Value \\
\hline & Report Description: & Summary Report \\
\hline & Report Date/Time: & $2017-10-3017: 47: 0$ \\
\hline & MOVES Output Database: & VehicleClass_Out \\
\hline & Emission Process: & All \\
\hline 33 & Run Date/Time: & $2017-10-2601: 09: 46.0$ \\
\hline 33 & Run Specification: & 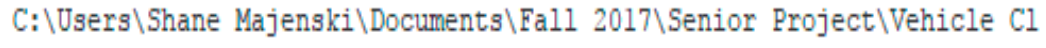 \\
\hline 33 & Run Spec File Date/Time: & $2017-10-2601: 09: 18.0$ \\
\hline 33 & Run Spec Description: & Vehicle Classification Run \\
\hline 33 & Mass Units: & $g$ \\
\hline 33 & Energy Units: & KJ \\
\hline 33 & Distance Units: & $\mathrm{mi}$ \\
\hline 33 & Time Units: & hour \\
\hline
\end{tabular}

Figure A8. Step 4, MOVES Run Specification output information. 


\begin{tabular}{|c|c|c|}
\hline Run & TotalEnergy & CO2_Equiv \\
\hline 33 & 82416 & 6072 \\
\hline
\end{tabular}

Figure A9. Step 4, MOVES output.

Step 5

Table A6. Step 5, MOVES interpolation—no change in MOVES output from $0 \mathrm{~m} / \mathrm{km}$ International Roughness Index (IRI) to $19.1 \mathrm{~m} / \mathrm{km}$ IRI.

\begin{tabular}{|c|c|c|c|c|c|c|c|c|c|c|c|c|c|c|c|}
\hline \\
\hline Length (Miles) & s)] Grade I & & $\mathrm{me}$ & & $m+s^{5} 2$ & & & & & & & ourcel & & & 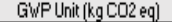 \\
\hline & 1 & 0 & 60 & 26.8224 & & 0 & 0.000252 & 0.059 & 6.448402596 & 35 & Good & 11 & 3 & 2.689 & 0.194 \\
\hline & 1 & 0 & 60 & 26.8224 & & 0.25 & 0.000252 & 0.062 & 6.520946694 & 35 & Good & 11 & 3 & 2.689 & 0.19 \\
\hline & 1 & 0 & 60 & 26.8224 & & 0.5 & 0.000252 & 0.065 & 6.593490792 & 35 & Good & 11 & 3 & 2.689 & 0.19 \\
\hline & 1 & 0 & 60 & 26.8224 & & 0.75 & 0.000252 & 0.067 & 6.66603489 & 35 & Good & 11 & 3 & 2.689 & 0.19 \\
\hline & 1 & 0 & 60 & 26.8224 & & 0 & 0.000252 & 0.070 & 6.738578987 & 35 & Good & 11 & 3 & 2.689 & 0.19 \\
\hline & 1 & 0 & 60 & 26.8224 & & 1.25 & 0.000252 & 0.073 & 6.811123085 & 35 & Good & 11 & 3 & 2.689 & 0.19 \\
\hline & 1 & 0 & 60 & 26.8224 & & 1.5 & 0.000252 & 0.075 & 6.883667183 & 35 & Good & 11 & 3 & 2.689 & 0.19 \\
\hline & 1 & 0 & 60 & 26.8224 & & 1.75 & 0.000252 & 0.078 & 6.956211281 & 35 & Acceptable & 11 & 3 & 2.689 & 0.19 \\
\hline & 1 & 0 & 60 & 26.8224 & & 0 & 0.000252 & 0.081 & 7.028755378 & 35 & Acceptable & 11 & 3 & 2.689 & 0.19 \\
\hline & 1 & 0 & 60 & 26.8224 & & 2.25 & 0.000252 & 0.083 & 7.101299476 & 35 & Acceptable & 11 & 3 & 2.689 & 0.19 \\
\hline & 1 & 0 & 60 & 26.8224 & & 2.5 & 0.000252 & 0.086 & 7.173843574 & 35 & Acceptable & 11 & 3 & 2.689 & 0.19 \\
\hline & 1 & 0 & 60 & 26.8224 & & 2.75 & 0.000252 & 0.089 & 7.246387672 & 35 & Bad & 11 & 3 & 2.689 & 0.19 \\
\hline & 1 & 0 & 60 & 26.8224 & & 0 & 0.000252 & 0.092 & 7.318931769 & 35 & Bad & 11 & 3 & 2.689 & 0.19 \\
\hline & 1 & 0 & 60 & 26.8224 & & 3.25 & 0.000252 & 0.094 & 7.391475867 & 35 & Bad & 11 & 3 & 2.689 & 0.19 \\
\hline & 1 & 0 & 60 & 26.8224 & & 3.5 & 0.000252 & 0.097 & 7.464019965 & 35 & Bad & 11 & 3 & 2.689 & 0.19 \\
\hline & 1 & 0 & 60 & 26.8224 & & 19.1 & 0.000252 & 0.266 & 11.99077166 & 35 & Bad & 11 & 3 & 2.689 & 0.19 \\
\hline & 1 & 0 & 60 & 26.8224 & & 19.2 & 0.000252 & 0.267 & 12.0197893 & 37 & Bad & 11 & 35 & 3.44 & 0.24 \\
\hline
\end{tabular}

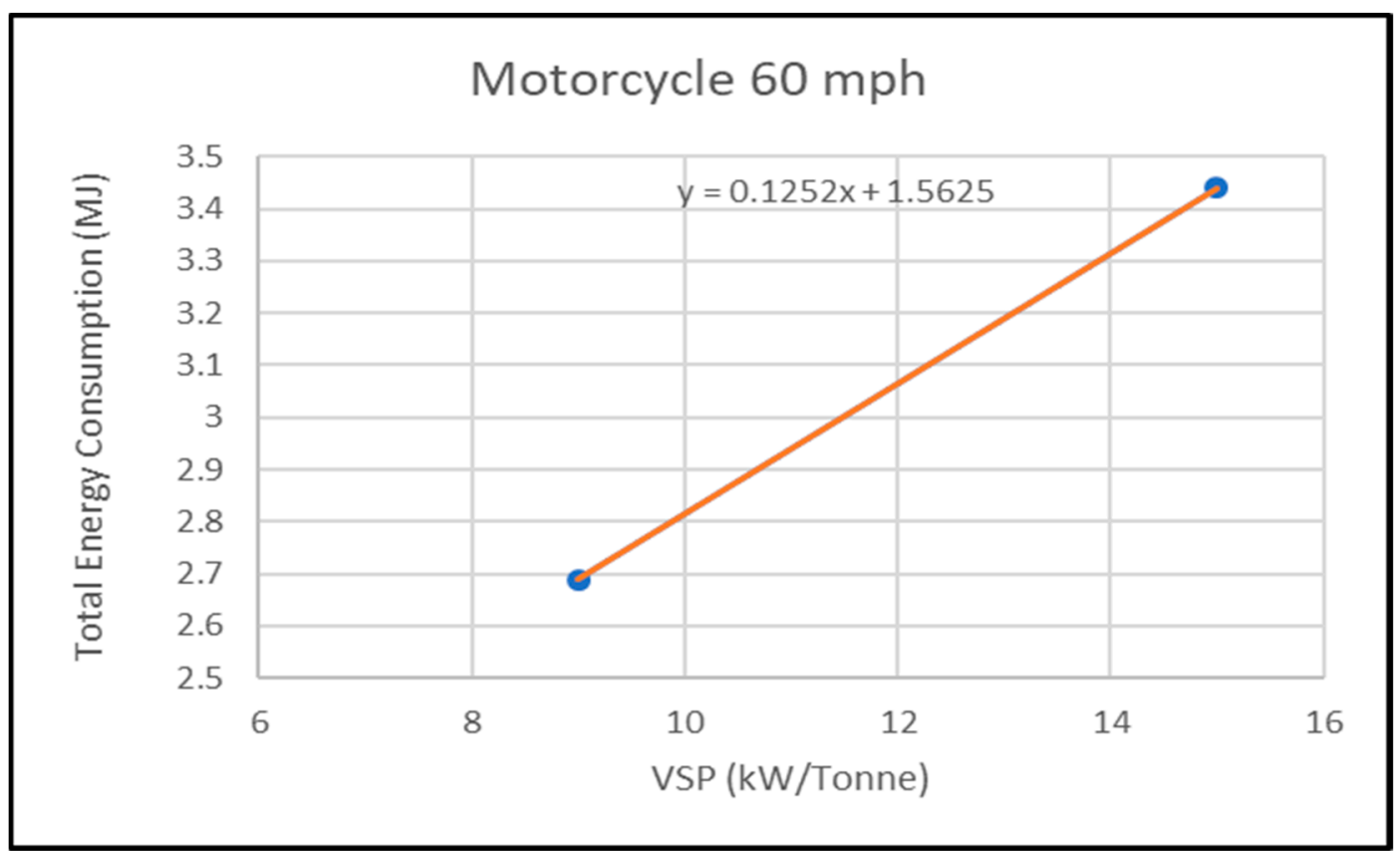

Figure A10. Step 5, MOVES interpolation for total energy consumption. 


\section{Step 6}

Table A7. Step 6, MOVES interpolation output for varying vehicle classifications and traffic conditions. Colors represent traffic congestion and resulting speeds where green is free flow at posted speed limit of $60 \mathrm{mph}$, orange is $40 \mathrm{mph}$, red is $20 \mathrm{mph}$ and dark red is $10 \mathrm{mph}$.

\begin{tabular}{|c|c|c|c|c|c|c|c|c|c|c|c|c|c|c|c|}
\hline \multirow[b]{2}{*}{ Color } & \multirow[b]{2}{*}{ Acceleration/Deceleration } & \multirow[b]{2}{*}{ Speed $(\mathrm{mph})$} & \multicolumn{13}{|c|}{ Total Energy Consumption (MJ)/ 1 Mile } \\
\hline & & & Motorcycle & Car & Light Truck & Bus & $2 \mathrm{ASU}$ & 3ASU & $>3 \mathrm{ASU}$ & $\angle 5 A 2 U$ & $5 \mathrm{~A} 2 \mathrm{U}$ & $>5 \mathrm{~A} 2 \mathrm{U}$ & $<6 \mathrm{~A}>2 \mathrm{~A}$ & $6 \mathrm{~A}>2 \mathrm{~A}$ & $>6 \mathrm{~A}>2 \mathrm{~A}$ \\
\hline Green & None & 60| & 2.370 & 2.823 & 3.483 & 55.351 & 32.963 & B 45.902 & 234.629 & 82.416 & 82.416 & 82.552 & 82.552 & 82.552 & 82.552 \\
\hline Green & Deceleration & 60 & 2.689 & 2.023 & 2.374 & 24.605 & 5.269 & 7) 20.848 & 6.615 & 82.416 & 82.416 & 82.552 & 82.552 & 82.552 & 82.552 \\
\hline Orange & None & 40 & 3.011 & 2.600 & 2.824 & 46.748 & 26.751 & $1 \quad 44.902$ & 20.535 & 123.787 & 123.787 & 123.992 & 123.992 & 123.992 & 123.992 \\
\hline Orange & Deceleration & 40 & 2.590 & 2.101 & 2.436 & 19.818 & 6.310 & 17.810 & 2.406 & 157.131 & 157.131 & 157.389 & 157.389 & 157.389 & 157.389 \\
\hline Orange & Acceleration & 40 & 4.339 & 7.671 & 8.930 & 104.757 & 72.103 & B 99.465 & 66.715 & 123.787 & 123.787 & 123.992 & 123.992 & 123.992 & 123.992 \\
\hline Ted & None & 20 & 3.229 & 3.829 & 4.126 & 42.795 & 24.344 & 42.045 & 28.862 & 95.475 & 95.475 & 95.633 & 95.633 & 95.633 & 95.633 \\
\hline Sed & Deceleration & 20 & 3.446 & 3.123 & 3.674 & 20.755 & 3.083 & $\begin{array}{ll}3 & 19.807\end{array}$ & 5.965 & 95.475 & 95.475 & 95.633 & 95.633 & 95.633 & 95.633 \\
\hline ed & Acceleration & 20 & 4.846 & 8.287 & 9.300 & 79.295 & 76.308 & $\begin{array}{l}3 \quad 79.466 \\
\end{array}$ & 572.208 & 95.475 & 95.475 & 95.633 & 95.633 & 95.633 & 95.633 \\
\hline irk Red & None & 10 & 6.117 & 7.172 & 7.567 & 50.880 & 31.609 & 7) 50.384 & 38.325 & 145.543 & 145.543 & 145.782 & 145.782 & 145.782 & 145.782 \\
\hline ark Red & Deceleration & 10 & 6.542 & 6.246 & 7.349 & 29.312 & 5.941 & $\begin{array}{l}1 \quad 28.622 \\
\end{array}$ & 11.928 & 118.315 & 118.315 & 118.511 & 118.511 & 118.511 & 118.511 \\
\hline lark Red & Acceleration & 10 & 7.986 & 11.849 & 13.149 & 89.985 & 66.780 & 87.226 & $5 \quad 74.648$ & 190.950 & 190.950 & 191.265 & 191.265 & 191.265 & 191.265 \\
\hline
\end{tabular}

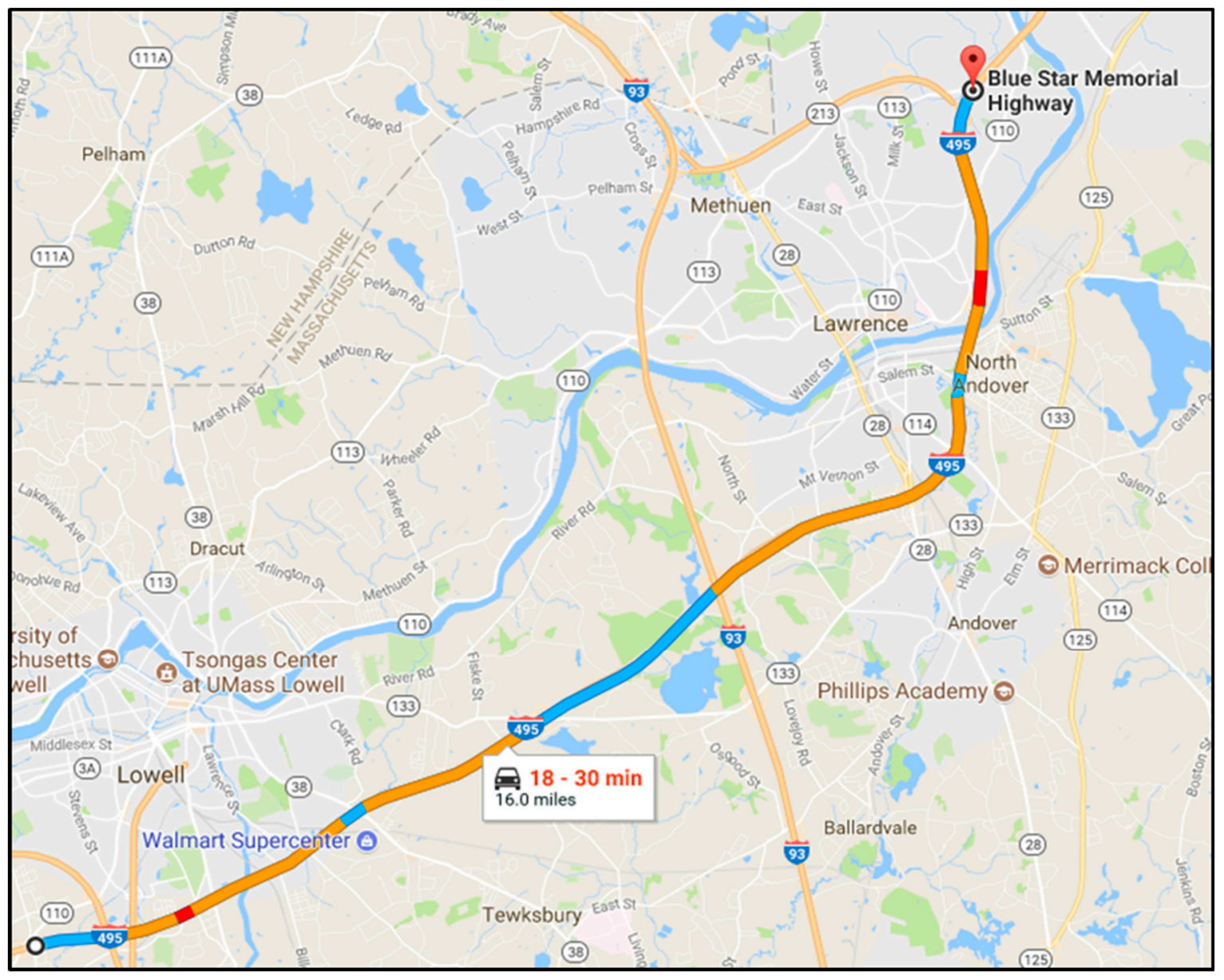

Figure A11. Step 6, Google Maps@traffic conditions for Interstate I-495 [17]. 
Table A8. Step 6, example of Massachusetts Department of Transportation Data Management System information database on vehicle classification [16].

\begin{tabular}{|c|c|c|c|c|c|c|c|c|c|c|c|c|c|c|c|c|}
\hline \multicolumn{17}{|c|}{ FHWA-Scheme F Classification (?) } \\
\hline $\begin{array}{l}\text { Start } \\
\text { Time }\end{array}$ & $\begin{array}{l}\text { Motor } \\
\text { cycle }\end{array}$ & Car & $\begin{array}{c}\text { Pick } \\
\text { up }\end{array}$ & Bus & $\begin{array}{l}2 A \\
S U\end{array}$ & $\begin{array}{l}3 A \\
\text { SU }\end{array}$ & $\begin{array}{c}>3 \mathrm{~A} \\
\mathrm{SU}\end{array}$ & $\begin{array}{l}<5 \mathrm{~A} \\
2 \mathrm{U}\end{array}$ & $\begin{array}{l}5 \mathrm{~A} \\
2 \mathrm{U}\end{array}$ & $\begin{array}{c}>5 \mathrm{~A} \\
2 \mathrm{U}\end{array}$ & $\begin{array}{l}<6 \mathrm{~A} \\
>2 \mathrm{U}\end{array}$ & $\begin{array}{c}6 \mathrm{~A} \\
>2 \mathrm{U}\end{array}$ & $\begin{array}{l}>6 \mathrm{~A} \\
>2 \mathrm{U}\end{array}$ & 14 & 15 & TOTAL \\
\hline $12: 00 \mathrm{AM}$ & 3 & 474 & 119 & 5 & 11 & 8 & 0 & 12 & 133 & 6 & 8 & 10 & 3 & 0 & 0 & 792 \\
\hline 1:00 AM & 6 & 317 & 87 & 3 & 10 & 4 & 0 & 10 & 142 & 5 & 10 & 3 & 2 & 0 & 0 & 599 \\
\hline 2:00 AM & 6 & 269 & 70 & 5 & 11 & 9 & 0 & 9 & 136 & 6 & 8 & 3 & 5 & 0 & 0 & 537 \\
\hline 3:00 AM & 3 & 300 & 101 & 1 & 24 & 11 & 0 & 21 & 169 & 5 & 8 & 4 & 2 & 0 & 0 & 649 \\
\hline 4:00 AM & 7 & 751 & 238 & 4 & 32 & 17 & 0 & 23 & 222 & 21 & 14 & 4 & 5 & 0 & 0 & 1338 \\
\hline 5:00 AM & 16 & 3056 & 1003 & 10 & 88 & 42 & 6 & 45 & 299 & 31 & 20 & 5 & 14 & 0 & 0 & 4635 \\
\hline 6:00 AM & 15 & 6284 & 1640 & 24 & 140 & 88 & 9 & 71 & 372 & 49 & 14 & 9 & 19 & 0 & 0 & 8734 \\
\hline 7:00 AM & 24 & 8821 & 1486 & 18 & 152 & 55 & 16 & 56 & 351 & 25 & 16 & 6 & 22 & 0 & 0 & 11048 \\
\hline $8: 00 \mathrm{AM}$ & 71 & 6286 & 1028 & 28 & 117 & 109 & 15 & 60 & 283 & 33 & 12 & 11 & 25 & 0 & 0 & 8078 \\
\hline 9:00 AM & 38 & 5798 & 1288 & 25 & 180 & 73 & 19 & 68 & 527 & 45 & 14 & 13 & 20 & 0 & 0 & 8108 \\
\hline $10: 00 \mathrm{AM}$ & 16 & 4297 & 1166 & 20 & 147 & 68 & 15 & 69 & 451 & 45 & 2 & 4 & 14 & 0 & 0 & 6314 \\
\hline $11: 00 \mathrm{AM}$ & 13 & 3847 & 1098 & 12 & 139 & 101 & 14 & 65 & 402 & 27 & 6 & 4 & 21 & 0 & 0 & 5749 \\
\hline 12:00 PM & 16 & 4572 & 1302 & 19 & 144 & 79 & 12 & 62 & 484 & 29 & 3 & 3 & 20 & 0 & 0 & 6745 \\
\hline 1:00 PM & 17 & 4451 & 1250 & 24 & 132 & 81 & 6 & 55 & 461 & 38 & 4 & 2 & 30 & 0 & 0 & 6551 \\
\hline 2:00 PM & 34 & 6077 & 1512 & 22 & 153 & 68 & 6 & 59 & 449 & 32 & 5 & 3 & 18 & 0 & 0 & 8438 \\
\hline 3:00 PM & 21 & 7313 & 1626 & 13 & 130 & 59 & 4 & 59 & 351 & 26 & 4 & 3 & 23 & 0 & 0 & 9632 \\
\hline 4:00 PM & 17 & 7925 & 1376 & 13 & 94 & 40 & 1 & 46 & 329 & 14 & 2 & 2 & 21 & 0 & 0 & 9880 \\
\hline 5:00 PM & 24 & 7711 & 1163 & 12 & 69 & 21 & 3 & 48 & 267 & 10 & 2 & 2 & 22 & 0 & 0 & 9354 \\
\hline 6:00 PM & 5 & 5982 & 895 & 14 & 47 & 12 & 1 & 45 & 233 & 4 & 4 & 3 & 11 & 0 & 0 & 7256 \\
\hline 7:00 PM & 6 & 3796 & 667 & 9 & 52 & 9 & 0 & 35 & 197 & 9 & 7 & 3 & 11 & 0 & 0 & 4801 \\
\hline 8:00 PM & 6 & 2416 & 423 & 8 & 38 & 4 & 0 & 28 & 148 & 10 & 10 & 4 & 7 & 0 & 0 & 3102 \\
\hline 9:00 PM & 10 & 1903 & 339 & 7 & 19 & 6 & 0 & 32 & 202 & 7 & 23 & 6 & 7 & 0 & 0 & 2561 \\
\hline 10:00 PM & 5 & 1307 & 230 & 4 & 16 & 3 & 0 & 23 & 195 & 6 & 12 & 6 & 2 & 0 & 0 & 1809 \\
\hline 11:00 PM & 13 & 1030 & 191 & 3 & 14 & 6 & 2 & 17 & 148 & 5 & 6 & 11 & 2 & 0 & 0 & 1448 \\
\hline TOTAL & 392 & 94983 & 20298 & 303 & 1959 & 973 & 129 & 1018 & 6951 & 488 & 214 & 124 & 326 & 0 & 0 & 128158 \\
\hline
\end{tabular}

Vehicle Classifications

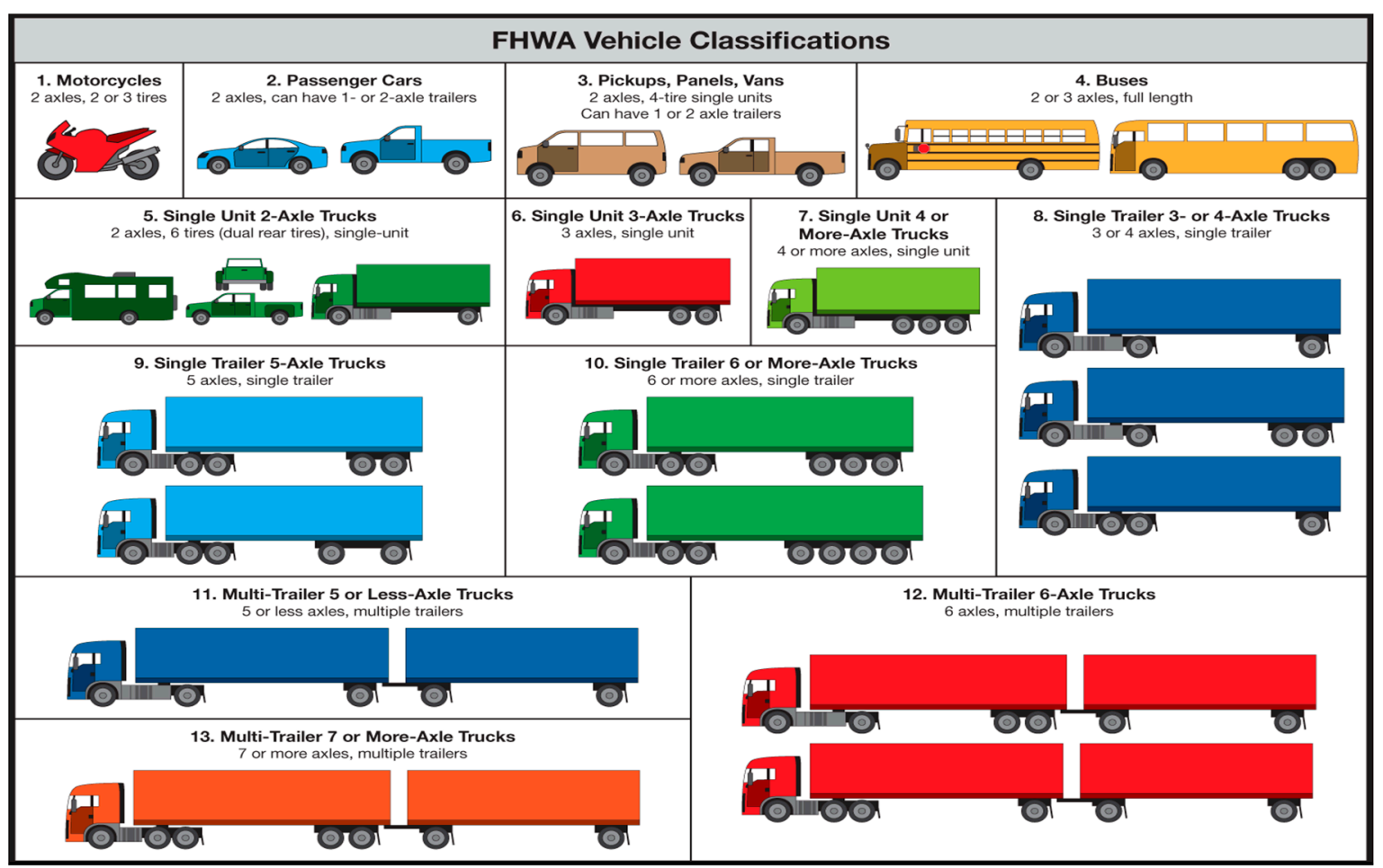

Figure A12. MassDOT's Transportation Data Management System information vehicle classification chart [16]. 


\begin{tabular}{|l|}
\hline Combination Long-haul Truck \\
Combination Short-haul Truck \\
Intercity Bus \\
Light Commercial Truck \\
Motor Home \\
Motorcycle \\
Passenger Car \\
Passenger Truck \\
Refuse Truck \\
School Bus \\
Single Unit Long-haul Truck \\
Single Unit Short-haul Truck \\
Transit Bus \\
\hline
\end{tabular}

Figure A13. MOVES vehicle classifications.

\begin{tabular}{|c|c|c|c|c|c|c|c|c|}
\hline \multicolumn{9}{|c|}{$\begin{array}{l}\text { Trips by Maximum Acceleration and } \% \text { Rur Frwy }<4 \text { Lns } \\
\qquad \% \text { Rur Frwy }<4 \text { Lns }\end{array}$} \\
\hline & $0.0-20.0$ & $20.0-40.0$ & $40.0 \cdot 60.0$ & $60.0-80.0$ & $80.0-100.0$ & $>=100.0$ & NULL (no value) & Total \\
\hline$<0.0$ & 0 & 0 & 0 & 0 & 0 & 0 & 0 & 0 \\
\hline $0.0 \cdot 0.1$ & 0 & 0 & 0 & 0 & 7.6 & 0 & 0 & 7.6 \\
\hline $0.1 \cdot 0.2$ & 0 & 0 & 0 & 0 & 22.5 & 0 & 0 & 22.5 \\
\hline $0.2 \cdot 0.3$ & 0 & 0 & 0 & 0 & 40.7 & 0 & 0 & 40.7 \\
\hline $0.3 \cdot 0.4$ & 0 & 0 & 0 & 0 & 25.1 & 0 & 0 & 25.1 \\
\hline $0.4 \cdot 0.5$ & 0 & 0 & 0 & 0 & 3.5 & 0 & 0 & 3.5 \\
\hline $0.5 \cdot 0.6$ & 0 & 0 & 0 & 0 & 0.2 & 0 & 0 & 0.2 \\
\hline $0.6 \cdot 0.7$ & 0 & 0 & 0 & 0 & 0 & 0 & 0 & 0 \\
\hline$>=0.7$ & 0 & 0 & 0 & 0 & 0.2 & 0 & 0 & 0.2 \\
\hline NULL (no value) & 0 & 0 & 0 & 0 & 0.3 & 0 & 0 & 0.3 \\
\hline Total & 0 & 0 & 0 & 0 & 100.0 & 0 & 0 & 100.0 \\
\hline
\end{tabular}

Figure A14. SHRP 2 NDS acceleration data [16]. 
Table A9. NCHRP-720 HDM4 vehicle and tire classifications [12].

\begin{tabular}{|c|c|c|c|c|c|c|c|c|c|c|c|c|c|c|c|c|}
\hline Vehicle Class & $\begin{array}{c}\text { Number of } \\
\text { Axles }\end{array}$ & $\mathrm{N} w$ & $\begin{array}{c}\mathrm{M} \\
\text { (tons) }\end{array}$ & Kcr2 & $\mathrm{CD}$ & $\begin{array}{l}\mathrm{AF} \\
\left(\mathrm{m}^{2}\right)\end{array}$ & WD & $\begin{array}{l}\text { Tire } \\
\text { Type }\end{array}$ & CR1 & $b 11$ & $b 12$ & $b 13$ & $\begin{array}{c}\mathrm{C}_{0 \mathrm{lc}} \\
\left(\mathrm{dm}^{3} / \mathrm{MNm}\right)\end{array}$ & \begin{tabular}{c|}
$\mathrm{C}_{\mathrm{tcle}}$ \\
$\left(\mathrm{dm}^{3} / \mathrm{MNm}\right)$
\end{tabular} & $\operatorname{VOL}\left(\mathrm{dm}^{3}\right)$ & VEHF AC \\
\hline Small car & 2 & 4 & 1.9 & 0.5 & 0.42 & 1.9 & 0.62 & Radial & 1 & 22.2 & 0.11 & 0.13 & 0.01747 & 0.001 & 1.4 & 2 \\
\hline Medium car & 2 & 4 & 1.9 & 0.5 & 0.42 & 1.9 & 0.62 & Radial & 1 & 22.2 & 0.11 & 0.13 & 0.01747 & 0.001 & 1.4 & 2 \\
\hline Large car & 2 & 4 & 1.9 & 0.5 & 0.42 & 1.9 & 0.62 & Radial & 1 & 22.2 & 0.11 & 0.13 & 0.01747 & 0.001 & 1.4 & 2 \\
\hline Van & 2 & 4 & 2.54 & 0.67 & 0.5 & 2.9 & 0.7 & Radial & 1 & 25.9 & 0.09 & 0.1 & 0.01602 & 0.00092 & 1.6 & 2 \\
\hline Four-wheel drive & 2 & 4 & 2.5 & 0.58 & 0.5 & 2.8 & 0.7 & Radial & 11 & 25.9 & 0.09 & 0.1 & 0.01602 & 0.00092 & 1.6 & 2 \\
\hline Light truck & 2 & 4 & 4.5 & 0.99 & 0.6 & 5 & 0.8 & Radial & 1 & 29.6 & 0.08 & 0.08 & 0.01602 & 0.00092 & 1.6 & 2 \\
\hline Medium truck & 2 & 6 & 6.5 & 0.99 & 0.6 & 5 & 0.8 & Bias & 1.3 & 29.6 & 0.08 & 0.11 & 0.02999 & 0.00099 & 6 & 1 \\
\hline Heavy truck & 3 & 10 & 13 & 1.1 & 0.7 & 8.5 & 1.05 & Bias & 1.3 & 38.85 & 0.06 & 0.11 & 0.03829 & 0.00135 & 8 & 1 \\
\hline Articulated truck & 5 & 18 & 15.6 & 1.1 & 0.8 & 9 & 1.05 & Bias & 1.3 & 38.85 & 0.06 & 0.2 & 0.04328 & 0.00153 & 8 & 1 \\
\hline Mni bus & 2 & 4 & 2.16 & 0.67 & 0.5 & 2.9 & 0.7 & Radial & 1 & 25.9 & 0.09 & 0.1 & 0.01747 & 0.00092 & 1.6 & 2 \\
\hline Light bus & 2 & 4 & 2.5 & 0.99 & 0.5 & 4 & 0.8 & Radial & 1 & 29.6 & 0.08 & 0.08 & 0.01747 & 0.00092 & 1.6 & 2 \\
\hline Medium bus & 2 & 6 & 4.5 & 0.99 & 0.6 & 5 & 1.05 & Bias & 1.3 & 38.85 & 0.06 & 0.06 & 0.02999 & 0.00099 & 6 & 1 \\
\hline Heavy bus & 3 & 10 & 13 & 1.1 & 0.7 & 6.5 & 1.05 & Bias & 1.3 & 38.85 & 0.06 & 0.06 & 0.03829 & 0.00135 & 8 & 1 \\
\hline Coach & 3 & 10 & 13.6 & 1.1 & 0.7 & 6.5 & 1.05 & Bias & 1.3 & 38.85 & 0.06 & 0.06 & 0.03829 & 0.00135 & 8 & 1 \\
\hline
\end{tabular}

Table A10. Vehicle classification combinations and distributions.

\begin{tabular}{|c|c|c|c|}
\hline \multicolumn{4}{|c|}{ Vehicle Classifications } \\
\hline FHWA Traffic Count & NCHRP 720 & MOVES & Distribution (\%) \\
\hline Car & Car & Car & 100 \\
\hline Motorcycle & Motorcycle & Motorcycle & 100 \\
\hline Pick Up & Four-wheel Drive & Passenger Truck & 100 \\
\hline & Light Bus & School Bus & 80 \\
\hline Bus & Medium Bus & Transit Bus & 5 \\
\hline & Coach & Single-Unit Long Haul Truck & 100 \\
\hline 2A SU & Light Truck & Single-Unit Long Haul Truck & 100 \\
\hline 3A SU & Medium Truck & Single-Unit Long Haul Truck & 90 \\
\cline { 2 - 4 } >3A SU & Heavy Truck & Refuse Truck & 10 \\
\hline <5A SU and 5A SU & Articulated Truck & Combination Short Haul Truck & 100 \\
\hline >5A 2U and higher & Articulated Truck & Combination Long Haul Truck & 100 \\
\hline
\end{tabular}


Appendix A.4. Pavement ME Inputs

Appendix A.4.1. Material Characteristic Inputs

Table A11. Pavement ME material characteristics for each layer.

\begin{tabular}{|c|c|c|c|c|c|c|c|c|}
\hline \multicolumn{2}{|c|}{ Asphalt Material Properties } & \multicolumn{7}{|c|}{ Mixture Name } \\
\hline & & ARGG-1 & ARGG-2 & T-1 & THS-1 & SHM-1 & B-1 & BB-1 \\
\hline \multirow{4}{*}{$\begin{array}{l}\text { Aggregate } \\
\text { gradation }\end{array}$} & Cum $\%$ rt. $3 / 4$ in sieve & 100 & 100 & 100 & 100 & 100 & 99 & 88 \\
\hline & Cum $\%$ rt. $3 / 8$ in sieve & 84 & 85 & 81 & 84 & 86 & 74 & 56 \\
\hline & Cum \% rt. \#4 sieve & 40 & 37 & 57 & 57 & 59 & 46 & 36 \\
\hline & \% Passing \#200 sieve & 3.5 & 3.5 & 3.8 & 4 & 3.7 & 3.5 & 3.5 \\
\hline Asphalt Binder & Superpave (PG) & $58-28$ & $58-28$ & $64-28$ & $76-28$ & 70-34 PMA & $64-28$ & $64-28$ \\
\hline \multirow{7}{*}{ Asphalt General } & Reference temp (F) & 70 & 70 & 70 & 70 & 70 & 70 & 70 \\
\hline & Poisson's ratio & 0.36 & 0.35 & 0.36 & 0.36 & 0.35 & 0.36 & 0.36 \\
\hline & Effective binder \% & 6.68 & 6.32 & 4.9 & 4.9 & & 4.39 & 4.35 \\
\hline & Air voids \% & 5.36 & 3.01 & 3.5 & 6.21 & 4 & 5.18 & 4.38 \\
\hline & Total Unit weight (pcf) & 144.8 & 146.9 & 158.7 & 155.6 & 151.5 & 149.5 & 151.3 \\
\hline & Thermal conductivity AC & 0.67 & 0.67 & 0.67 & 0.67 & 0.67 & 0.67 & 0.67 \\
\hline & Heat capacity asphalt & 0.23 & 0.23 & 0.23 & 0.23 & 0.23 & 0.23 & 0.23 \\
\hline
\end{tabular}

Appendix A.4.2. Dynamic Modulus (E*) Pavement ME Input

Table A12. Dynamic modulus input for ARGG-1 cross-section.

\begin{tabular}{|c|c|c|c|c|}
\hline \multirow{2}{*}{ Temp (F) } & \multicolumn{4}{c|}{ ARGG-1 } \\
\cline { 2 - 5 } & $\mathbf{0 . 1}$ & $\mathbf{1}$ & $\mathbf{1 0}$ & $\mathbf{2 5}$ \\
\hline 10 & $1,688,550.19$ & $1,966,960.96$ & $2,175,448.5$ & $2,240,515.8$ \\
\hline 40 & $687,552.7197$ & $979,985.536$ & $1,331,318.2$ & $1,476,540$ \\
\hline 70 & $169,907.9615$ & $304,180.895$ & $522,202.28$ & $636,736.3$ \\
\hline 100 & $56,526.39519$ & $96,813.0315$ & $179,173.21$ & $231,341.41$ \\
\hline 130 & $29,662.06475$ & $43,677.4749$ & $71,655.429$ & $89,572.235$ \\
\hline
\end{tabular}

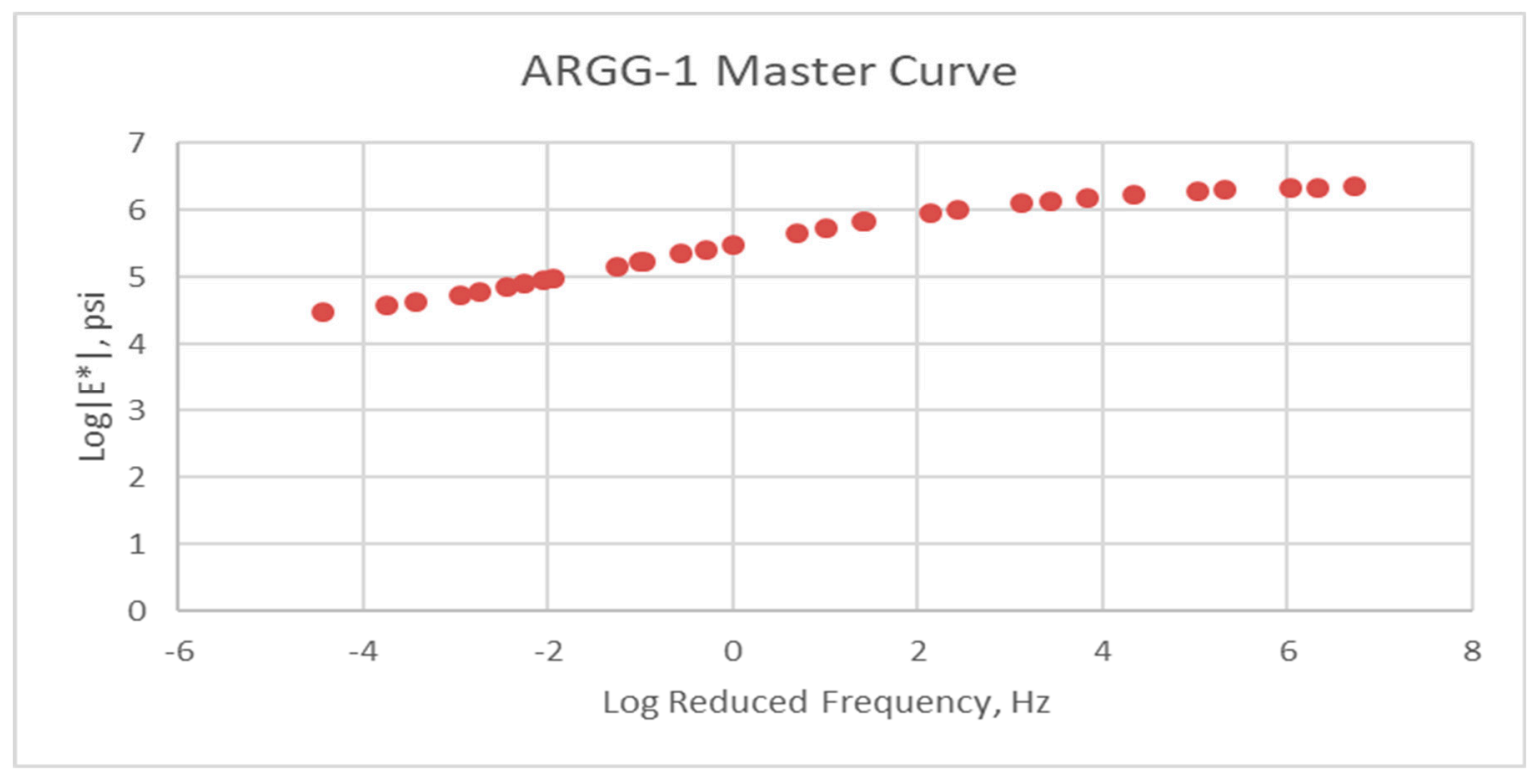

Figure A15. ARGG-1 cross-section master curve. 


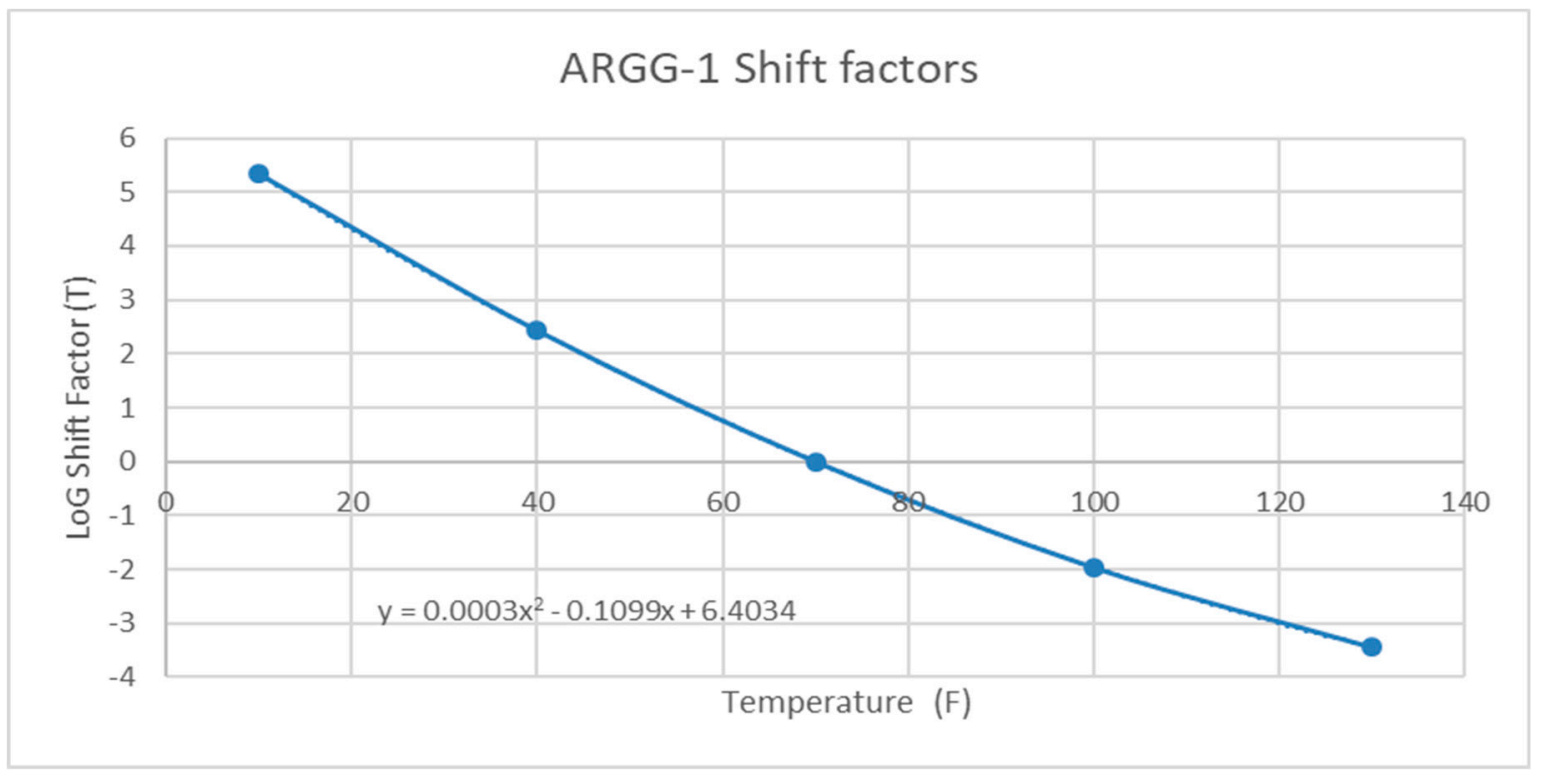

Figure A16. ARGG-1 cross-section shift factors.

Table A13. Dynamic modulus input for ARGG-2 cross-section.

\begin{tabular}{|c|c|c|c|c|}
\hline \multirow{2}{*}{ Temp (F) } & \multicolumn{4}{c|}{ ARGG-2 } \\
\cline { 2 - 5 } & $\mathbf{0 . 1}$ & $\mathbf{1}$ & $\mathbf{1 0}$ & $\mathbf{2 5}$ \\
\hline 10 & $2,014,657.96$ & $2,300,848$ & $2,516,240$ & $2,584,199$ \\
\hline 40 & $804,896.3419$ & $1,132,508$ & $1,517,460$ & $1,673,494$ \\
\hline 70 & $191,077.648$ & $350,222.3$ & $596,736.8$ & $723,122.5$ \\
\hline 100 & $58,660.58927$ & 106,064 & $203,032.5$ & $261,578.6$ \\
\hline 130 & $28,301.08178$ & $46,310.03$ & $83,084.46$ & $106,713.7$ \\
\hline
\end{tabular}

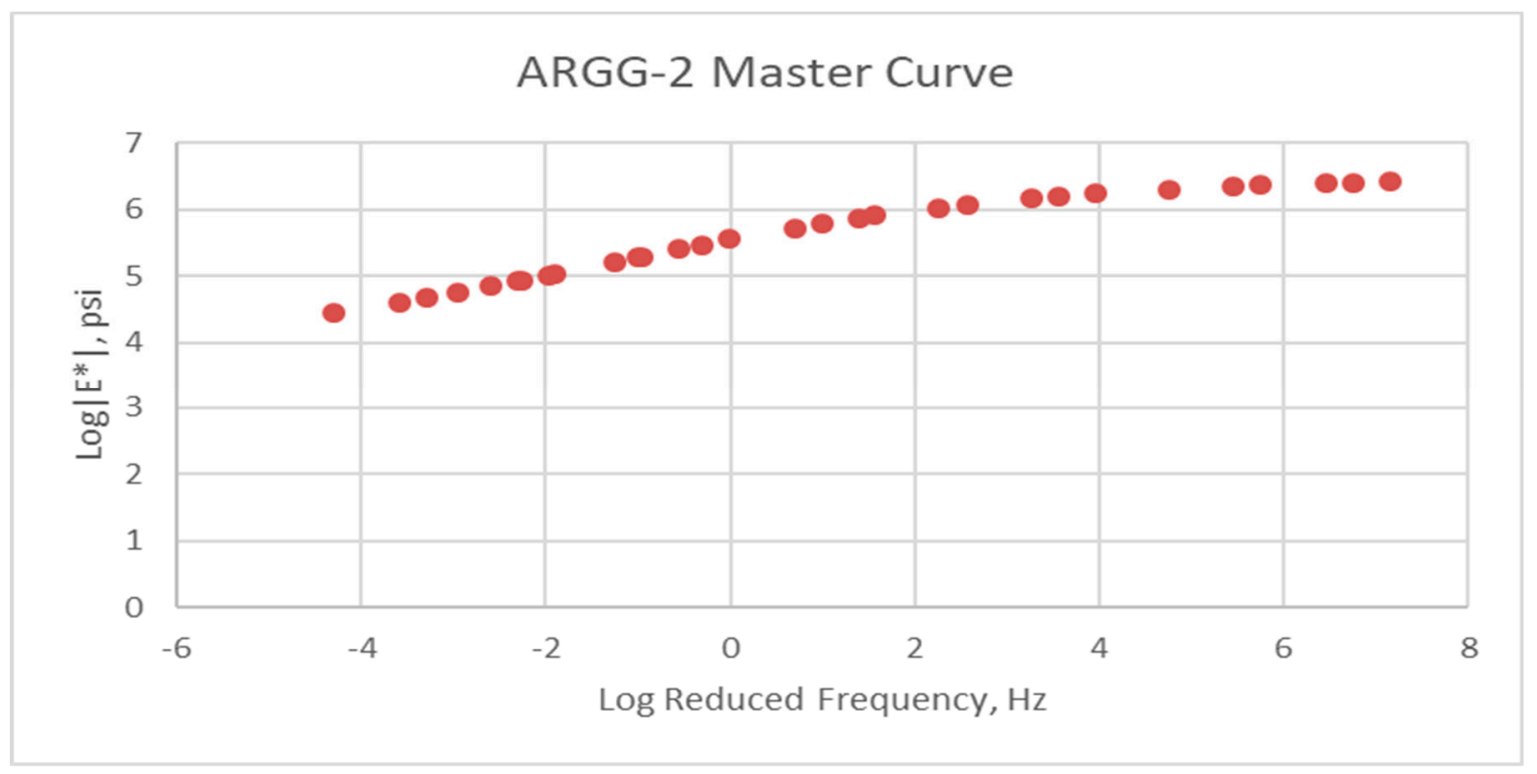

Figure A17. ARGG-2 cross-section master curve. 


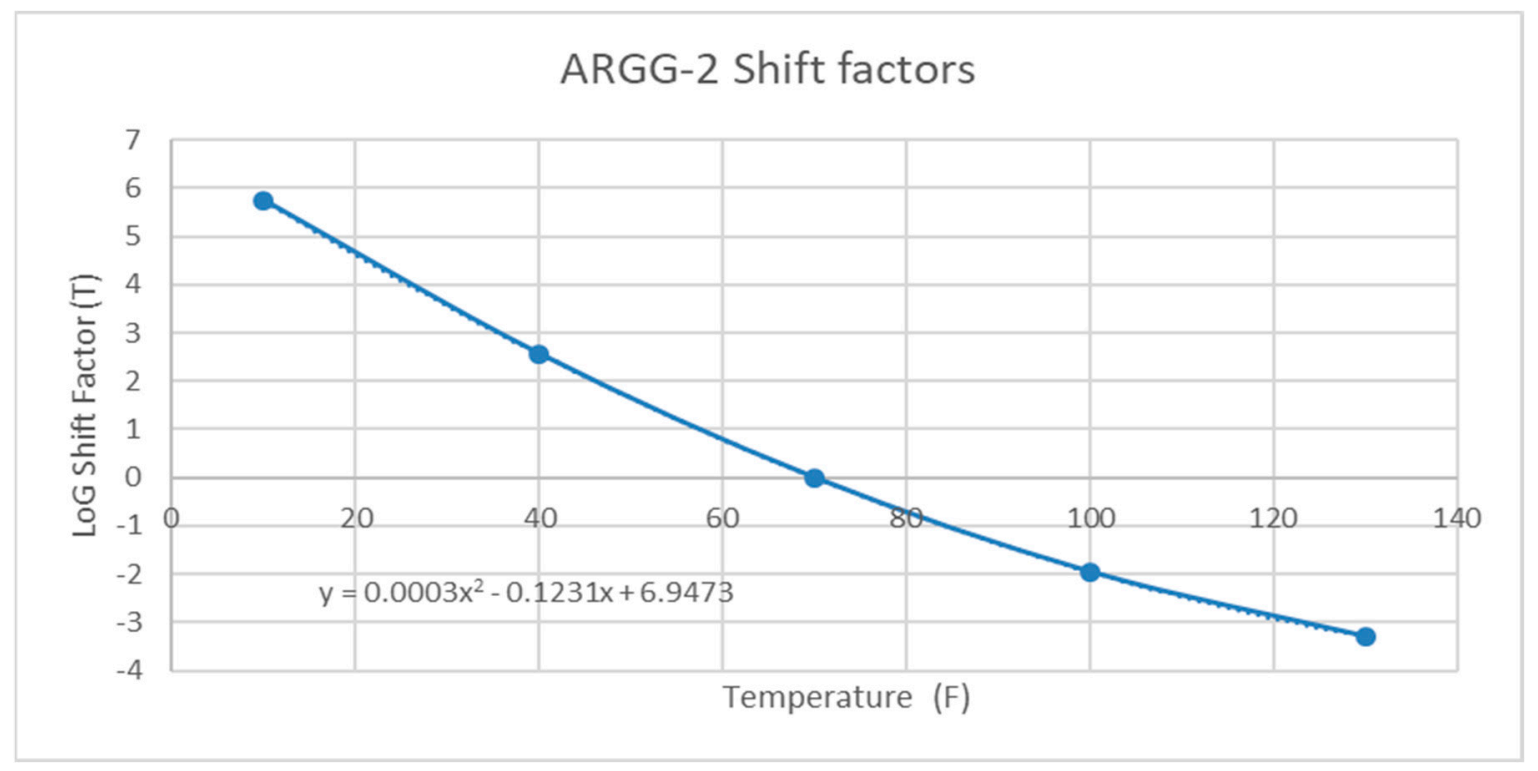

Figure A18. ARGG-2 cross-section shift factors.

Table A14. Dynamic modulus input for T-1 cross-section.

\begin{tabular}{|c|c|c|c|c|}
\hline \multirow{2}{*}{ Temp (F) } & $\mathbf{4}$ T-1 \\
\cline { 2 - 5 } & $\mathbf{0 . 1}$ & $\mathbf{1}$ & $\mathbf{1 0}$ & $\mathbf{2 5}$ \\
\hline 10 & $1,671,717.47$ & $2,057,179$ & $2,315,221$ & $2,387,669$ \\
\hline 40 & $655,208.6218$ & $1,081,775$ & $1,568,820$ & $1,770,225$ \\
\hline 70 & $111,555.0371$ & $262,359.1$ & $558,316.2$ & $716,218.8$ \\
\hline 100 & $32,156.70826$ & $57,201.74$ & $131,883.5$ & $188,498.1$ \\
\hline 130 & $14,663.03545$ & $19,164.5$ & $29,545.46$ & $37,104.88$ \\
\hline
\end{tabular}

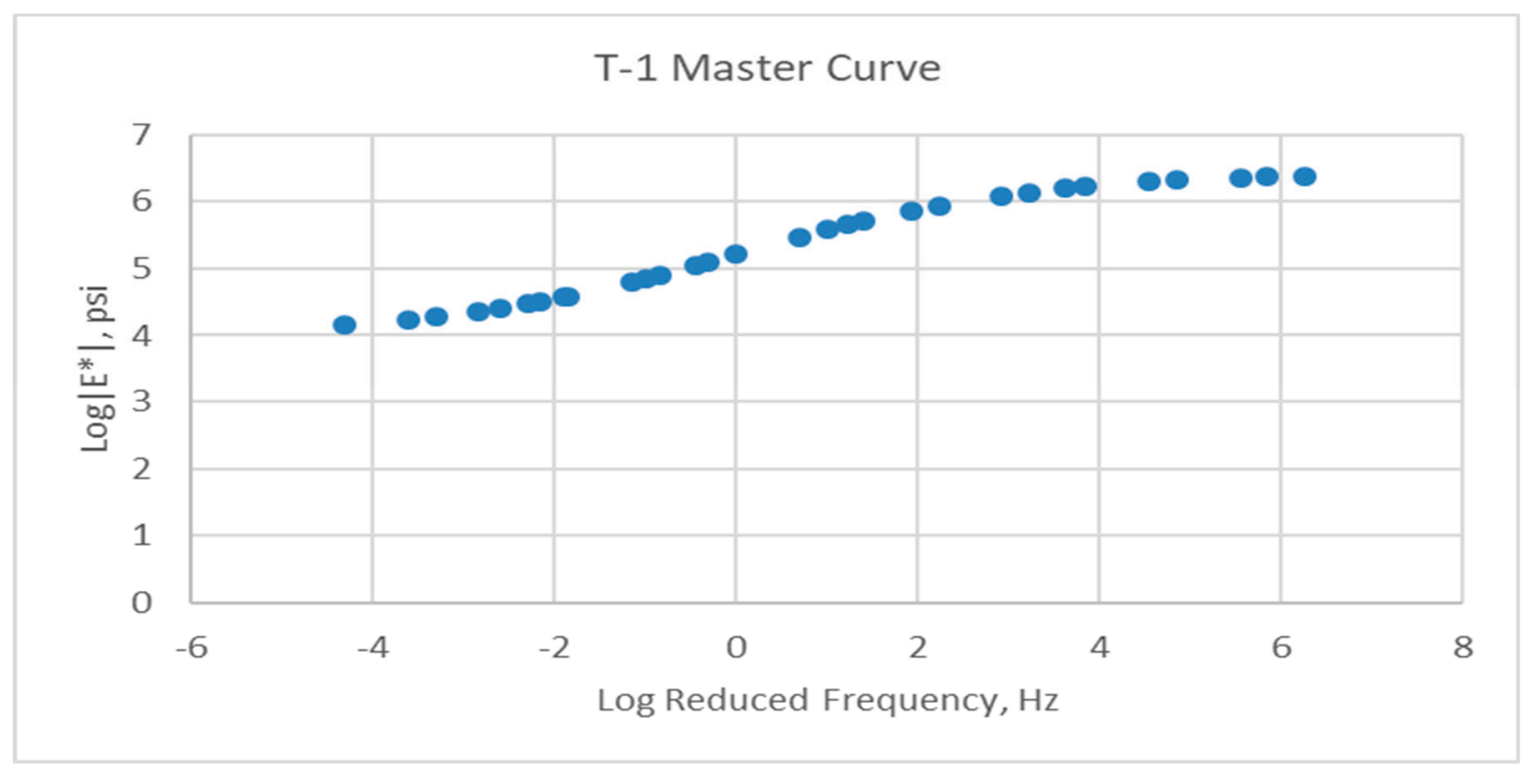

Figure A19. T-1 cross-section master curve. 


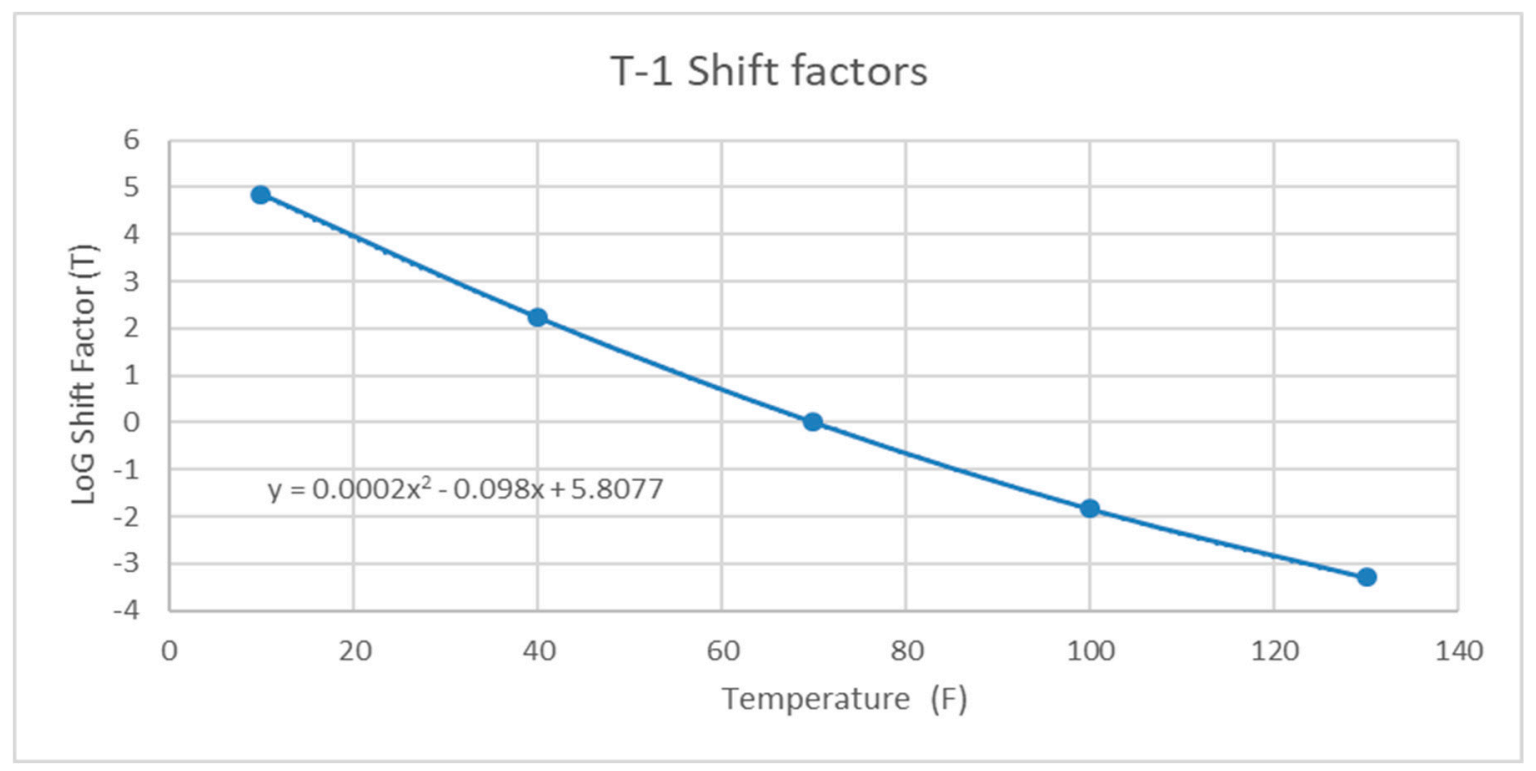

Figure A20. T-1 cross-section shift factors.

Table A15. Dynamic modulus input for THS-1 cross-section.

\begin{tabular}{|c|c|c|c|c|}
\hline \multirow{2}{*}{ Temp (F) } & $\mathbf{4}$ THS-1 \\
\cline { 2 - 5 } & $\mathbf{0 . 1}$ & $\mathbf{1}$ & $\mathbf{1 0}$ & $\mathbf{2 5}$ \\
\hline 10 & $2,468,122.901$ & $2,773,966$ & $2,962,146$ & $3,013,166$ \\
\hline 40 & $1,060,744.307$ & $1,530,931$ & $2,067,423$ & $2,278,389$ \\
\hline 70 & $198,413.424$ & $427,556.5$ & $820,621.8$ & $1,016,861$ \\
\hline 100 & $55,629.35472$ & $102,580.4$ & $233,180.4$ & $324,235.4$ \\
\hline 130 & $27,789.83053$ & $41,829.18$ & $75,808.53$ & 100,861 \\
\hline
\end{tabular}

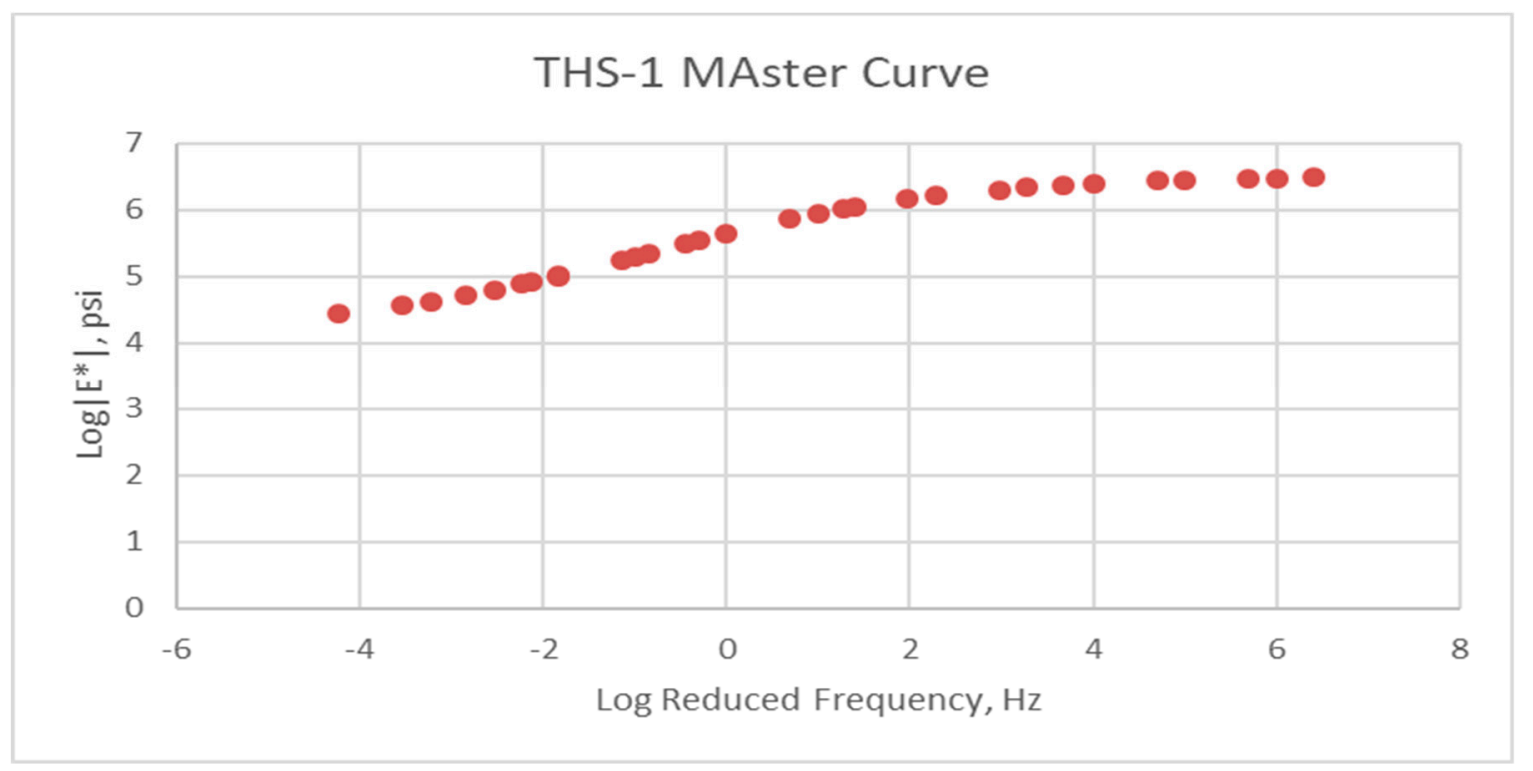

Figure A21. THS-1 cross-section master curve. 


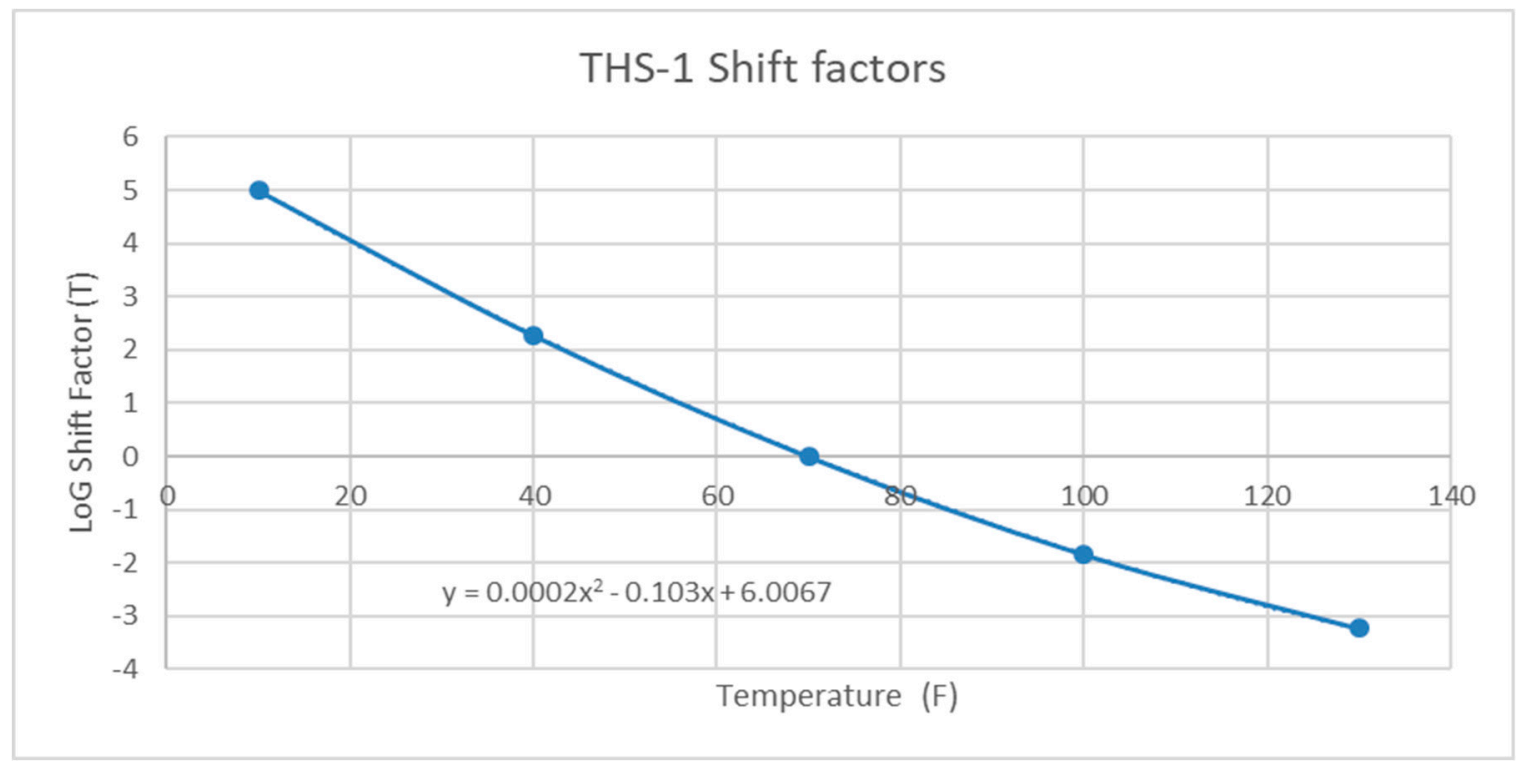

Figure A22. THS-1 cross-section shift factors.

Table A16. Dynamic modulus input for SHM-1 cross-section.

\begin{tabular}{|c|c|c|c|c|}
\hline \multirow{2}{*}{ Temp (F) } & $\mathbf{4}$ SHM-1 \\
\cline { 2 - 5 } & $\mathbf{0 . 1}$ & $\mathbf{1}$ & $\mathbf{1 0}$ & $\mathbf{2 5}$ \\
\hline 10 & $1,334,184.018$ & $1,721,320$ & $1,987,313$ & $2,061,850$ \\
\hline 40 & $323,538.2494$ & $648,593.7$ & $1,092,120$ & $1,273,953$ \\
\hline 70 & $70,265.07206$ & $135,411.7$ & $289,778.7$ & $390,499.8$ \\
\hline 100 & $34,666.43581$ & $48,370.83$ & $81,156.58$ & $105,082.9$ \\
\hline 130 & $27,227.06839$ & 31,853 & $41,968.07$ & $48,997.99$ \\
\hline
\end{tabular}

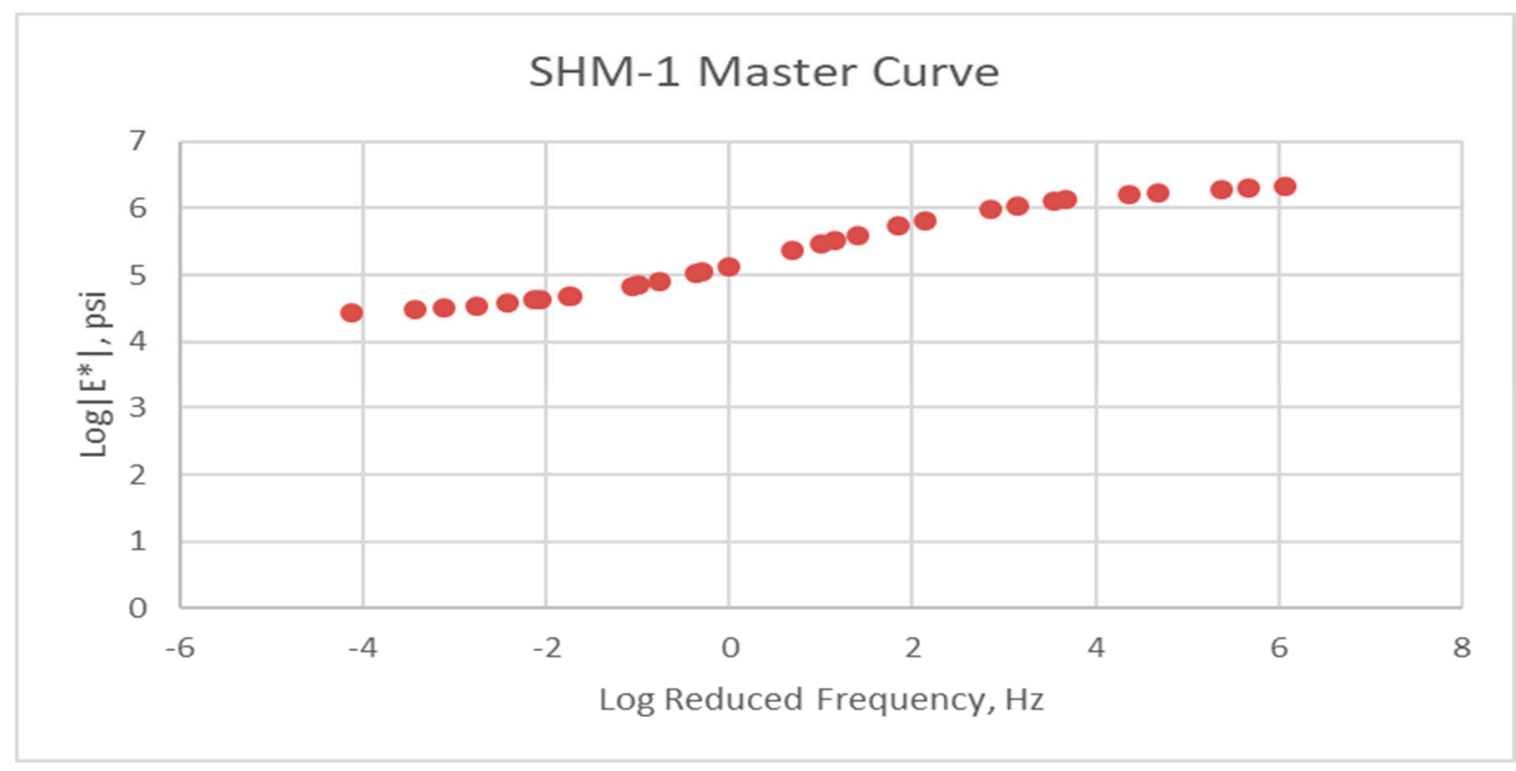

Figure A23. SHM-1 cross-section master curve. 


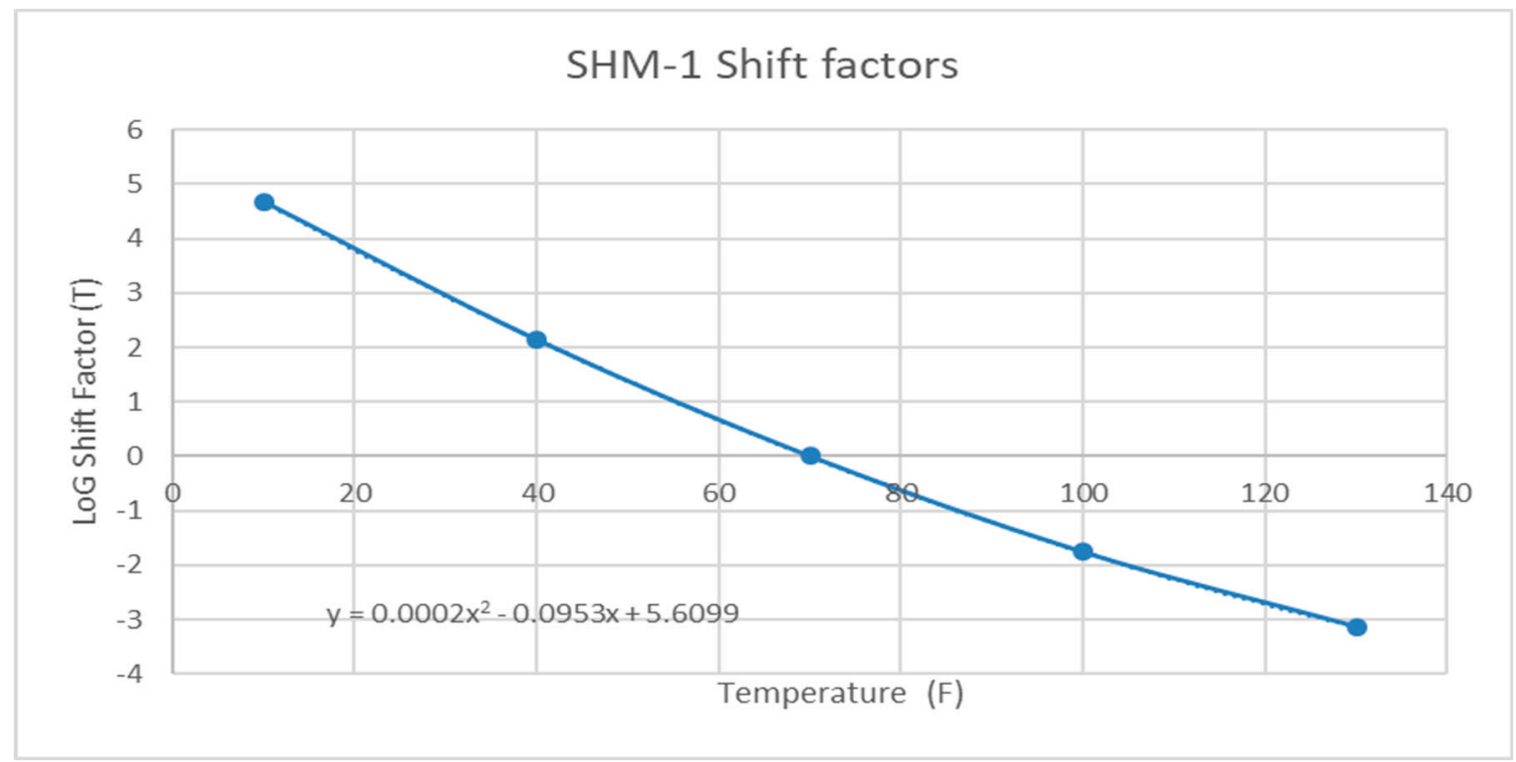

Figure A24. SHM-1 cross-section shift factors.

Table A17. Dynamic modulus input for B-1 cross-section.

\begin{tabular}{|c|c|c|c|c|}
\hline \multirow{2}{*}{ Temp (F) } & \multicolumn{4}{c|}{ B-1 } \\
\cline { 2 - 5 } & $\mathbf{0 . 1}$ & $\mathbf{1}$ & $\mathbf{1 0}$ & $\mathbf{2 5}$ \\
\hline 10 & $2,389,826$ & $2,739,077$ & $2,977,744$ & $3,047,586$ \\
\hline 40 & $1,022,230$ & $1,482,512$ & $1,986,847$ & $2,187,285$ \\
\hline 70 & $222,885.2$ & $461,931.6$ & $853,728.2$ & $1,047,307$ \\
\hline 100 & $53,774.47$ & $112,214.4$ & 255,679 & $350,569.3$ \\
\hline 130 & $21,303.35$ & $37,603.73$ & $77,110.14$ & $105,669.7$ \\
\hline
\end{tabular}

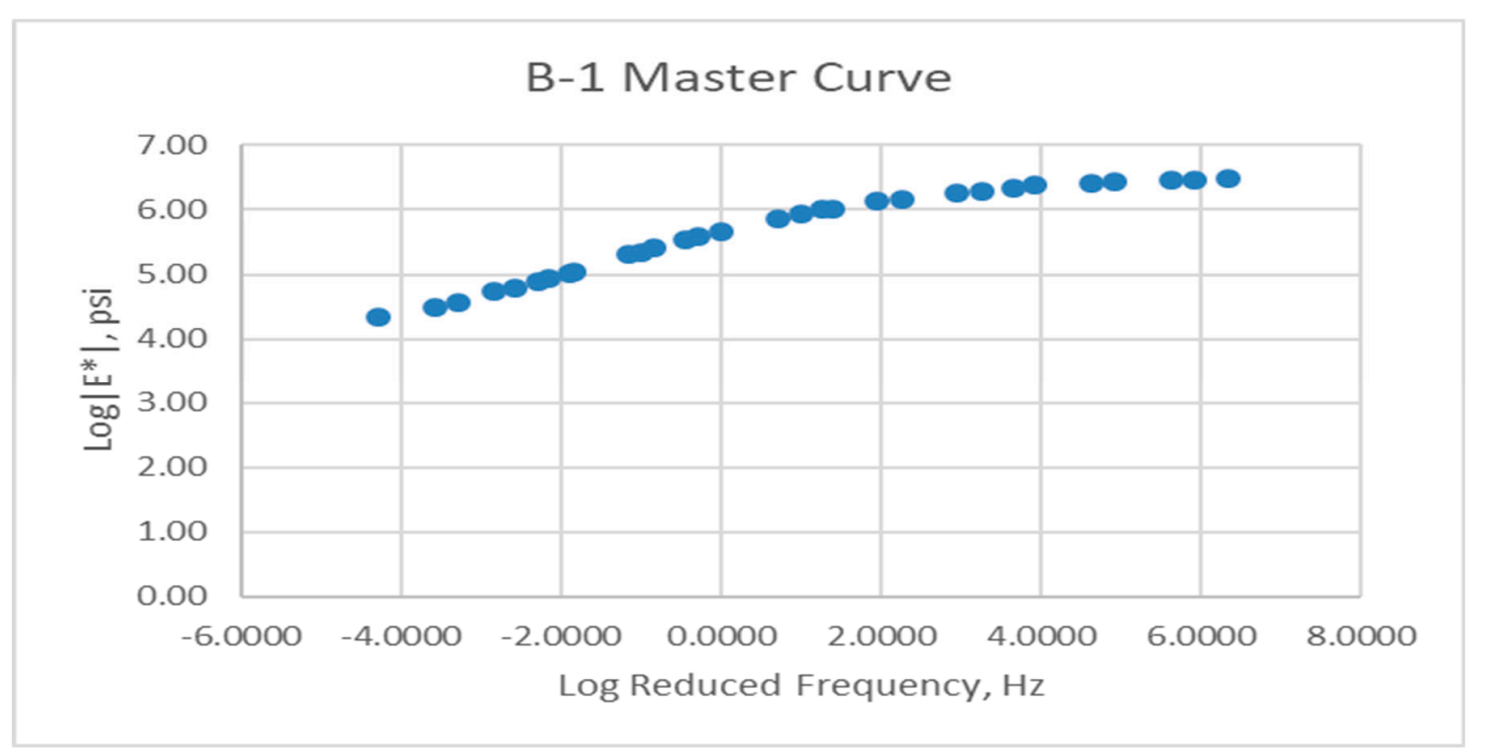

Figure A25. B-1 cross-section master curve. 


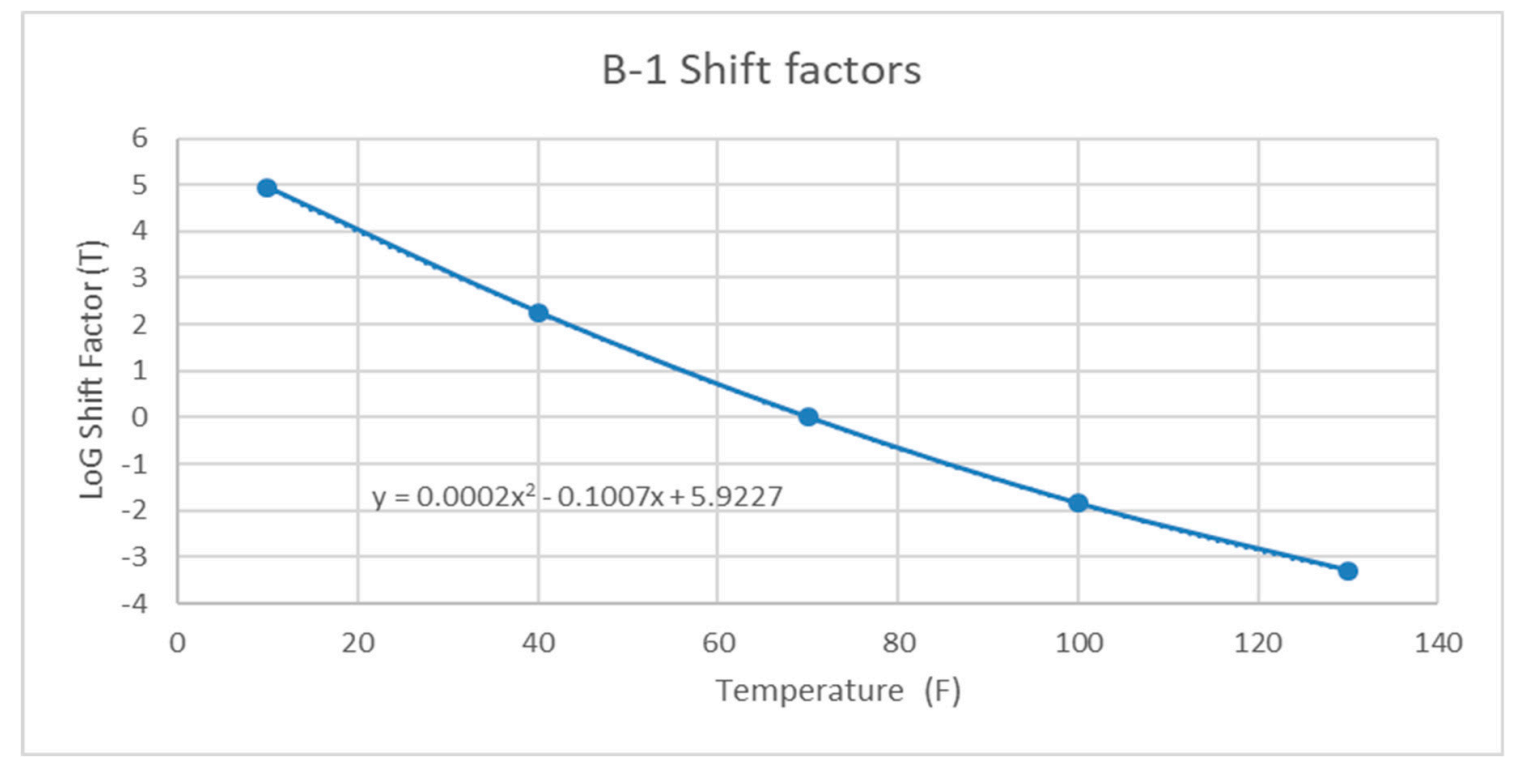

Figure A26. B-1 cross-section shift factors.

Table A18. Dynamic modulus input for BB-1 cross-section.

\begin{tabular}{|c|c|c|c|c|}
\hline \multirow{2}{*}{ Temp (F) } & $\mathbf{5 . 1}$ & \multicolumn{4}{c|}{ BB-1 } \\
\cline { 2 - 5 } & $\mathbf{0 . 1}$ & $\mathbf{1}$ & $\mathbf{1 0}$ & $\mathbf{2 5}$ \\
\hline 10 & $2,442,356.456$ & $2,576,548$ & $2,662,972$ & $2,687,742$ \\
\hline 40 & $948,857.5471$ & $1,360,029$ & $1,820,795$ & $2,000,413$ \\
\hline 70 & $159,373.9746$ & $363,308.6$ & 678,359 & $835,859.2$ \\
\hline 100 & $41,299.4409$ & $81,029.95$ & $185,399.2$ & $256,839.6$ \\
\hline 130 & $23,343.24016$ & $46,724.3$ & $102,701.4$ & $141,528.8$ \\
\hline
\end{tabular}

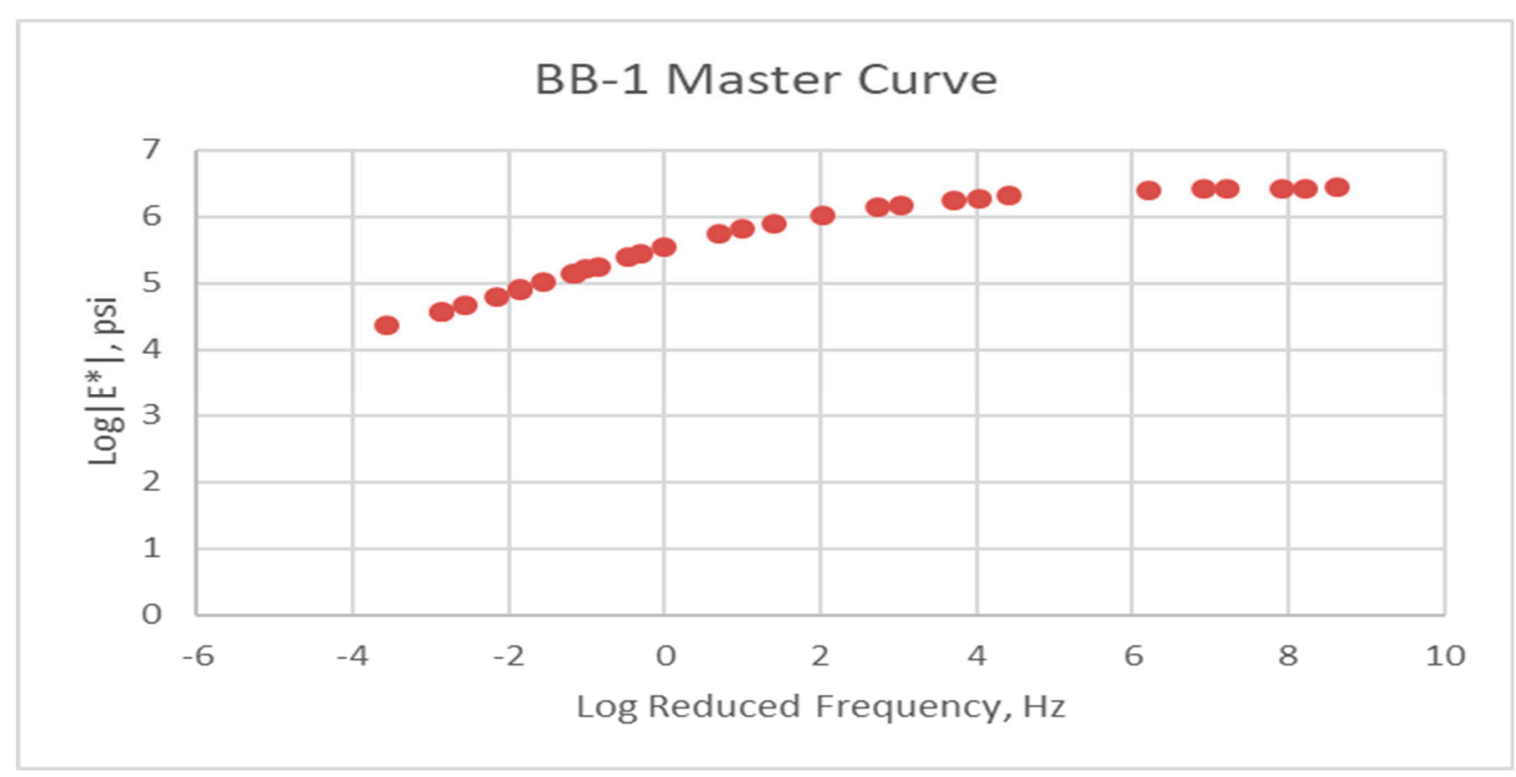

Figure A27. BB-1 cross-section master curve. 


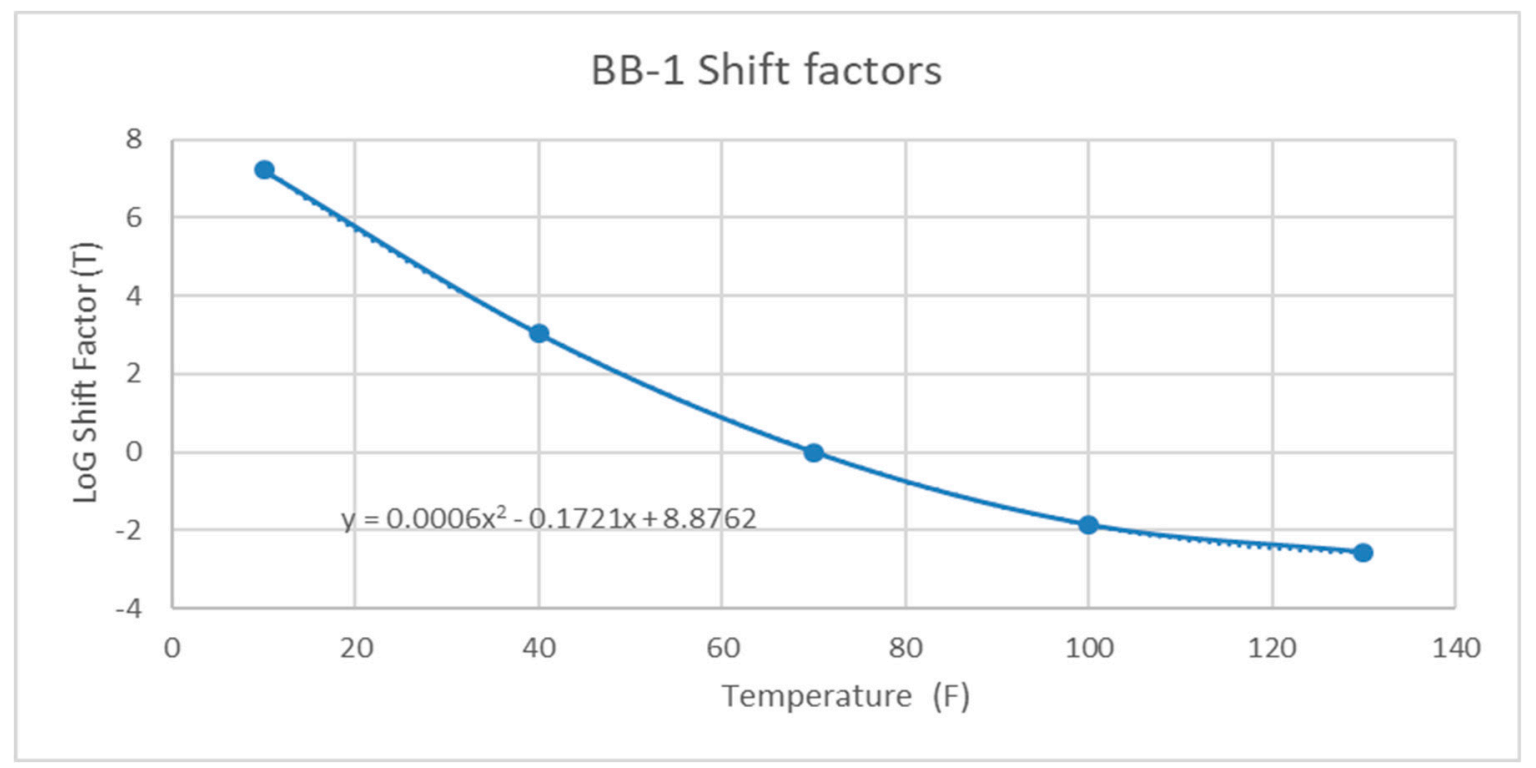

Figure A28. BB-1 cross-section shift factors.

Appendix A.4.3. Complex Shear Modulus ( $\left.G^{*}\right)$ Pavement ME Binder Input

Table A19. Summary of Superpave performance grade (PG) information for each mixture.

\begin{tabular}{|c|c|c|c|c|}
\hline \multirow{4}{*}{$\begin{array}{c}\text { B-1 } \\
\text { PG 64-28 }\end{array}$} & Temp (C) & Temp (F) & $\mathrm{G}^{*}(\mathrm{~Pa})$ & Phase Angle \\
\hline & 64 & 147.2 & 1193 & 86 \\
\hline & 70 & 158 & 300 & 87.5 \\
\hline & 76 & 168.8 & 250 & 89 \\
\hline \multirow{4}{*}{$\begin{array}{c}\text { BB-1 } \\
\text { PG 64-28 }\end{array}$} & Temp (C) & Temp (F) & $\mathrm{G}^{*}(\mathrm{~Pa})$ & Phase Angle \\
\hline & 64 & 147.2 & 1107 & 82.93 \\
\hline & 70 & 158 & 300 & 85.97 \\
\hline & 76 & 168.8 & 250 & 89 \\
\hline \multirow{4}{*}{$\begin{array}{l}\text { ARGG-1 } \\
\text { PG 58-28 }\end{array}$} & Temp (C) & Temp (F) & $\mathrm{G}^{*}(\mathrm{~Pa})$ & Phase Angle \\
\hline & 58 & 136.4 & 1505 & 85.93 \\
\hline & 64 & 147.2 & 700 & 87.47 \\
\hline & 70 & 158 & 300 & 89 \\
\hline \multirow{4}{*}{$\begin{array}{l}\text { ARGG-2 } \\
\text { PG 58-28 }\end{array}$} & Temp (C) & Temp (F) & $\mathrm{G}^{*}(\mathrm{~Pa})$ & Phase Angle \\
\hline & 58 & 136.4 & 1479 & 86.18 \\
\hline & 64 & 147.2 & 700 & 87.59 \\
\hline & 70 & 158 & 300 & 89 \\
\hline \multirow{4}{*}{$\begin{array}{c}\text { T-1 } \\
\text { PG 64-28 }\end{array}$} & Temp (C) & Temp (F) & $\mathrm{G}^{*}(\mathrm{~Pa})$ & Phase Angle \\
\hline & 64 & 147.2 & 1100 & 82.76 \\
\hline & 70 & 158 & 300 & 85.88 \\
\hline & 76 & 168.8 & 250 & 89 \\
\hline \multirow{4}{*}{$\begin{array}{c}\text { THS-1 } \\
\text { PG 76-28 }\end{array}$} & Temp (C) & Temp (F) & $\mathrm{G}^{*}(\mathrm{~Pa})$ & Phase Angle \\
\hline & 76 & 168.8 & 1301 & 67.83 \\
\hline & 82 & 179.6 & 200 & 78.42 \\
\hline & 88 & 190.4 & 100 & 89 \\
\hline \multirow{4}{*}{$\begin{array}{c}\text { SHM-1 } \\
\text { PG 70-34 }\end{array}$} & Temp (C) & Temp (F) & $\mathrm{G}^{*}(\mathrm{~Pa})$ & Phase Angle \\
\hline & 70 & 158 & 1245 & 54.21 \\
\hline & 76 & 168.8 & 250 & 71.61 \\
\hline & 82 & 179.6 & 200 & 89 \\
\hline
\end{tabular}


Appendix A.5. Maintenance and Rehabilitation Alternative Emission Results

Table A20. ARGG-1 M\&R alternative emissions from Palate 2.0 software.

\begin{tabular}{|c|c|c|c|}
\hline \multicolumn{4}{|c|}{ ARGG-1 Cross Section } \\
\hline & eline & Energy [MJ] & $\mathrm{CO}_{2}[\mathrm{Mg}]=\mathrm{GWP}$ \\
\hline \multirow{3}{*}{ Initial Construction } & Materials Production & $37,972,888,683$ & $2,004,224$ \\
\hline & Materials Transportation & $2,003,300,632$ & 149,765 \\
\hline & Processes (Equipment) & $193,655,431$ & 14,535 \\
\hline \multirow{2}{*}{\multicolumn{2}{|c|}{ Mill and Fill }} & $40,169,844,745$ & $2,168,524$ \\
\hline & & Energy [MJ] & $\mathrm{CO}_{2}[\mathrm{Mg}]=\mathrm{GWP}$ \\
\hline \multirow{3}{*}{ Maintenance } & Materials Production & $6,865,339,512$ & 368,288 \\
\hline & Materials Transportation & $405,995,727$ & 30,352 \\
\hline & Processes (Equipment) & $54,425,489$ & 4,085 \\
\hline \multirow{2}{*}{\multicolumn{2}{|c|}{ SUM }} & $7,325,760,728$ & 402,725 \\
\hline & & Energy [MJ] & $\mathrm{CO}_{2}[\mathrm{Mg}]=\mathrm{GWP}$ \\
\hline \multirow{3}{*}{ Maintenance } & Materials Production & $5,149,004,634$ & 276,216 \\
\hline & Materials Transportation & $340,644,743$ & 25,466 \\
\hline & Processes (Equipment) & $49,098,146$ & 3,685 \\
\hline \multirow{2}{*}{\multicolumn{2}{|c|}{ Microsurface }} & $5,538,747,523$ & 305,368 \\
\hline & & Energy [MJ] & $\mathrm{CO}_{2}[\mathrm{Mg}]=\mathrm{GWP}$ \\
\hline \multirow{4}{*}{ Maintenance } & Materials Production & $3,432,669,756$ & 184,144 \\
\hline & Materials Transportation & $275,293,760$ & 20,581 \\
\hline & Processes (Equipment) & $41,779,821$ & 3,136 \\
\hline & SUM & $3,749,743,337$ & 207,861 \\
\hline
\end{tabular}

Table A21. ARGG-1 M\&R alternative emissions from Palate 2.0 software.

\begin{tabular}{|c|c|c|c|}
\hline \\
\hline \multicolumn{2}{|r|}{ Baseline } & Energy [MJ] & $\mathrm{CO}_{2}[\mathrm{Mg}]=\mathrm{GWP}$ \\
\hline \multirow{3}{*}{ Initial Construction } & Materials Production & $37,972,888,683$ & $2,004,224$ \\
\hline & Materials Transportation & $2,003,300,632$ & 149,765 \\
\hline & Processes (Equipment) & $193,655,431$ & 14,535 \\
\hline \multirow{2}{*}{\multicolumn{2}{|c|}{ Mill and Fill }} & $40,169,844,745$ & $2,168,524$ \\
\hline & & Energy [MJ] & $\mathrm{CO}_{2}[\mathrm{Mg}]=\mathrm{GWP}$ \\
\hline \multirow{3}{*}{ Maintenance } & Materials Production & $6,795,577,992$ & 363,862 \\
\hline & Materials Transportation & $412,709,701$ & 30,854 \\
\hline & Processes (Equipment) & $55,053,496$ & 4,132 \\
\hline \multirow{2}{*}{\multicolumn{2}{|c|}{ SUM }} & $7,263,341,189$ & 398,848 \\
\hline & & Energy [MJ] & $\mathrm{CO}_{2}[\mathrm{Mg}]=\mathrm{GWP}$ \\
\hline \multirow{3}{*}{ Maintenance } & Materials Production & $5,096,683,494$ & 272,897 \\
\hline & Materials Transportation & $345,680,224$ & 25,843 \\
\hline & Processes (Equipment) & $49,569,152$ & 3,720 \\
\hline \multirow{2}{*}{\multicolumn{2}{|c|}{ Microsurface }} & $5,491,932,870$ & 302,460 \\
\hline & & Energy [MJ] & $\mathrm{CO}_{2}[\mathrm{Mg}]=\mathrm{GWP}$ \\
\hline \multirow{3}{*}{ Maintenance } & Materials Production & $3,397,788,996$ & 181,931 \\
\hline & Materials Transportation & $278,650,747$ & 20,832 \\
\hline & Processes (Equipment) & $42,093,825$ & 3,159 \\
\hline & SUM & $3,718,533,568$ & 205,922 \\
\hline
\end{tabular}


Table A22. THS-1 M\&R alternative emissions from Palate 2.0.

\begin{tabular}{|c|c|c|c|}
\hline \multicolumn{4}{|c|}{ THS-1 Cross Section } \\
\hline & seline & Energy [MJ] & $\mathrm{CO}_{2}[\mathrm{Mg}]=\mathrm{GWP}$ \\
\hline \multirow{3}{*}{ Initial Construction } & Materials Production & $37,972,888,683$ & $2,004,224$ \\
\hline & Materials Transportation & $2,003,300,632$ & 149,765 \\
\hline & Processes (Equipment) & $193,655,431$ & 14,535 \\
\hline \multirow{2}{*}{\multicolumn{2}{|c|}{ Mill and Fill }} & $40,169,844,745$ & $2,168,524$ \\
\hline & & Energy [MJ] & $\mathrm{CO}_{2}[\mathrm{Mg}]=\mathrm{GWP}$ \\
\hline \multirow{3}{*}{ Maintenance } & Materials Production & $5,381,887,465$ & 284,662 \\
\hline & Materials Transportation & $404,968,158$ & 30,275 \\
\hline & Processes (Equipment) & $54,198,337$ & 4,068 \\
\hline \multirow{2}{*}{\multicolumn{2}{|c|}{ SUM }} & $5,841,053,960$ & 319,005 \\
\hline & & Energy [MJ] & $\mathrm{CO}_{2}[\mathrm{Mg}]=\mathrm{GWP}$ \\
\hline \multirow{3}{*}{ Maintenance } & Materials Production & $4,036,415,599$ & 213,497 \\
\hline & Materials Transportation & $339,874,066$ & 25,409 \\
\hline & Processes (Equipment) & $48,927,782$ & 3,672 \\
\hline \multirow{2}{*}{\multicolumn{2}{|c|}{ Microsurface }} & $4,425,217,448$ & 242,578 \\
\hline & & Energy [MJ] & $\mathrm{CO}_{2}[\mathrm{Mg}]=\mathrm{GWP}$ \\
\hline \multirow{3}{*}{ Maintenance } & Materials Production & $2,690,943,733$ & 142,331 \\
\hline & Materials Transportation & $274,779,975$ & 20,542 \\
\hline & Processes (Equipment) & $41,666,245$ & 3,127 \\
\hline & SUM & $3,007,389,953$ & 166,001 \\
\hline
\end{tabular}

Table A23. T-1 M\&R alternative emissions from Palate 2.0 software.

\begin{tabular}{|c|c|c|c|}
\hline \\
\hline \multicolumn{2}{|r|}{ Baseline } & Energy [MJ] & $\mathrm{CO}_{2}[\mathrm{Mg}]=\mathrm{GWP}$ \\
\hline \multirow{3}{*}{ Initial Construction } & Materials Production & $37,972,888,683$ & $2,004,224$ \\
\hline & Materials Transportation & $2,003,300,632$ & 149,765 \\
\hline & Processes (Equipment) & $193,655,431$ & 14,535 \\
\hline \multirow{2}{*}{\multicolumn{2}{|c|}{ Mill and Fill }} & $40,169,844,745$ & $2,168,524$ \\
\hline & & Energy [MJ] & $\mathrm{CO}_{2}[\mathrm{Mg}]=\mathrm{GWP}$ \\
\hline \multirow{3}{*}{ Maintenance } & Materials Production & $5,442,180,423$ & 287,509 \\
\hline & Materials Transportation & $412,579,971$ & 30,844 \\
\hline & Processes (Equipment) & $54,922,550$ & 4,122 \\
\hline \multirow{2}{*}{\multicolumn{2}{|c|}{ SUM }} & $5,909,682,943$ & 322,475 \\
\hline & & Energy [MJ] & $\mathrm{CO}_{2}[\mathrm{Mg}]=\mathrm{GWP}$ \\
\hline \multirow{3}{*}{ Maintenance } & Materials Production & $4,081,635,317$ & 215,631 \\
\hline & Materials Transportation & $345,582,926$ & 25,835 \\
\hline & Processes (Equipment) & $49,470,942$ & 3,713 \\
\hline \multirow{2}{*}{\multicolumn{2}{|c|}{ Microsurface }} & $4,476,689,185$ & 245,180 \\
\hline & & Energy [MJ] & $\mathrm{CO}_{2}[\mathrm{Mg}]=\mathrm{GWP}$ \\
\hline \multirow{4}{*}{ Maintenance } & Materials Production & $2,721,090,211$ & 143,754 \\
\hline & Materials Transportation & $278,585,882$ & 20,827 \\
\hline & Processes (Equipment) & $42,028,352$ & 3,154 \\
\hline & SUM & $3,041,704,445$ & 167,736 \\
\hline
\end{tabular}


Table A24. SHM-1 M\&R alternative emissions from Palate 2.0 software.

\begin{tabular}{|c|c|c|c|}
\hline \multicolumn{4}{|c|}{ SHM-1 Cross Section } \\
\hline & seline & Energy [MJ] & $\mathrm{CO}_{2}[\mathrm{Mg}]=\mathrm{GWP}$ \\
\hline \multirow{3}{*}{ Initial Construction } & Materials Production & $37,972,888,683$ & $2,004,224$ \\
\hline & Materials Transportation & $2,003,300,632$ & 149,765 \\
\hline & Processes (Equipment) & $193,655,431$ & 14,535 \\
\hline \multirow{2}{*}{\multicolumn{2}{|c|}{ Mill and Fill }} & $40,169,844,745$ & $2,168,524$ \\
\hline & & Energy [MJ] & $\mathrm{CO}_{2}[\mathrm{Mg}]=\mathrm{GWP}$ \\
\hline \multirow{3}{*}{ Maintenance } & Materials Production & $5,492,078,801$ & 290,431 \\
\hline & Materials Transportation & $411,118,915$ & 30,735 \\
\hline & Processes (Equipment) & $54,788,931$ & 4,112 \\
\hline \multirow{2}{*}{\multicolumn{2}{|c|}{ SUM }} & $5,957,986,647$ & 325,278 \\
\hline & & Energy [MJ] & $\mathrm{CO}_{2}[\mathrm{Mg}]=\mathrm{GWP}$ \\
\hline \multirow{3}{*}{ Maintenance } & Materials Production & $4,119,059,101$ & 217,823 \\
\hline & Materials Transportation & $344,487,134$ & 25,754 \\
\hline & Processes (Equipment) & $49,370,728$ & 3,706 \\
\hline \multirow{2}{*}{\multicolumn{2}{|c|}{ Microsurface }} & $4,512,916,963$ & 247,282 \\
\hline & & Energy [MJ] & $\mathrm{CO}_{2}[\mathrm{Mg}]=\mathrm{GWP}$ \\
\hline \multirow{3}{*}{ Maintenance } & Materials Production & $2,746,039,401$ & 145,215 \\
\hline & Materials Transportation & $277,855,354$ & 20,772 \\
\hline & Processes (Equipment) & $41,961,542$ & 3,149 \\
\hline & SUM & $3,065,856,297$ & 169,137 \\
\hline
\end{tabular}

\section{References}

1. American Society of Civil Engineers (ASCE). 2017 Infrastructure Report Card-Roads. 2017. Available online: http://www.infrastructurereportcard.org/wp-content/uploads/2017/01/Roads-Final.pdf (accessed on 6 November 2018).

2. TRIP. National Fact Sheet. September 2018. Available online: http://www.tripnet.org/docs/Fact_Sheet_ National.pdf (accessed on 6 May 2018).

3. Wang, T.; Lee, I.S.; Kendall, A.; Harvey, J.; Lee, E.B.; Kim, C. Life cycle energy consumption and GHG emission from pavement rehabilitation with different rolling resistance. J. Clean. Prod. 2012, 33, 86-96. [CrossRef]

4. Kang, S.; Yang, R.; Ozer, H.; Al-Qadi, I.L. Life-cycle greenhouse gases and energy consumption for material and construction phases of pavement with traffic delay. Transp. Res. Rec. 2014, 2428, 27-34. [CrossRef]

5. Qing, L.; Fred, L.M.; Xin, C. A Life Cycle Assessment Framework for Pavement Maintenance and Rehabilitation Technologies or An Integrated Life Cycle Assessment (LCA)-Life Cycle Cost Analysis (LCCA) Framework for Pavement Maintenance and Rehabilitation; Center for Transportation, Environment, and Community Health (CTECH) Final Report. US DOT; 31 January 2018.

6. Pavement Life Cycle Assessment Workshop. University of California: Davis, CA, USA, May 2010. Available online: http://www.ucprc.ucdavis.edu/p-lca/presentations.html (accessed on 6 November 2018).

7. Ventura, A.; Roche, C.D.L. International Symposium on Life Cycle Assessment and Construction-Civil Engineering and Buildings; 2012 RILEM Publications SARL; ISBN 978-2-35158-127-8.

8. International Symposium on Pavement LCA 2014. Pavement LCA 2014. 2014. Available online: http: //www.ucprc.ucdavis.edu/p-lca2014/Papers.aspx (accessed on 14 March 2019).

9. Al-Qadi, I.; Ozer, H.; Harvey, J. Pavement LCA Symposium 2017. University of Illinois at Urbana-Champaign: Champaign, April 2017. Available online: http://lcasymposium.ict.illinois.edu/proceedings/ (accessed on 14 March 2019).

10. Harvey, J.; Meijer, J.; Al-Qadi, I.L.; Saboori, A. Pavement Life Cycle Assessment Framework; Federal Highway Administration: Washington, DC, USA, July 2016. Available online: http://www.fhwa.dot.gov/pavement/ sustainability/hif16014.pdf (accessed on 28 January 2019).

11. Zaabar, I.; Karim, C. Calibration of HDM-4 models for estimating the effect of pavement roughness on fuel consumption for US conditions. Transp. Res. Rec. J. Transp. Res. Board 2010, 2155, 105-116. [CrossRef]

12. Chatti, K.; Imen, Z. Estimating the Effects of Pavement Condition on Vehicle Operating Costs; Transportation Research Board: Washington, DC, USA, 2012; Volume 720. 
13. Robbins, M.M.; Tran, N. Literature review: The effect of pavement roughness on vehicle operating costs. Natl. Cent. Asph. Technol. Rep. 2015. Available online: http://www.eng.auburn.edu/research/centers/ncat/ files/technical-reports/rep15-02.pdf (accessed on 28 January 2019).

14. Ziyadi, M.; Ozer, H.; Kang, S.; Al-Qadi, I.L. Vehicle energy consumption and an environmental impact calculation model for the transportation infrastructure systems. J. Clean. Prod. 2018, 174, 424-436. [CrossRef]

15. DeCarlo, C.; Mo, W.; Dave, E.V.; Locore, J. Sustainable Pavement Rehabilitation Strategy Using Consequential Life Cycle Assessment. In Proceedings of the 10th International Conference on the Bearing Capacity of Roads, Railways and Airfields, Athens, Greece, 28-30 June 2017. [CrossRef]

16. MassDOT. Transportation Data Management System (MS2). 2018. Available online: http://mhd.ms2soft.com/ tcds/tsearch.asp?loc=Mhd\&mod= (accessed on 9 April 2018).

17. Google. Google maps. Available online: https:/www.google.com/maps/dir/42.603823,-71.3501962/42. 7392095,-71.1416834/@42.7452328,-71.134279,14.71z/data=!4m2!4m1!3e0 (accessed on 8 January 2018).

18. Nemati, R.; Dave, E.V.; Daniel, J.S. Statistical Evaluation of Effect of Mix Design Properties on Performance Indices of Asphalt Mixtures. ASTM J. Test. Eval. 2019, in press.

19. SimaPro 8.0.0 (2013). Software. Available online: https://simapro.com (accessed on 12 June 2019).

20. Horvath, A. Pavement Life-Cycle Assessment Tool for Environmental and Economic Effects (PaLATE); Consortium on Green Design and Manufacturing from the University of California-Berkeley; University of California-Berkeley: Berkeley, CA, USA, 2013.

21. CalTrans. LIFE-CYCLE COST ANALYSIS PROCEDURES MANUAL; California Department of Transportation: Sacramento, CA, USA, 2013; p. 158.

22. Mousa, M.; Elseifi, M.A.; Bashar, M.; Zhang, Z.; Gaspard, K. Field Evaluation and Cost Effectiveness of Crack Sealing in Flexible and Composite Pavements. Transp. Res. Rec. J. Transp. Res. Board 2018, 2672, 51-61. [CrossRef]

23. Cole, M.; Geib, J. MnDOT's Experience: Efforts to Improve Micro Surfacing Performance. 2016. Available online: https://www.dot.state.mn.us/materials/pavementpreservation/mndotexperiences/ documents/EffortstoImproveMicroSurfacingPerformance.pdf (accessed on 9 April 2018).

24. Damp, S. Cold In-Place Recycling: Southeast Pavement Preservation Partnership. Available online: http://www. pavementpreservation.org/wp-content/uploads/presentations/Cold\%20In-Place\%20Recycling.pdf (accessed on 9 April 2018).

25. Lane, B.; Kazmierowski, T. Short Term Performance of an Innovative Cold In-Place Recycling Technology in Ontario. In Proceedings of the 2005 Annual Conference of the Transportation Association of Canada, Calgary, AB, Canada, 18-21 September 2005; Available online: http://conf.tac-atc.ca/english/resourcecentre/ readingroom/conference/conf2005/docs/s15/lane.pdf (accessed on 9 April 2018).

26. Fitts, G.L. Thin Overlays for Pavement Preservation and Functional Rehabilitation. Available online: http://www.ltrc.lsu.edu/ltc_09/pdf/Fitts,\%20Gary.pdf (accessed on 6 May 2018).

27. Nair, H.; McGhee, K.K.; Habib, A.; Shatty, S. Assessment of an Incentive Only Ride Specification for Asphalt Pavements; Final Report VCTIR 16-R2; Virginia Center for Transportation Innovation and Research: Charlottesville, VA, USA, 10 September 2015.

28. Transportation Research Board (TRB). InSight Data Access Website-SHRP2 Naturalistic Driving Study. 2018. Available online: https://insight.shrp2nds.us/ (accessed on 9 April 2018).

29. Environmental Protection Agency (EPA). MOtor Vehicles Emissions Simulator (MOVES), MOVES2014a ed.; EPA: Washington, DC, USA, 2014.

30. AASHTOWare. Pavement ME Design; Version 2.3; AASHTOWare: Washington, DC, USA, 17 July 2015.

31. Wilde, J.W. Implementation of An International Roughness Index for mn/DOT Pavement Construction and Rehabilitation; No. MN/RC-2007-09; Minnesota Department of Transportation: Saint Paul, MN, USA, 2007; Available online: http://www.lrrb.org/PDF/200709.pdf (accessed on 9 January 2019).

32. Loprencipe, G.; Pantuso, A.; Di Mascio, P. Sustainable pavement management system in urban areas considering the vehicle operating costs. Sustainability 2017, 9, 453. [CrossRef]

33. Kerali, H.G. HDM-4: Highway Development and Management: Volume One: Overview of HDM-4; The World Road Association (PIARC): Paris, France; The World Bank: Washington, DC, USA, 2000.

34. Walls, J.; Smith, M.R. Life-Cycle Cost Analysis in Pavement Design: In Search of Better Investment Decisions; Federal Highway Administration: Washington, DC, USA, 1998. 
35. New England (PADD 1A) Regular All Formulations Retail Gasoline Prices. Petroleum and Other Liquids. US Energy Information Administration, April 2017. Available online: http://www.eia.gov/petroleum/ gasdiesel/ (accessed on 6 May 2018).

36. Ogwang, A.; Samer, M.; Arpad, H. Optimal Cracking Threshold Resurfacing Policies in Asphalt Pavement Management to Minimize Costs and Emissions. J. Infrastruct. Syst. 2019, 25. [CrossRef]

37. Pantuso, A.; Loprencipe, G.; Bonin, G.; Teltayev, B.B. Analysis of pavement condition survey data for effective implementation of a network level pavement management program for Kazakhstan. Sustainability 2019, 11, 901. [CrossRef]

38. Chehovits, J.; Larry, G. Energy usage and greenhouse gas emissions of pavement preservation processes for asphalt concrete pavements. In Proceedings of the 1st International Conference of Pavement Preservation, Newport Beach, CA, USA, 13-15 April 2010.

(C) 2019 by the authors. Licensee MDPI, Basel, Switzerland. This article is an open access article distributed under the terms and conditions of the Creative Commons Attribution (CC BY) license (http://creativecommons.org/licenses/by/4.0/). 